\title{
SR-BI as a target of natural products and its significance in cancer
}

Wang, Dongdong ; Huang, Jiansheng ; Gui, Ting ; Yang, Yaxin ; Feng, Tingting ; Tzvetkov, Nikolay T ; Xu, Tao ; Gai, Zhibo ; Zhou, Ying ; Zhang, Jingjie ; Atanasov, Atanas G

\begin{abstract}
Scavenger receptor class B type I (SR-BI) protein is an integral membrane glycoprotein. SR-BI is emerging as a multifunctional protein, which regulates autophagy, efferocytosis, cell survival and inflammation. It is well known that SR-BI plays a critical role in lipoprotein metabolism by mediating cholesteryl esters selective uptake and the bi-directional flux of free cholesterol. Recently, SR-BI has also been identified as a potential marker for cancer diagnosis, prognosis, or even a treatment target. Natural products are a promising source for the discovery of new drug leads. Multiple natural products were identified to regulate SR-BI protein expression. There are still a number of challenges in modulating SR-BI expression in cancer and in using natural products for modulation of such protein expression. In this review, our purpose is to discuss the relationship between SR-BI protein and cancer, and the molecular mechanisms regulating SR-BI expression, as well as to provide an overview of natural products that regulate SR-BI expression.
\end{abstract}

DOI: https://doi.org/10.1016/j.semcancer.2019.12.025

Posted at the Zurich Open Repository and Archive, University of Zurich

ZORA URL: https://doi.org/10.5167/uzh-184702

Journal Article

Accepted Version

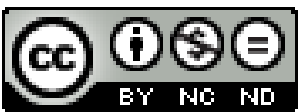

The following work is licensed under a Creative Commons: Attribution-NonCommercial-NoDerivatives 4.0 International (CC BY-NC-ND 4.0) License.

Originally published at:

Wang, Dongdong; Huang, Jiansheng; Gui, Ting; Yang, Yaxin; Feng, Tingting; Tzvetkov, Nikolay T; Xu, Tao; Gai, Zhibo; Zhou, Ying; Zhang, Jingjie; Atanasov, Atanas G (2022). SR-BI as a target of natural products and its significance in cancer. Seminars in Cancer Biology, 80:18-38.

DOI: https://doi.org/10.1016/j.semcancer.2019.12.025 


\section{$\mathrm{SR}-\mathrm{BI}$ as a target of natural products and its significance in cancer}

Dongdong Wang ${ }^{1 \dagger}$, Jiansheng Huang ${ }^{2 \dagger}$, Ting Gui ${ }^{\dagger \dagger}$, Yaxin Yang ${ }^{1}$, Tingting Feng ${ }^{4}$, Nikolay T. Tzvetkov $^{5}$, Tao Xu' ${ }^{1}$, Zhibo Gai6, Ying Zhou ${ }^{4 *}$, Jingjie Zhang ${ }^{1 *}$, Atanas G. Atanasov ${ }^{7,8,9 *}$

tThese authors contributed equally.

*Corresponding authors: Dr. Atanas G. Atanasov (atanas.atanasov@univie.ac.at), Dr. Jingjie Zhang (374037510@qq.com), and Dr. Ying Zhou (1962573782@qq.com).

${ }^{1}$ The Second Affiliated Hospital of Guizhou University of Traditional Chinese Medicine, Fei Shan Jie 32, 550003 Guiyang, China.

${ }^{2}$ Department of Medicine, Vanderbilt University Medical Center, 318 Preston Research Building, 2200 Pierce Avenue, Nashville, Tennessee 37232, USA.

${ }^{3}$ Key Laboratory of Traditional Chinese Medicine for Classical Theory, Ministry of Education, Shandong University of Traditional Chinese Medicine, Jinan 250355, China.

${ }^{4}$ College of Pharmacy, Guizhou University of Traditional Chinese Medicine, Huaxi university town, 550025 Guiyang, China.

${ }^{5}$ Department of Biochemical Pharmacology and Drug Design, Institute of Molecular Biology "Roumen Tsanev", Bulgarian Academy of Sciences, 21 Acad. G. Bonchev Str., 1113 Sofia, Bulgaria.

${ }^{6}$ Department of Clinical Pharmacology and Toxicology, University Hospital Zurich, University of Zurich, Zurich, Switzerland.

${ }^{7}$ Department of Molecular Biology, Institute of Genetics and Animal Breeding of the Polish Academy of Sciences, 05-552 Jastrzębiec, Poland.

${ }^{8}$ Department of Pharmacognosy, University of Vienna, Althanstrasse 14, 1090 Vienna, Austria. Institute of Neurobiology, Bulgarian Academy of Sciences, 23 Acad. G. Bonchev Str., 1113 Sofia, Bulgaria. 


\section{Contents}

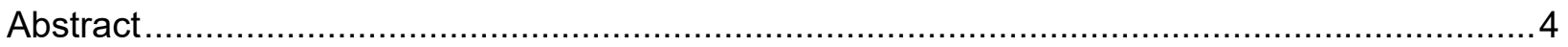

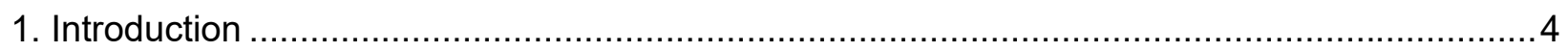

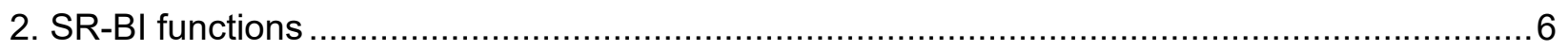

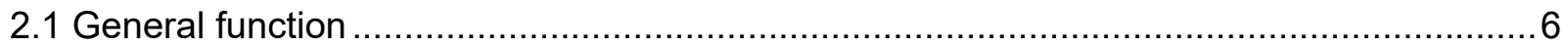

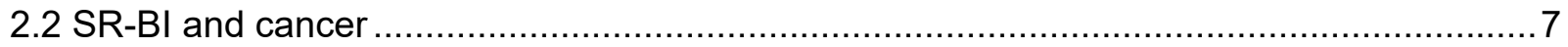

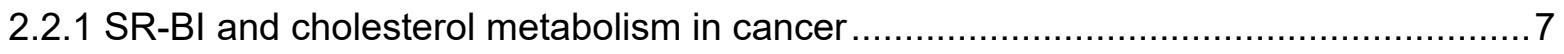

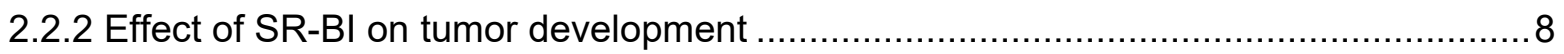

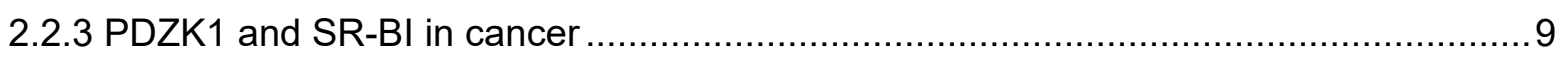

2.2.4 Effects of SR-BI on macrophage polarization and cholesterol efflux in tumorassociated macrophages (TAMs) and tumor progression .............................................

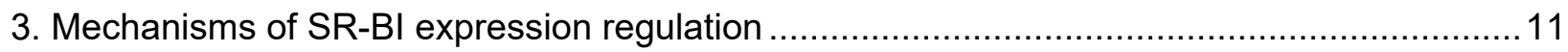

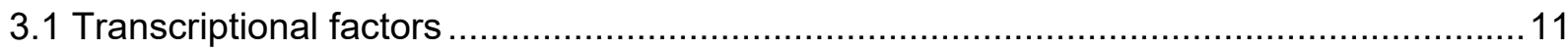

3.1.1 LXR

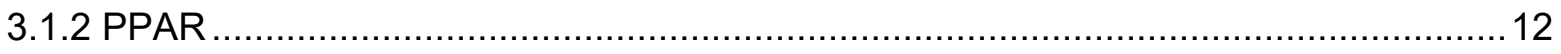

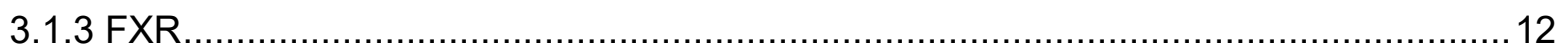

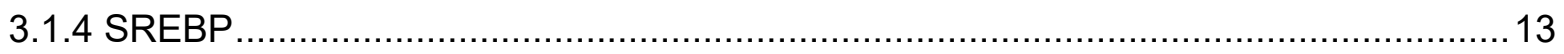

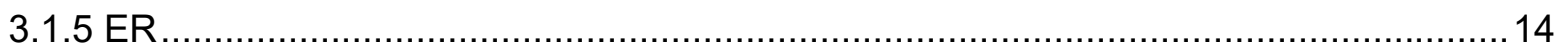

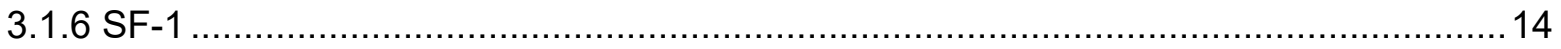

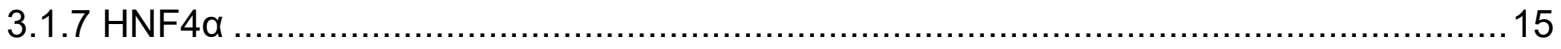

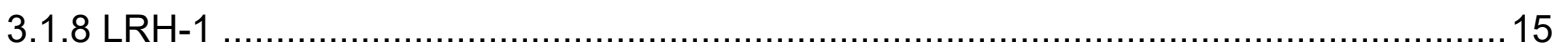

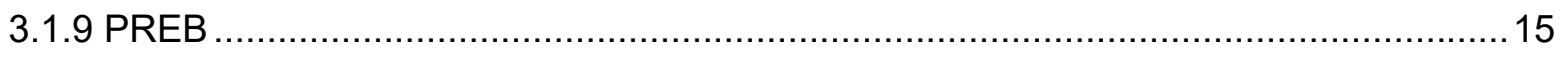

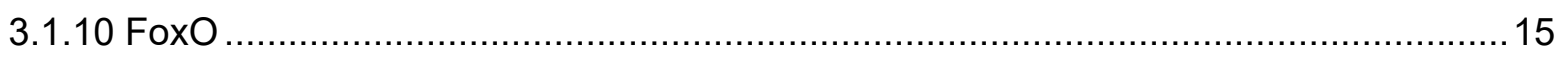

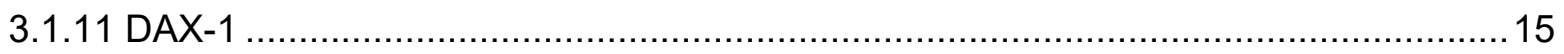

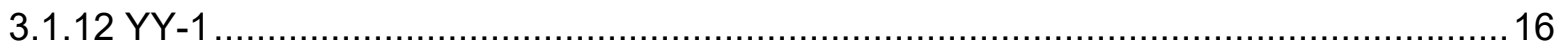

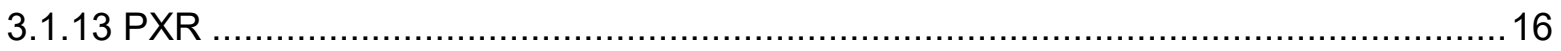




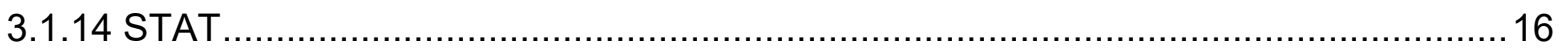

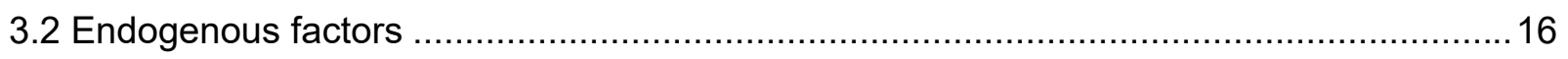

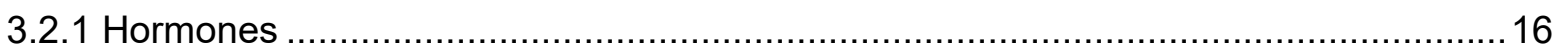

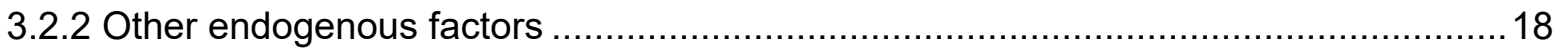

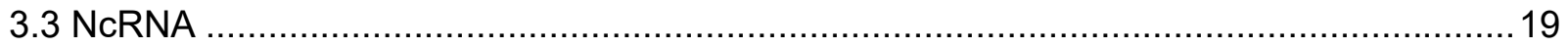

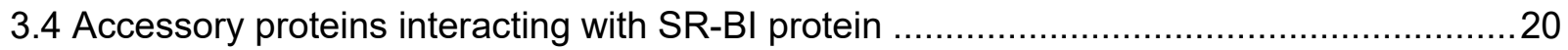

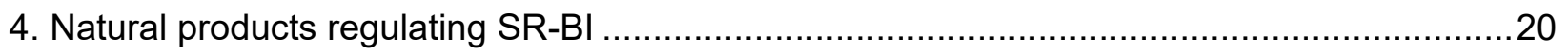

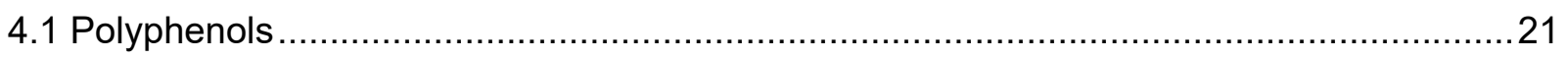

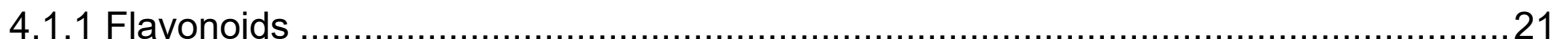

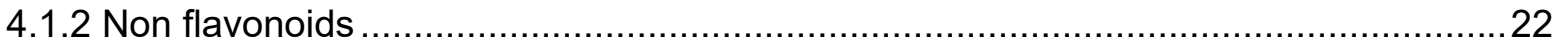

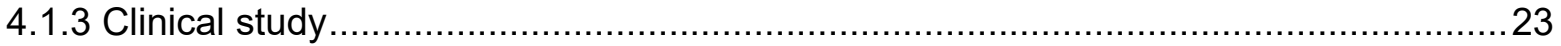

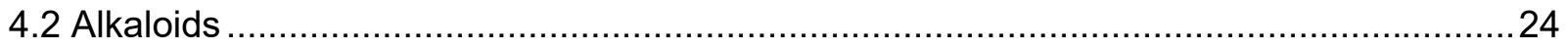

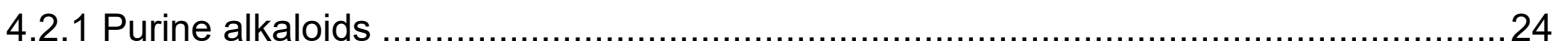

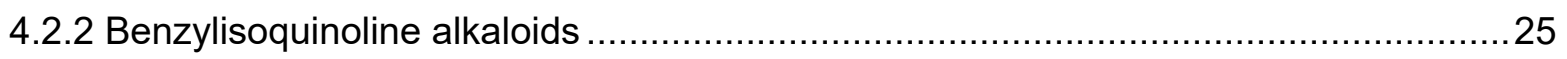

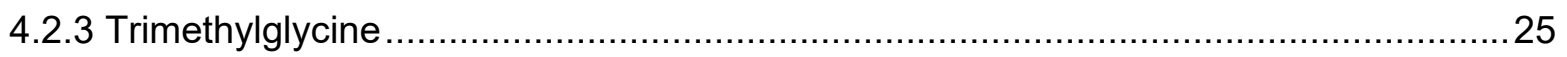

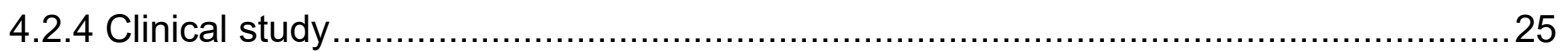

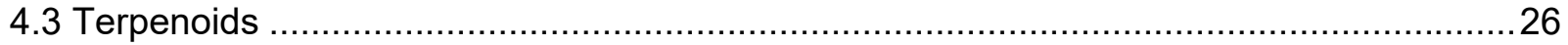

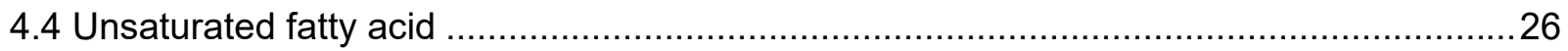

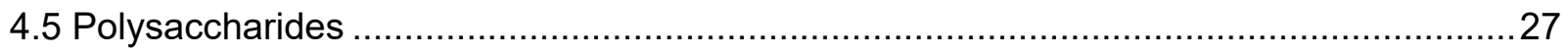

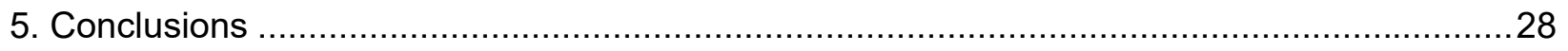

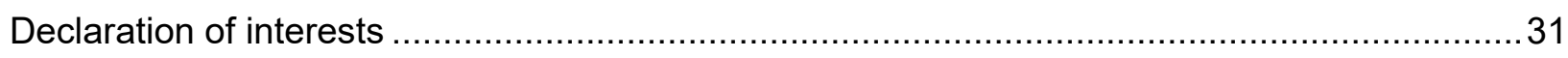

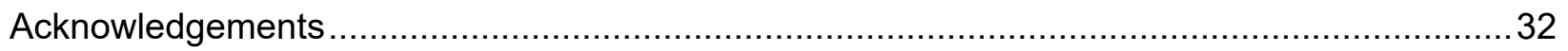

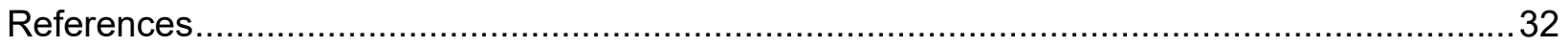




\section{Abstract}

Scavenger receptor class B type I (SR-BI) protein is an integral membrane glycoprotein. SR-BI is emerging as a multifunctional protein, which regulates autophagy, efferocytosis, cell survival and inflammation. It is well known that SR-BI plays a critical role in lipoprotein metabolism by mediating cholesteryl esters selective uptake and the bi-directional flux of free cholesterol. Recently, SR-BI has also been identified as a potential marker for cancer diagnosis, prognosis, or even a treatment target. Natural products are a promising source for the discovery of new drug leads. Multiple natural products were identified to regulate SR-BI protein expression. There are still a number of challenges in modulating SR-BI expression in cancer and in using natural products for modulation of such protein expression. In this review, our purpose is to discuss the relationship between SR-BI protein and cancer, and the molecular mechanisms regulating SR-BI expression, as well as to provide an overview of natural products that regulate SR-BI expression.

Keywords: natural products; scavenger receptor class B type I; cancer; molecular mechanisms.

\section{Introduction}

Scavenger receptor class B type I (SR-BI) protein was first isolated and identified by Calvo et al. [1] based on a sequence closely related to cluster of differentiation 36 (CD36) and lysosomal integral membrane protein (LIMP) analogous-1. The gene of human SR-BI located on chromosome 12, initially named CLA-1, now is called SCARB1 and comprises 13 exons and 12 introns [2]. SR-BI protein is an $82 \mathrm{kDa}$ integral membrane glycoprotein, which (together with LIMP2 ) is a member of CD36 superfamily of scavenger receptor proteins [3]. SR-BI has a hairpinlooped structure with two short $\mathrm{N}$ - and C-terminal transmembrane domains, two cytoplasmic tails, and a large extracellular loop [4, 5]. A full-length human SR-BI protein contains 509 amino acids, of which a large extracellular domain (ECD) includes 408 amino acids, $\mathrm{N}$ - and C-terminal transmembrane domains include 22 and 23 amino acids respectively, as well as $\mathrm{N}$ - and $\mathrm{C}$ terminal cytoplasmic domain include 9 and 44 amino acids, respectively [6]. ECD contains multiple sites for $\mathrm{N}$-linked glycosylation of SR-BI [6]. 
With the conserved function across various species, SR-BI is expressed in many normal and hormonally altered tissues and cell types, including liver, brain, intestine, placenta, and steroidogenic tissues, as well as macrophages, endothelial cells, smooth muscle cells, keratinocytes and adipocytes [2, 7, 8]. SR-BI predominantly expresses in the liver and steroidogenic tissues (adrenal gland, gonads) [9-11]. A previous study suggests that SR-BI protein located in caveolae of IdIA7-SR-BI cells and murine adrenocortical Y1-BS1 cells based on partial colocalization with caveolin-1 [12]. It was reported, however, that SR-BI is majorly localized in clusters of microvillar extensions on the plasma membrane rather than caveolae [13]. Expression of recombinant SR-BI induced the formation of double-membraned channel structures, which increased the uptake of high-density lipoprotein-cholesteryl esters (HDL-CE) [14, 15].

It was demonstrated that the SR-BI is critical to lipoprotein metabolism by mediating CE selective uptake and the bi-directional flux of free cholesterol [16]. SR-BI is emerging as a multifunctional receptor in different cellular types [2]. Hepatic SR-BI selectively takes up HDL-CE for the delivery of cholesterol to bile, which perseveres HDL functions, and is also critical in the clearance of remnant lipoproteins and lipoprotein(a) $(\operatorname{Lp}(a))[2,17]$. SR-BI can facilitate the efflux of cholesterol from peripheral tissues including macrophages, then back to liver [17]. In addition, in human and mouse macrophages SR-BI influences autophagy [2]. In both macrophages and endothelial cells, SR-BI could also regulate signaling pathways involved in efferocytosis, cell survival, and inflammation [2]. It was shown that SR-BI mediated the uptake of vitamins as well as viral entry into cells [17]. Recently, SR-BI has also been identified as a potential marker for cancer diagnosis and prognosis [17]. It was reported that abnormal expression of SR-BI may have been associated with tumorigenesis and malignant transformation [18-20]. For example, several patient tumors display higher expression of SR-BI compared to healthy tissue, including adrenal tumors, breast cancer, prostate cancer, lymphoma, nasopharyngeal carcinoma, pancreatic cancer, prostate bone metastasis, and testicular cancer [18-20]. SR-BI could also serve as a promising target for the delivery of therapeutic agents by reconstituted HDL, which directly binds to the SR-BI protein on plasma membrane $[19,20]$.

Natural products are a promising source for the discovery of new drug leads [21]. Some natural products, including such from plants, fungi and marine sources, are reported to regulate SR-BI protein expression (reviewed in [22]). It was reported that only about $6 \%$ of the existing higher plants have been investigated pharmacologically, highlighting that there is still a lot of unexplored potential [23]. In our review, we discuss the relationship between SR-BI protein and cancer, and 
the molecular mechanism regulating $\mathrm{SR}-\mathrm{BI}$ expression, as well as provide an overview of natural products that regulate SR-BI expression.

\section{SR-BI functions}

\subsection{General function}

Hepatic SR-BI mediates selective HDL-CE uptake from peripheral tissues and the transhepatic transport of HDL cholesterol into bile regulates the reverse cholesterol transport (RCT) [24-26]. $\mathrm{SR}-\mathrm{BI}$ is a multifunctional receptor, with recent studies demonstrating that $\mathrm{SR}-\mathrm{BI}$ affects gastrointestinal, endocrine, reproductive, and cardiovascular pathophysiology [27-32]. SR-BI is involved in both cholesterol uptake and efflux in cells (Figure 1) [33,34] and has been shown to be the key gatekeeper for specific delivery of cholesterol in human steroidogenic cells [35]. SR$\mathrm{BI}$ promoted the production of glucocorticoids and modulated inflammatory response to protect from endotoxemia and septic death [36, 37]. Along the same line, human patients with SR-BI P297S had a remarkable decrease in urinary steroid secretion, an impaired response to corticotropin stimulation [38, 39], and symptoms resembled with impaired adrenal function. These observations suggest that SR-BI was critical for adrenal steroid synthesis. In addition, SR-BI was shown to be involved in improving inflammation, limiting cell death and regulating efferocytosis of apoptotic cells [2]. In this context, there was increased oxidative stress in SR-BI knockout (KO) mice with dysfunctional HDL [40, 41]. SR-BI increased the protein expression of endothelial nitric oxide synthase (eNOS) in endothelial cells through Akt (also known as protein kinase B (PKB)) and mitogen-activated protein kinase (MAPK) signaling pathway [42-44]. In addition, recent studies demonstrated that SR-BI was responsible for red blood cell maturation, lymphocyte homeostasis, and deficiency of SR-BI resulted in systemic autoimmune disorders by modulating the proliferation of lymphocytes as well as the cytokine production by lymphocytes and macrophages in mice [45-47]. SR-BI also modulated platelet cholesterol contents, platelet activity and thrombosis in dyslipidemia [48, 49]. SR-BI deficient macrophages were defective in autophagy following stress [50], and impaired autophagy, promoted atherosclerosis [51]. Therefore, SR-BI is a receptor with pleiotropic functions and may affect cell functions by mediating the bi-directional flux and net movement of cellular free cholesterol [50]. Future studies need to establish the mechanisms by which SR-BI regulates autophagy in human macrophages, and 
whether its role is associated with CE mobilization, macrophage apoptosis and the chronic inflammatory diseases.

Macrophages from patients with loss-of-function SR-BI variants had impaired ability to promote cholesterol efflux [38, 39], suggesting that macrophage SR-BI played an important role in cholesterol homeostasis and chronic inflammatory diseases [52]. Recent epidemiologic studies demonstrated that there was a significant inverse relationship between HDL-cholesterol (HDL-C) levels, HDL particle numbers and risk of cancer development and prognosis [53-56]. Up to now, there are several SR-BI variants identified from human subjects with abnormal HDL-C levels (Table 1). Two missense mutations S112F (Serine to Phenylalanine), T175A (Threonine to Alanine) were associated with $37 \%$ increased HDL-C in heterozygotes, and P297S (Proline to Serine) was associated with increased HDL-C and reduced cholesterol efflux capacity. It has been shown that a coding variant of SR-BI I179N (Isoleucine to Asparagine) remarkably promoted atherosclerosis in mice [57]. It is worth to note that the new variant P376L (Proline to Leucine) resulted in the complete loss of function, which led to high HDL-C phenotype in human [58]. The heterozygotes had a 2.8-fold increase and the homozygotes had a 6.1-fold increase in large HDL2 particles compared with noncarrier control. The further characterizations of these point mutations of SR-BI, including cell surface expression, binding activity to HDL, and SR-BI signaling pathway were intriguing. The binding ability of SR-BI P376L to HDL was almost completely abolished and the binding ability of P297S to HDL was decreased to half of SR-BI wild type (WT). More importantly, P376L mutation of SCARB1 was associated with increased risk of coronary heart disease (CHD) [58, 59]. However, three rare SR-BI mutations identified from human patients (G319V, V111M, and V32M) were associated with elevated levels of HDL-C, but not with coronary artery disease (CAD) [60]. It remains to be addressed whether there is causal relationship between loss of function mutations of SR-BI and tumor progression.

\subsection{SR-BI and cancer}

\subsubsection{SR-BI and cholesterol metabolism in cancer}

Changes in cholesterol metabolism resulted in the alteration of intratumoral synthesis of androgens in castration-resistant prostate cancer [61]. Cytochrome P450 (CYP) 27A1, also known as sterol 27-hydroxylase, is an important enzyme in both the acidic and neutral pathways of bile acid and cholesterol metabolism [62]. CYP27A1 oxidizes the terminal carbon of the 
cholesterol isooctyl side-chain to an alcohol and subsequently to an acid introducing $\mathrm{R}$ stereochemistry at C-25 [63]. Given its key role in bile acid biosynthesis and cholesterol metabolism, CYP27A1 dysregulation results in dysfunction of cholesterol metabolism and disease in humans [64]. It has been shown that CYP27A1 is significantly down-regulated in human prostate cancer. Restoring CYP27A1 expression in cells reduced tumor growth in vitro and in vivo model with tumor xenografts [65]. Blocking CYP27A1, which encodes enzyme required for 27hydroxycholesterol biosynthesis, remarkably prevented metastasis in relevant animal models of cancer, while the cholesterol metabolite 27-hydroxycholesterol promoted breast cancer metastasis through activation of neutrophils [66], which overall points out that cholesterol metabolism plays important roles in cancer development and metastasis. Although there is no study examining the specific mechanisms implying SR-BI in development of cancer [67], it has been demonstrated that cancer cells can take up CE via HDL/SR-BI pathway and use it as the substrate to enhance malignant phenotypes [68, 69]. For example, SR-BI was required for uptake of CE from HDL3 in the breast cancer cell line HBL-100 [70]. SR-BI was also needed for selective CE uptake providing cholesterol as precursor for production of steroid hormones and for storage in intracellular CE droplets of Leydig cells from rat testis [71]. HDL also inhibited the activation of sterol regulatory element-binding protein-1 (SREBP-1), which resulted in the transcription of $\beta$ Hydroxy $\beta$-methylglutaryl-CoA (HMG-CoA) reductase, a key enzyme of cholesterol biosynthesis. It would be intriguing to determine the effect of SR-BI modulation on SREBP-1 activation and cholesterol metabolism for steroid hormones (e.g., androgens and estrogens) in relevant cancers, such as breast cancer and prostate cancer.

\subsubsection{The effect of SR-BI on tumor development}

Recent studies demonstrated that the protein expression level of SR-BI was correlated with aggressiveness and poor survival in breast and prostate cancer [72]. SR-BI protein expression was shown to be remarkably increased in malignant tissues compared to surrounding diseasefree tissues in breast cancer [73], while low SR-BI expression was associated with gastric adenocarcinoma tumor aggressiveness [74]. There was abundant expression of SR-BI in malignant human epithelial cells and hepatoma cells $[73,75,76]$. SR-BI expression was also increased in Leydig cell tumors, prostate cancers, colorectal cancer, ovarian cancer and pancreatic cancer $[70,77]$. Specifically, SR-BI promoted the proliferation of the breast cancer cell line MCF-7 through the phosphoinositide 3-kinase (PI3K)/activator protein-1 (AP-1) signaling pathway $[68,78]$. Along the same line, overexpression of SR-BI protected breast cancer MCF-7 
cells against tumor necrosis factor (TNF)-a-induced apoptosis, whereas expression of the ECD of SR-BI remarkably prevented the cell proliferation [78]. Abolishing SR-BI reduced prostate specific antigen (PSA) secretion and viability of prostate cancer cells [79]. Pharmacological inhibition of SR-BI reduced breast cancer cell proliferation, prevented tumor growth in xenograft tumor mice by inhibition of angiogenesis and Akt activation [68, 69]. In addition, SR-BI was involved in the melanoma pigmentation pathway, and deficiency of SR-BI decreased the melanocyte master regulator microphthalmia-associated transcription factor (MITF) and inhibited extracellular vesicle release in human melanoma [80]. Taken together, SR-BI plays an important role in cancer cell proliferation and apoptosis, thus, has a potential major impact in carcinogenesis and metastasis.

\subsubsection{PDZK1 and SR-BI in cancer}

The SR-BI scaffold protein PDZK1 is critical for the cell surface expression of SR-BI [81]. KO of PDZK1 resulted in a post-transcriptional, tissue-specific reduction in SR-BI protein level, and there was an increase in plasma total HDL-C and the size of HDL particles in PDZK1 deficient mice, which exhibited the similar phenotypes to those observed in SR-BI KO mice [82]. PDZK1 belongs to the estrogen-regulated genes expressed in hormone-responsive breast cancer [83]. Recent study demonstrated that PDZK1 promoted estrogen receptor (ER)- $\alpha$-mediated growth of breast cancer, indirectly regulated by insulin-like growth factor-1 receptor (IGF-1R), therefore identifying a new oncogenic role of PDZK1 in breast cancer [84]. Furthermore, knockdown of PDZK1 abolished ER-dependent cell growth and decreased c-Myc expression in MCF-7 cells, whereas overexpression of PDZK1 promoted cell proliferation through c-Myc. Previous studies demonstrated that expression of breast cancer resistance protein (BCRP, gene symbol ABCG2), an ATP-binding cassette (ABC) efflux transporter, was reduced in PDZK1 KO mice [85]. PDZK1 was highly overexpressed in ER-positive breast cancers as compared with ER-negative breast cancers, which probably affected SR-BI function and cancer development. However, whether the effect of PDZK1 on the growth of cancer cells is dependent on SR-BI needs to be further studied. Further studies need to address whether co-transfected cells with PDZK1 and SR-BI mutants affects cancer cell surface expression of SR-BI mutants (e.g., P297S, P376L) to regulate cancer cell cholesterol metabolism and cell proliferation.

\subsubsection{Effects of SR-BI on macrophage polarization and cholesterol efflux in tumor-associated macrophages (TAMs) and tumor progression}


Mounting evidence supported that TAMs were associated with tumor progression, invasion and metastasis, and poor prognosis [86]. At the initial stage of tumor development, TAMs were observed to exhibit a pro-inflammatory gene profile, which is distinct from that of naive resident macrophages. However, TAMs rapidly took on a substitute phenotype with tumor promoting immunosuppressive function within the tumor microenvironment [87, 88], although there was a specific subsets of macrophages with intrinsic tumoricidal activity [86]. In established tumors, TAMs were observed to display a phenotype similar to resident macrophages, which indicated a dynamic reprogramming of TAM phenotype during tumor progression. Recent study has shown that SR-BI deficiency promoted pro-inflammatory macrophage phenotype and upregulated proinflammatory gene expression. SR-BI KO macrophages promoted the M1 phenotype and failed to exhibit an M2 phenotype. Furthermore, SR-BI deficiency promoted activation of ERK1/2 MAPK signaling in macrophages stimulated with LPS [89]. These studies demonstrate SR-BI regulates macrophage phenotype switching and cholesterol metabolism. Recent studies have shown that an unexpected influence for membrane-cholesterol efflux resulted in driving TAM-regulated tumorigenesis (Figure 2) [90]. Interestingly, KO of ABCA1/G1 restored the tumor-promoting functions of TAMs. Ovarian cancer cell-derived hyaluronic acid (HA) remarkably increased membrane cholesterol efflux of TAMs [90], which was associated with increased interleukin (IL)4-mediated signaling pathway and inhibition of interferon (IFN) $\gamma$-induced gene expression, leading to transcriptional and functional reprogramming of TAMs. Specifically, reduction of membrane cholesterol in macrophages promoted PI3K activity and mammalian target of rapamycin complex (mTORC)2-mediated Akt phosphorylation. PI3K was recently shown to be an essential pathway to preserve the pro-tumor functions of TAMs [91], and mTORC2 have been associated with IL-4-regulated macrophage activation in different contexts [92-94]. The possible mechanistic scenario is that cholesterol-rich membrane micro-domains are required to recruit negative mediators of PI3K activity, such as the lipid phosphatase - the SH-2 containing inositol5'-polyphosphatase-1 (SHIP-1). SHIP-1 may reside in detergent resistant membrane fractions [95], and it is known to inhibit IL-4 signaling in macrophages [93]. However, it remains to be determined whether SR-BI contributes to membrane cholesterol efflux in TAMs and whether reprogramming of TAMs affects tumorigenesis through SR-BI. This will be an important area of investigation, that might provide exciting new insights into the lipoprotein metabolism, tumor associated macrophages and tumor progression as well. Taken together, SR-BI is critical for regulating the cholesterol homeostasis and inflammatory response. Identification of the detailed mechanism by which SR-BI functions, including its adaptor proteins, signaling molecules, and 
transcriptional regulators, will lay a solid foundation for potential discovery of novel diagnostic or therapeutic approaches for cancer.

\section{Mechanisms of SR-BI expression regulation}

The SR-BI expression can be regulated by transcriptional factors, other endogenous factors, noncoding RNAs (ncRNA), as well as its accessory proteins at transcriptional, post-transcriptional, or post-translational levels (Table 2 and Figure 3 ).

\subsection{Transcriptional factors}

SR-BI is regulated by many transcriptional factors, such as the liver $X$ receptor $(L X R)$, peroxisome proliferator-activated receptor (PPAR), farnesoid $X$ receptor (FXR), retinoid $X$ receptor (RXR), SREBP, ER, steroidogenic factor-1 (SF-1), hepatic nuclear factor $4 \alpha$ (HNF4a), liver receptor homolog-1 ( $\mathrm{LRH}-1$ ), prolactin regulatory element-binding protein (PREB), forkhead box protein $\mathrm{O}$ (FoxO), dosage-sensitive sex adrenal hypoplasia congenital critical region on the $\mathrm{X}$ chromosome, gene-1 (DAX-1), Yin Yang-1 (YY-1), pregnane $X$ receptor (PXR), and signal transducer and activator of transcription (STAT).

\subsubsection{LXR}

The LXR a and $\beta$ form heterodimers with the RXR for transcriptional activity [96]. Oxysterolactivated $L X R \alpha / R X R$ and $L X R \beta / R X R$ induced $S R-B I$ transcription in human and murine hepatoma cell lines, and in 3T3-L1 preadipocytes by binding to putative $L X R$ response element (LXRE) in the promoter region to induce SR-BI-promoter activity, independently of SREBP-1 [97]. On the contrary, LXR reduced levels of SR-BI in Caco-2/TC7 cells via a post-transcriptional mechanism that involves microRNAs (miR) [98]. In vivo it was demonstrated that treating normolipidemic hamsters with LXR agonist GW3965 did not effectively induce the mRNA and protein levels of SR-BI in the liver [99]. Furthermore, another animal study indicated that LXR activation by its ligand TO901317 reduced SR-BI protein, but not mRNA levels in hepatic membranes of C57BI/6J mice, which is not due to changing PDZK1 [100]. The contradictory observed effects of LXR on $\mathrm{SR}-\mathrm{BI}$ expression possibly is due to the different cell types and different animal models. 


\subsubsection{PPAR}

The PPARa can form heterodimers with the RXR to regulate gene expression [101]. PPARa/RXR increased the activity of the SR-BI promoter in the human bladder HTB-9 cells, human promyelocytic leukemia HL-60 cells, and human monocytic leukemia THP-1 cells by binding to a PPAR response element (PPRE) in the SR-BI promoter [102]. The PPARa specific ligand WY14643 increased SR-BI level in the rat hepatocytes and HepG2 hepatoma cells, as well as liver endothelial cells [103]. The influence of PPARa on hepatic SR-BI expression in animal studies is controversial. In hamsters, dietary polyunsaturated fatty acids (PUFA, a strong inducer of PPARa) for 6 weeks, up-regulated hepatic SR-BI mRNA and protein levels [104]. SR-BI expression was also increased in atherosclerotic lesions of apolipoprotein (apo)E-deficient mice treated with the PPARa ligand Wy14643 [105]. On the contrary, treatment with fibrate, a potent PPARa agonist, suppressed SR-BI protein expression in the liver without changing steady state of mRNA in both wild-type C57BL/6 mice [106] and PDZK1-deficient mice [107], which may be due to down-regulation of Clamp, a putative SR-BI-stabilizing protein found in the hepatic plasma membrane, but independent of PDZK1. Moreover, fenofibrate-decreased SR-BI stability was also independent of the proteasome, calpain protease, or the lysosome [107]. It remains to further identify the precise mechanisms regulating hepatic SR-BI by PPARa. Noteworthy, in human, SRBI mRNA level in circulating mononuclear cells was not changed by fenofibrate [108].

A selective PPARY agonists induced SR-BI expression in rat hepatocytes, endothelial cells, Hepa 1c1c-7 and Kupffer cells by a mechanism involving co-activation of HNF4 $\alpha$ [103]. In addition, the PPARy agonist thiazolidinediones increased hepatic SR-BI mRNA and protein levels in HepG2 by binding to the SR-BI promoter region to induce SR-BI promoter activity [109]. In vivo, the PPARY agonist GW7845 (20 mg/kg/day) significantly increased SR-BI protein expression in adipose tissue, but not liver of C57BL/6 mice [110]. SR-BI expression was also increased in atherosclerotic lesions of apoE-deficient mice treated with the PPARY ligand PG-J2 [105].

\subsubsection{FXR}

The regulation of SR-BI expression by FXR is contradictory. On the one hand, bile acid (chenodeoxycholic acid)-activated FXR/RXR suppressed SR-BI expression in hepatocytes by inducing the expression of the Small Heterodimer Partner (NROB2, SHP), which inhibited LRH-1transactivation of SR-BI [111]. It was assumed that chenodeoxycholic acid influenced SR-BI 
possibly through multiple pathways, since it also activated other gene expression regulatory pathways besides selective agonism of FXR [112, 113]. A specific FXR agonist GW4064 also down-regulated the expression of SR-BI protein in Huh7.5 cells [114]. On the other hand, it was reported that GW4064 induced mRNA and protein levels of hepatic SR-BI in vitro and in vivo by increasing HNF4 $\alpha$ protein expression, which directly targeted HNF4a response elements in the SR-BI promoter [115]. Similarly, an FXR agonist obeticholic acid increased hepatic SR-BI mRNA and protein levels in hyperlipidemic hamsters, but not in normolipidemic hamsters [116]. FXR can directly bind to the intronic inverse repeat separated by one nucleotide (IR1), a FXR response element (FXRE), in the mouse SR-BI promoter to increase its expression [117]. In human HepG2, FXR can bind to a directed repeat DNA motif DR8 to up-regulate SR-BI expression [118]. In addition, in the FXR-deficient mouse model SR-BI expression was significantly decreased [119].

Recently, it was demonstrated that FXR and LXR bound to their recognition sequences within the intronic region (containing FXRE (IR-1) and LXRE) of the SR-BI gene and transactivated the SR-BI reporter gene in a synergistic manner [99]. In in vivo model, combined treatment of FXR and LXR agonists significantly increased the mRNA and protein levels of SR-BI in the liver, while FXR or LXR agonists alone did not have such effect [99]. Although the intronic FXRE and LXRE regulatory region was not conserved in the human SR-BI genomic sequence, higher mRNA expression level of SR-BI was observed in human primary hepatocytes and HepG2 cells exposed to combined treatment of FXR and LXR agonists, compared with individual agonist treatment [99].

RXR forms heterodimers with the LXRa, LXR, PPAR , and FXR for transcriptional regulation of SR-BI [97, 102, 111]. The RXR agonist 9-cis retinoic acid induced the expression of SR-BI mRNA in human umbilical vein endothelial cells (HUVECs) [120].

\subsubsection{SREBP}

SREBP-1a is a key protein in the transcriptional regulation of some genes by sterols [121]. SREBP-1a activated transcription of rat SR-BI by binding to sterol response elements (SRE) in the promoter of SR-BI in response to altered intracellular sterol levels [121]. SREBP-1a requires the presence of a coactivator like simian-virus-40-protein-1 (Sp1) to promote maximum activation of the SR-BI promoter [122]. SREBP-1a is also a potential coactivator of the estrogen-ERdependent upregulation of SR-BI gene [123]. 
SREBP-2 increased SR-BI mRNA and protein levels in transfected HEK293 and HepG2 cells by binding to SR-BI promoter [124]. This study also suggests that SREBP-2 is a more potent inducer for SR-BI promoter activity than the SREBP-1a isoform in the studied models [124]. On the contrary, in SREBP-1a and -1c transgenic mice on normal chow, hepatic SR-BI was transcriptionally down-regulated [125].

\subsubsection{ER}

Estradiol (E2) significantly increased SR-BI promoter activity by activation of ER- $\alpha$ and $-\beta$ and following binding to ER element (ERE) 1, 2, and 4 in vitro [123]. Along with ERs, mixed-lineage leukemia (MLL) histone methylases, including MLL1 and MLL2, play important roles in E2mediated SR-BI activation, through binding to SR-BI promoter and further control of the assembly of transcription pre-initiation complex and RNA polymerase II recruitment [126]. MLL2 knockdown in mice reduced SR-BI expression in mouse liver [126]. In addition, high-dose estrogen treatment, however, dramatically reduced SR-BI in the liver and increased SR-BI expression in the adrenal gland and corpus luteal cells of the ovary in rats [127]. Further study indicated that in the rat liver the decrease in SR-BI by 17a-ethinyl estradiol treatment was due to the estrogen-increased lowdensity lipoprotein receptor (LDLR) activity, while in the adrenal glands the increase in SR-BI was due to inhibition of adrenocorticotropic hormone (ACTH) production [128]. Recently, it was reported that estrogen caused down-regulation of endothelial SR-BI in human coronary artery endothelial cells depending on G-protein-coupled ER (GPER), but there was no effect on SR-BI expression in liver cells because of low expression of GPER in hepatocytes [129]. The estrogen regulation mechanisms of the SR-BI gene were reviewed elsewhere [130].

\subsubsection{SF-1}

SF-1, an orphan member of the nuclear hormone receptor gene family, plays a key role in the regulation of steroidogenesis [131]. SF-1 was shown to directly bind to the SR-BI promoter in a sequence-specific manner [131], and activated transcription of the SR-BI gene in both human HTB9 bladder carcinoma and mouse Y-1 tumor cells, which effect was enhanced by cyclic AMP (cAMP) by increasing phosphorylation of SF-1 at Ser 430 by PKA [132]. Furthermore, no SR-BI mRNA was detected in the gonadal ridge of day 11.5 SF-1 KO embryos, suggesting SF-1 also regulated SR-BI in vivo [133]. 


\subsubsection{HNF4a}

In cultured hepatocytes, HNF4a increased SR-BI expression at both mRNA and protein levels, which can be inhibited by a PPARY antagonist BADGE [134]. In vivo, hepatic overexpression of HNF4a upregulated SR-BI mRNA and protein levels in rat liver possibly by the upregulation of PPARY [134].

\subsubsection{LRH-1}

LRH-1 induced SR-BI expression by binding to an LRH-1 response element in the promoter of $\mathrm{SR}-\mathrm{BI}$, which associated with histone $\mathrm{H} 3$ acetylation on the SR-BI promoter in vitro [135]. In vivo, the SR-BI mRNA levels were decreased in the livers of the heterozygous LRH-1-KO mice [135]. LRH-1 was also involved in FXR/RXR-suppressed SR-BI expression by bile acid (chenodeoxycholic acid) in hepatocytes through inhibition of LRH-1-transactivation of SR-BI [111].

\subsubsection{PREB}

PREB is a transcription factor that regulates prolactin promoter activity in the rat anterior pituitary [136]. Overexpression of PREB using a PREB-expressing adenovirus increased the expression of the SR-BI protein in the adrenocortical cell line $\mathrm{Y}-1$ cells by binding to the PREB-responsive cis-element in the SR-BI promoter under conditions that increase cellular cAMP levels [137].

\subsubsection{FoxO}

Recently, it was reported that mice with liver-specific triple FoxO KO (FoxO1,3,4) had substantially decreased hepatic SR-BI expression [138]. In our experiments, knockdown of FoxO1 did not change SR-BI mRNA and protein expression in primary human aortic endothelial cells.

\subsubsection{DAX-1}

The nuclear receptor NROB1 (DAX-1) plays an important role in adrenal development [6]. DAX-1 repressed activation of the SR-BI promoter not only through interaction with SREBP-1a to prevent subsequent binding of SREBP-1a to SR-BI promoter, but also by formation of a complex with SF- 
1 protein on the DNA to prevent activation of SR-BI promoter in transfected adrenal Y-1, HTB-9, and HepG2 cells [139].

\subsubsection{YY-1}

The ubiquitous zinc finger transcription factor $Y Y-1$ has been shown to repress several sterolresponsive gene promoters [140]. YY-1 also repressed the activity of the SR-BI promoter, and attenuated the transcriptional synergy caused by the combined actions of SREBP-1a and a coactivator like simian-virus-40-protein-1 (Sp1) by inhibiting the binding of SREBP-1a to SR-BI promoter in transfected HTB9 cells [141].

\subsubsection{PXR}

SR-BI was inhibited by the PXR activators rifampicin and lithocholic acid in HepG2 cells, as well as by pregnenolone 16a-carbonitrile (PCN) in primary rat hepatocytes [142]. In vivo study demonstrated that PCN decreased hepatic SR-BI level in ApoE3-Leiden (E3L) and E3L.CETP mice [143].

\subsubsection{STAT}

The mutagenesis of a STAT1/STAT2 response element in the SR-BI promoter abolished the ability of IFNa to suppress SR-BI promoter activity [144].

\subsection{Endogenous factors}

\subsubsection{Hormones}

In steroidogenic cells, the expression of SR-BI is regulated by trophic hormones in concert with the regulation of steroid hormone production [145]. The protein and mRNA expression of SR-BI were increased in cultured murine Y1-BS1 adrenal cells treated with ACTH [146]. ACTHstimulation of SR-BI can be mediated through CAMP-increased binding of SF-1 to the SR-BI promoter [17]. It was reported that in vivo ACTH treatment increased SR-BI protein expression in adrenal glands of C57BL/6 mice, which was suppressed by treatment with the glucocorticoid 
dexamethasone phosphate [147]. In addition, in the acute phase of adrenocortical steroidogenesis, ACTH rapidly stimulated the metabolism of sphingolipids and the secretion of sphingosine-1-phosphate (S1P), which further increased the expression of SR-BI [148]. ACTH treatment can modulate SR-BI expression at the transcriptional and posttranscriptional levels, and the underlying mechanisms were recently summarized by Shen et al. [149].

Glucocorticoids suppressed SR-BI expression in adrenocortical H295R and ovarian SKOV-3 cells depending on the glucocorticoid receptor (GR), which cannot directly bind to the SR-BI promoter [150]. Further study showed that glucocorticoids repressed SR-BI expression through the region between nucleotides -201 and -62 in the human SR-BI promoter, which included putative binding sites for transcriptional repressors for SR-BI gene transcription [150]. In vivo, SR-BI mRNA level was upregulated in adrenals of corticosterone-deficient mice, whereas corticosterone treatment inhibited SR-BI gene expression in these mice [150]. Treatment with metyrapone, an inhibitor of corticosterone synthesis, increased SR-BI mRNA level in adrenals from wild-type mice [150]. On the contrary, the glucocorticoid dexamethasone increased SR-BI mRNA expression in primary rat hepatocytes, which was reduced by the addition of the anti-glucocorticoid mifepristone [151]. The stimulation effect of dexamethasone was not observed in HepG2 cells and THP-1 macrophages [151].

Angiotensin II (Ang II) was reported to suppress SR-BI expression in human umbilical vein endothelial cells by PI3K/Akt/FoxO1 pathway by downregulating SR-BI promoter activity, which was rescued by the Ang II receptor type 1 (AT1) blocker olmesartan [152]. Ang II treatment also down-regulated SR-BI protein and mRNA expression in a mouse proximal tubular cell line MCT cells, which effect was attenuated by an AT1 antagonist, but not an AT2 antagonist [153]. In vivo, Ang II-infusion into rats induced a significant decrease of SR-BI protein expression in isolated tubules [153]. On the contrary, in the human adrenocortical carcinoma cell line NCI-H295R cells Ang II stimulated SR-BI mRNA and protein expression by activation of the human SR-BI promoter [154].

Insulin increased both mRNA and protein levels of SR-BI in polarized CaCo-2 cells, which effects were abrogated by PI3K, Akt, or mTOR pharmacological antagonism [155]. In vivo, SR-BI expression was increased in all intestinal segments in two diet-induced animal models of insulin resistance (fructose-fed hamster and high-fat-fed mouse) [156]. It was reported that IGF-1 decreased SR-BI mRNA and protein levels by the PI3K/Akt signaling pathway in THP-1-derived 
macrophages [157]. Similarly, IGF-1 suppressed expression of SR-BI in cultured HepG2 cells [158]. Consistent with in vitro data, in rats infused with IGF-I for 7 days SR-BI mRNA level was decreased [158]. The PI3K/Akt pathway participated in IGF-1-inhibited SR-BI expression by suppression of activity of the human SR-BI promoter [158]. Pregnancy-associated plasma proteinA (PAPP-A)-decreased SR-BI expression in THP-1 macrophage-derived foam cells was mediated through the IGF-1/PI3K/Akt signaling pathway [158]. In vivo, PAPP-A knockdown by PAPP-A shRNA in apoE-deficient mice reduced the IGF-1 levels, repressed the PI3K/Akt pathway, and in turn increased SR-BI expression in both aorta and peritoneal macrophages [159].

It was also reported that thyroid hormone receptor $\beta(T R \beta)$, hepatic lipase $(H L)$, testosterone and leptin also can regulate SR-BI expression. Activation of TR $\beta$ by its agonist GC-1 increased SR$\mathrm{BI}$ expression [160]. Inhibition of HL in mice up-regulated the SR-BI expression in adrenal gland [161, 162]. Testosterone up-regulated SR-BI mRNA and protein levels in both cultivated HepG2 cells and primary human monocyte-derived macrophages (HMDMs) [163]. In leptin-deficient mice, the hepatic SR-BI protein level was reduced [164]. Treatment with leptin for 2 days dosedependently increased hepatic SR-BI protein and mRNA levels in leptin-deficient mice [164].

A recent study suggested that DNA methylation may participate in hormonal regulation of SR-BI expression in a tissue-specific manner [145]. The SR-BI gene contains one CG island (CGI) in its promoter and seven CGIs in its intronic regions [145]. It was demonstrated that the seven intron CGls were methylated differentially in mouse adrenal $\mathrm{Y}-1$ cells, mouse Leydig tumor cells (MLTCs), ovarian granulosa cells, and mouse liver Hepa 1-6 cells through N(6), 2'-O-

dibutyryladenosine3':5'-cyclic monophosphate regulation [145]. In addition, DNA hypermethylation of the SR-BI promoter in rat fetal adrenal glands may lead to decreased SR-BI expression [165].

\subsubsection{Other endogenous factors}

The cytokine IFNa suppressed SR-BI expression in HepG2 cells by a pathway involving phosphorylation of STAT1/STAT2, which in turn bound to STAT1/STAT2 response element in the SR-BI promoter to inhibit SR-BI promoter activity [144]. The second messenger cAMP increased SR-BI mRNA expression in transfected 293T cells, human granulosa SVOG-4o cells, and in primary cultures of rat theca-interstitial cells by the cAMP response element binding protein (CREB), which directly bound to promoter of SR-BI to induce its activation [166]. 
It was shown that administration of liver growth factor (LGF) to ethane dimethanesulfonate (EDS)treated rats resulted in a remarkable increase in the levels of SR-BI protein [167]. Hormonesensitive lipase (HSL) KO male mice have increased SR-BI protein expression, but not mRNA levels in the testis [168]. The molecular mechanisms by which LGF and HSL regulated SR-BI expression remain to be further studied.

It was shown that high glucose $(25-30 \mathrm{mM})$ decreased SR-BI mRNA and protein levels in HMDMs [169], Caco-2/15 cells [170], and HepG2 cells [171]. Further study indicated that glucose-induced suppression of hepatic SR-BI expression was partially mediated by the activation of the p38 MAPK-specificity protein-1 pathway [171]. In vivo, hepatic expression of SR-BI was lower in diabetic rats than in euglycemic rats [171]. On the other side, in J774A.1 macrophage-like cells, high glucose (30 mM) increased SR-BI mRNA and protein expression [172]. Furthermore, SR-BI mRNA and protein expression were significantly increased in mouse peritoneal macrophages (MPM) harvested from C57BI/6 diabetic mice, compared to MPM from control non-diabetic mice [172]. In addition, one study showed that high glucose (25 mM) did not modify SR-BI abundance in polarized CaCo-2 cells [155].

\subsection{NcRNA}

Recently, ncRNA, such as miRs have been investigated in the regulation of SR-BI expression. MiRs regulate SR-BI expression at the post-transcriptional level by directly binding to complementary sequences in the 3'-untranslated regions (3'-UTR) of SR-BI mRNA, causing RNA destabilization or translational repression. The miRs regulating SB-BI expression include miR-24, miR-96, miR-125a, miR-185, miR-217, miR-223, and miR-455.

Recent work demonstrated that miR-24 inhibited SR-BI protein expression in HepG2 and THP-1 cells by specifically targeting the 3'-UTR of SR-BI mRNA [173]. Another group also indicated that miR-24 decreased SR-BI level in steroidogenic cells MLTC and Y-1, as well as HepG2 cells [174]. In vivo, miR-24 administration decreased hepatic SR-BI expression and promoted atheromatous plaque formation in apoE-deficient mice [173]. It was shown that the level of SR-BI expression was repressed by miR-96, miR-185, and miR-223 in HepG2 cells, which directly targeted the 3'UTR of SR-BI mRNA with a coordinated effect [175]. Furthermore, the decrease of miR-185 and miR-96 is related to the increase of SR-BI in the liver of apoE-deficient mice exposed to a high fat 
diet (HFD) [175]. Another study found that miR-125a and miR-455 negatively regulated mRNA and protein levels of SR-BI in the rat Leydig tumor R2C cells and the CAMP-sensitive cells MLTCs [176]. Further study showed that miR-125a, but not miR-455 inhibited expression of hepatic SR$\mathrm{BI}$ in the mouse and rat livers as well as the mouse hepatic cell line Hepa 1-6 [176]. It was reported that miR-217 mimic administration in apoE-deficient mice significantly down-regulated SR-BI mRNA levels [177]. The mechanisms of miR-217-mediated regulation of SR-BI are not yet clear. Moreover, other miRs regulating the SR-BI expression remain to be further explored.

\subsection{Accessory proteins interacting with SR-BI protein}

Accessory proteins, PDZK1/Na+/H+ exchanger regulatory factor 3 (NHERF3), NHERF1 and NHERF2, can interact with SR-BI, which in turn can regulate the expression of SR-BI at the posttranslational level [17]. PDZK1 is expressed in liver, kidney and gut, but not in steroidogenic tissues [112], whereas NHERF1 and NHERF2 are expressed in steroidogenic cells of the adrenal gland, ovary and testis, as well as the liver [17, 178]. All NHERFs contain multiple "PDZ" domains (postsynaptic density (PSD-95), Drosophila disc large tumor suppressor (Dlg-1), and zona occludense-1 protein (ZO-1)) [6, 179], which bind and interact with the PDZ recognition motif in $\mathrm{SR}-\mathrm{BI}$ to regulate its protein stability $[180,181]$. It was reported that $\mathrm{SR}-\mathrm{BI}$ protein expression in PDZK1-deficient mice was reduced by $95 \%$ in the liver, $50 \%$ in the proximal intestine, but not affected in steroidogenic organs [178]. On the contrary, NHERF1 and NHERF2 overexpression down-regulated the SR-BI protein expression in liver and steroidogenic tissues/cells [180]. The regulation exerted by NHERFs on SR-BI expression was summarized by several reviews [6, 17 , 112]. The nuclear receptors $L X R \alpha-$ and PXR-regulatory action on SR-BI could also be through affecting PDZK1. One study indicated that activation of LXR enhanced mRNA expression of PDZK1 in HepG2 cells, while activation of PXR reduced the protein amount of PDZK1 [182].

\section{Natural products regulating SR-BI}

Natural products have been historically proven to be a promising pool of structures for drug discovery [21], and significant efforts have recently been taken to explore the SR-BI regulatory potential of natural products originating from traditional medicine or dietary source [183, 184]. Details of representative natural products are listed in Table 3. 


\subsection{Polyphenols}

Polyphenols are the most well-known natural products which possess many bioactivities, including regulation of SR-BI expression $[185,186]$. This class of phytochemicals is chemically characterized by common polyhydroxylated phenolic moieties. They include two main classes: flavonoids and non-flavonoids [187, 188].

\subsubsection{Flavonoids}

\subsubsection{Flavonols}

Some of the major flavonol compounds are quercetin and kaempferol. Onions, broccoli, apples, green tea, and black grapes are the sources of these flavonols. Most research on flavonols related to SR-BI expression focused on cellular cholesterol efflux [189]. Quercetin significantly increased the expression of SR-BI in HepG2 cells in a concentration- and time-dependent manner [190]. Moreover, quercetin induced the expression of SR-BI and the selective uptake of HDL-C through PPARy pathway [190]. Kaempferol, extracted from a classic Chinese medicine Carthami Flos which is used for promoting blood circulation and removing blood stasis, up-regulated SR-BI expression and further inhibited oxidized LDL (oxLDL) uptake in macrophages [191].

\subsubsection{Flavanols}

The dietary consumption of polyphenols consists principally of $80 \%$ flavanols, which mainly include catechins and tannins $[187,188]$. Treatment with catechins $(30 \mathrm{mg} / \mathrm{kg})$ in rats increased mRNA expression of SR-BI in aorta and in liver, which resulted in anti-atherogenic properties [192]. 1,2,3,4,6-penta-O-galloyl- $\beta$-D-glucose (PGG) is a prototypical gallotannin and the key compound in the biosynthetic pathway of hydrolysable tannins. It is highly enriched in medicinal herbals such as Rhus chinensis, Paeonia lactiflora, and Acer truncatum. PGG increased expression of SR-BI in both J774 and THP-1 macrophages [193].

\subsubsection{Flavones}


Flavones include apigenin, chrysin, diosmin, luteolin and baicalein, which could be detected in fruits, nuts, and vegetables [194]. Apigenin-7-O- $\beta$-D-glucuronide, which is present in Cirsium japonicum DC, was reported to enhance the expression of SR-BI and inhibit the uptake of oxLDL by macrophage [195]. Luteolin, a bioactive compound abundant in celery and green bell pepper, induced SR-BI expression and further inhibited oxLDL-elicited macrophage foam cell formation [196].

\subsubsection{Non flavonoids}

\subsubsection{Phenolic acids}

Phenolic acids are widely found in a variety of nuts and fruits, such as raspberries, grapes, strawberries, walnuts, cranberries, and black currants. These compounds exist predominantly as hydroxycinnamic acids ( $p$-coumaric acid, caffeic acid, ferulic acid, chlorogenic acid, and sinapic acids) and hydroxybenzoic acids (gallic acid, salicylic acid, protocatechuic acid, ellagic acid, gentisic acid) or alternatively as conjugated forms [197]. Caffeic acid and ferulic acid, the major phenolic acids isolated from coffee, were proven to regulate SR-BI expression, and have antiatherogenic properties by enhancing HDL-mediated cholesterol efflux from the macrophages [198]. Ellagic acid regulated PPARY-SR-BI signaling pathway and in turn downregulated macrophage lipid uptake and suppressed foam cell formation from macrophages with oxLDL treatment [199].

\subsubsection{Stilbenes}

Among stilbenes, resveratrol (3,5,4'-trihydroxy-trans-stilbene) is the well-studied stilbenoid. Resveratrol is a natural polyphenolic stilbene found in grape skin, nuts, and some herbal medicines, such as Fallopia japonica [200]. Resveratrol is widely used as an anti-cancer, antioxidant and anti-atherosclerosis dietary supplement [201]. Many molecular actions of resveratrol rely on the activation of AMP-activated protein kinase (AMPK) and sirtuin 1 (SIRT1) [202]. It has been demonstrated to be responsible for the protective effect in different pathological processes characterized by hyperlipidemia [203]. In human keratinocytes, resveratrol was able to increase SR-BI protein level in a dose-dependent manner [204]. Resveratrol has also been proved to decrease serum cholesterol level through induction of major cholesterol transporters (ABCA1, ABCG1 and SR-BI) in both human macrophages and endothelium, which in turn stimulated 
removal of free cholesterol and cholesterol esters [205]. Although positive effects of polyphenols have been observed in preclinical studies, it is important to point out that, in humans, most of the bioactive effects depend on the absorption and metabolism of these compounds [206-208]. Thus, further clinical studies are warranted to determine the bioactivity and biotransformation of polyphenols toward regulation of SR-BI expression in humans [209].

\subsubsection{Clinical study}

SR-BI plays a very important role in regulation of cholesterol metabolism in humans. Hepatic SRB1 mediates the selective uptake of HDL-CE into the liver for excretion in the bile and ultimately the faeces to decrease cholesterol level. Thus, most of clinical studies focus on the effect of compounds on the levels of total cholesterol, LDL-cholesterol, and HDL-cholesterol. Polyphenols were reported to exhibit the beneficial effects on hyperlipidemia while contrary opinions also exist. Dietary flavonoids were regarded as related factors of reduced total and LDL cholesterol and increased HDL fraction [210-214]. In the Moli-sani cohort, higher intake of polyphenols was associated with lower total and LDL cholesterol and higher HDL cholesterol levels [215]. In a subset cohort of the ATHENA study, total polyphenol intake was not associated with an improved lipid profile, but individuals with the serum paraoxonase/arylesterase 1 single nucleotide polymorphisms rs854549 and rs854552 showed a positive association between HDL cholesterol levels and total polyphenol intake [216]. A 4-week, double blind, randomized, placebo controlled trial involving 32 type 2 diabetes patients showed that flavonoid-rich grape seed extracts significantly improved the biomarkers of glycemia and hyperlipidemia [217]. A randomized, double-blind, placebo controlled trial with 48 diabetes patients revealed that a 12-week daily supplementation of pycnogenol $(125 \mathrm{mg}$ ), could reduce CVD risk factors (such as lowering cholesterol level) [218]. Red wine polyphenols were found to have a beneficial effect on plasma concentrations of lipoprotein and cholesterol in a randomized clinical trial involving 67 men with high cardiovascular risk [219]. In a randomized, controlled, cross-over study, a single dose of flavonoid-rich black tea was found to significantly reduce blood glucose and cholesterol in men and women without history of cardiovascular disease (CVD) or diabetes [220]. Another randomized controlled trial was launched in subjects with obesity and metabolic syndrome following an 8-week supplementation with green tea beverage (928 mg catechins) or encapsulated green tea extracts (870 mg catechins). Green tea consumption showed a decreasing trend in LDL cholesterol [221, 222]. The blood cholesterol-lowering effects of 
resveratrol were observed in type 2 diabetes [223], and in obese men with impaired insulin action [224].

On the contrary, a prospective cross-sectional study conducted on 38,018 women suggested there was no relationship between flavonols or flavones consumption and the risk of CVD [225]. Two randomized, double-blind, placebo controlled trials showed the supplementation of polyphenol might not improve cholesterol profile in non-diabetic subjects with impaired glucose tolerance [226]. Long-term randomized trials are warranted to reveal the effects of polyphenols in humans.

Ongoing and completed clinical trials have reported the safety and efficacy of polyphenols as anticancer agents [227]. A phase I study showed the efficacy and safety of muscadine grape skin extract (which contains ellagic acid, quercetin, and resveratrol) in men with biochemically recurrent prostate cancer [228]. Flavonoids might be specific components that could reduce ovarian cancer risk. 171,940 Nurses' Health Study participants were followed to examine associations between intakes of total flavonoids, including their subclasses flavanones, flavonols, anthocyanins, flavan-3-ols, flavones, and polymeric flavonoids, and risk of ovarian cancer by using Cox proportional hazards models. Participants in the highest quintiles of flavonol and flavanone intakes had modestly lower risk of ovarian cancer, especially the association for flavanone being stronger for serous invasive and poorly differentiated tumors [229]. Quercetins, which belongs flavonol subclass, are also proved to be related with ovarian cancer progress [230].

\subsection{Alkaloids}

\subsubsection{Purine alkaloids}

Purine alkaloids are produced in a variety of plant species, e.g., coffee, tea and cacao. The most abundant purine alkaloid is caffeine. Prenatal caffeine ingestion $(\mathrm{PCl})$ induced intrauterine growth retardation (IUGR). Further studies indicated that caffeine inhibited SR-BI-mediated cholesterol uptake in fetal adrenals, subsequently decreased glucocorticoid synthesis and induced IUGR. Moreover, caffeine induced long-term alterations in SR-BI expression and glucocorticoid synthesis in adult male offspring rat adrenals [231]. 


\subsubsection{Benzylisoquinoline alkaloids}

Benzylisoquinolines are mainly contained in basal angiosperms, e.g., in members of the Berberidaceae, Fumariaceae, Papaveraceae, Menispermaceae, and Ranunculaceae [232]. Berberine is the principal bioactive ingredient of Rhizoma coptidis, a common traditional Chinese herb used for the therapy of inflammatory disorders and diabetes mellitus [233]. Berberine upregulated SR-BI expression, and inhibited oxLDL-induced foam cell formation from macrophage by inhibiting the lectin-like oxidized LDL receptor-1 (LOX-1) [234].

\subsubsection{Trimethylglycine}

Trimethylglycine, also called betaine, is a crystalline alkaloid contained in sugar beets and other plants. Betaine serves as an animal and human nutrient, which has been well investigated in respect of its effects on lipid metabolism and CVD, as well as liver disease [235, 236]. Feeding pigs with betaine-supplemented diets during pregnancy and lactation increased hepatic LDLR and SR-BI gene expression [237]. Chronic ethanol markedly inhibited the glycosylation of SR-BI, resulting in the decreased localization of the mature SR-BI in the liver as well as alcoholic hyperlipidemia. Betaine effectively prevented chronic alcohol-mediated impairment of SR-BI glycosylation, plasma membrane localization, and consequent impaired cholesterol uptake function [238].

\subsubsection{Clinical study}

Several systematic reviews and meta-analyses of randomized controlled trials have consistently demonstrated the beneficial effects of alkaloids on blood cholesterol [230, 239-241]. To date, a number of human trials have been performed on subjects with different disease conditions including those with hypercholesterolemia [242-244], metabolic syndrome [245, 246] and CVD [247]. Meta-analysis of 11 clinical trials (including 874 participants) have revealed that the administration of berberine produced a significant reduction in total cholesterol, triglycerides and LDL cholesterol levels, with a remarkable increase in HDL [248]. The majority of the human trials showed reductions of $11-29 \%$ in total cholesterol and $8-25 \%$ in LDL cholesterol while a few did not show significant effects [245, 249]. 
Various human clinical studies have found that in addition to alkaloids' association with metabolic diseases, betaine intake is associated with cancers, such as lung cancer [250] and liver cancer [251]. In these studies, a higher betaine intake resulted in a lower risk of cancer. Furthermore, research has suggested that cancer incidence could be decreased by $11 \%$ by consuming choline plus betaine (100 mg/day) [252]. The association between caffeine intake and cancer has been extensively studied. Recently in a clinical trial on prostate, lung, colorectal, and ovarian cancer screening, of the 97,334 eligible individuals, 10,399 developed cancer. Caffeine intake was not associated with cancer risk in a dose-response manner [253].

\subsection{Terpenoids}

Terpenoids are a group of about 40000 compounds with diverse structures, all sharing the characteristic of being synthesized from isoprenoid building blocks. According to the number of these isoprene units, Terpenoids of 5, 10, 15, 20, 30 and 40 carbon atoms are classified as hemi-, mono-, sesqui-, di-, tri- and tetra-terpenes, respectively [254]. For instance, the sesquiterpenes isolated from various species of marine sponges exhibited various biological activities. New tetracyclic merosesquiterpenes, including both 19-methoxy-9,15-ene-puupehenol isolated from the marine sponge Hyrtios digitatus and the known 20-methoxy-9,15-ene-puupehenol could activate SR-BI in HepG2 cells [255]. Tetraterpenoids, also called carotenoids, comprise a group of tetraterpenes in plants. $\beta$-Carotene, the principal provitamin A carotenoid, partly controlled SR$\mathrm{BI}$ activity through a feedback regulation [256]. Indeed, studies have pointed out that SR-BI activity was partly controlled by cleaved $\beta$-carotene retinoids. Using both mouse models and human cell lines, it was specifically shown that retinoic acid induced the expression of the intestinal transcription factor intestine-specific homeobox (ISX) that repressed the expression of SR-BI [257], thus impacting both carotenoid conversion and uptake [258]. To the best of our knowledge, there are a large number of in vitro studies demonstrating the cytotoxicity of terpenoid molecules against various breast [259], prostate [260] and liver cancer cells [261], yet very few compounds have been evaluated in clinical study.

\subsection{Unsaturated fatty acid}

Omega-3 fatty acids, such as docosahexaenoic acid (DHA) and eicosapentaenoic acid (EPA), induced higher gene expression of SR-BI, ABCA1, and ABCG5, which might be the mechanisms 
by which these compounds increased fecal cholesterol excretion from obese hamster compared to control [262]. Olive oil, containing oleic acid, up-regulated the genes of SR-BI, ABCA1, PPARY and CD36 [263], which might contribute to the cardiovascular-protective effect of olive oil [263]. 13-hydroxy linoleic acid (13-HODE), which is the hydroxylated derivative of linoleic acid (LA), is a natural PPAR agonist [264]. 13-HODE increased protein levels of SR-BI, LXRa, ABCA1, and ABCG1 in macrophages, and further induced macrophage cholesterol efflux [265].

Dietary guidelines recommended by the American Heart Association (AHA) for health individuals include consumption of omega-3 fatty acids [266]. However, the increase in LDL-cholesterol is a potential disadvantage of omega-3 fatty acids consumption [267, 268]. On the contrary, the COMBOS study revealed a reduction from baseline in non-HDL-cholesterol was significantly greater with omega-3 acid ethyl esters (OM-3A EE) plus simvastatin than with simvastatin alone [269]. Treatment with OM-3-A EE also significantly reduced TG levels and VLDL-cholesterol levels compared with placebo. Many publications indicated the efficacy of omega- 3 fatty acids in cancer therapy. In an epidemiological study, women affected by metastatic breast cancer supplemented with $1.8 \mathrm{~g}$ of DHA during chemotherapy with anthracyclines could increase their survival by 8 months and decrease symptoms [270]. EPA (2.7 g/day) has been reported to be able to inhibit colorectal aberrant crypt foci, compared to placebo control group after one month of supplementation in a Japanese clinical trial [271]. Due to low side effects, high efficacy, and tolerability against chemotherapy and radiotherapy, a plenty of clinical studies has been performed on prostate, lung, gastric, pancreatic cancer [272].

\subsection{Polysaccharides}

Guar gum (GG) is a viscous polysaccharide extracted from the seed of the legume plant Cyamopsis tetragonolobus that has been reported to have hypocholesterolemic effects in guinea pigs [273], rats [274], and humans [275]. In pigs fed with an atherogenic diet, GG consumption reduced hepatic SR-BI mRNA to $36 \%$ of the control expression but did not affect SR-BI protein abundance [276]. $\beta$-Glucans comprise a group of $\beta$-D-glucose polysaccharides naturally localizing in the cell walls of cereals. It was reported that fungi $\beta$-glucan from oat fiber remarkably increased phagocytosis and SR-BI expression in the macrophage, decreased blood levels of LDLcholesterol (LDL-C) and reduced the risk of CVD [277]. 
It was shown that flavonoids (e.g., luteolin, quercetin, kaempferol), stilbenes (e.g., resveratrol, amorphastilbol), and unsaturated fatty acids (e.g., omega-3 fatty acids, oleic acid) can be acting as ligands of PPARs, which regulate SR-BI expression as discussion in section 3. It was also reported that the natural chenodeoxycholic acid, isolated from goose bile or Calculus bovis, could activate FXR and directly up-regulate SR-BI expression through intron binding on the FXRE [117].

\section{Conclusions}

SR-BI is a membrane glycoprotein and expressed in many normal and hormonally altered tissues and cell types. SR-BI is critical to lipoprotein metabolism by mediating selective uptake of CE from HDL in liver cells and the bi-directional flux of free cholesterol [16]. SR-BI is emerging as a multifunctional protein, which regulates clearance of remnant lipoproteins and Lp(a), autophagy, efferocytosis, autophagy, apoptosis, inflammation, adrenal steroid synthesis, oxidative stress, uptake of vitamins and viral entry into cells [2], as well as affects gastrointestinal, endocrine, reproductive, and cardiovascular pathophysiology [27-32]. In addition, SR-BI could also serve as a promising target for the delivery of therapeutic agents by reconstituted HDL [19, 20]. There are a number of studies trying to understand the relationship between functions of SR-BI and various diseases, including cancer and CVD.

It has been demonstrated that cholesterol metabolism was changed in cancer cells [61]. Cancer cells can take up CE via HDL/SR-BI pathway and use it as the substrate to enhance malignant phenotypes $[68,69]$. It was also shown that cholesterol metabolism plays an important role in cancer development and metastasis [66]. Furthermore, the protein expression level of SR-BI was demonstrated to correlate with development of some cancers, such as breast cancer, gastric adenocarcinoma tumor, prostate cancer, colorectal cancer, ovarian cancer and pancreatic cancer $[70,72,77]$. It was indicated that SR-BI plays an important role in cancer cell proliferation and apoptosis, suggesting its effect on carcinogenesis and metastasis. It was also shown that SR-BI regulates proliferation or apoptosis of cancer cells possibly through PI3K/AP-1, Akt or MITF pathways. It still remains to further examine the specific mechanisms for SR-BI involvement in development of cancer. SR-BI accessory protein PDZK1 is also involved in caner. PDZK1 regulated cell growth possibly by mediating c-Myc expression, which is often constitutively expressed in cancer cells. However, whether the effect of PDZK1 on the growth of cancer cells is 
dependent on SR-BI needs to be further studied. In addition, TAMs are associated with tumor progression, invasion and metastasis, and poor prognosis [86]. TAMs can switch to a phenotype promoting immunosuppressive function within the tumor microenvironment $[87,88]$, which may be mediated by SR-BI. The membrane cholesterol efflux of TAMs also influenced TAM-regulated tumorigenesis possibly by PI3K activity or mTORC2. Although SR-BI also mediates membrane cholesterol efflux, it remains to investigate the influence of SR-BI on membrane cholesterol efflux in TAMs and whether reprogramming of TAMs affects tumorigenesis through SR-BI. Although recent studies indicated SR-BI as a potential marker for cancer diagnosis and prognosis [17], it is important to further explore the role of SR-BI in cancer development, and investigate whether SR$\mathrm{BI}$ could be used as a target to treat cancer in the future.

The SR-BI protein expression can be regulated by transcriptional factors, endogenous factors, miRNAs, and its accessory proteins (NHERF1, NHERF2, PDZK1/NHERF3) at the transcriptional, post-transcriptional, or post-translational levels. The transcriptional factors regulating SR-B1 expression include LXR $\alpha / \beta$, PPAR $\alpha / \gamma, F X R$, RXR, SREBP-1a/1c/2, ER- $\alpha / \beta$, SF-1, HNF4a, LRH1, PREB, FoxO1/3/4, DAX-1, YY-1, PXR and STAT1/2. Endogenous factors regulating SR-B1 expression include hormones (ACTH, glucocorticoids, Ang II, insulin, IGF-1, PAPP-A, TRß, HL, testosterone and leptin), cytokine IFNa, LGF, HSL, and glucose. The regulation of SR-BI expression mediated by transcriptional factors and endogenous factors is very complicated. Some transcriptional factors (such as LXR and PPAR) and endogenous factors (such as ACTH) regulate SR-BI expression not only at the transcriptional level, but also at the post-transcriptional level. Additionally, the regulating effects of some factors (such as LXR, PPAR, FXR, ER, glucocorticoids) on SR-BI expression were inconsistent in literatures, which might be due to the different cell types and different animal models used. The detailed mechanisms of action of many factors regulating SR-BI expression are not clear and need further studies. Recently, several miRNAs, including miR-24, miR-96, miR-125a, miR-185, miR-217, miR-223, and miR-455, have been found to regulate the $S R-B I$ expression. It remains to further explore other miRNA regulating SR-BI expression. Another kind of ncRNA, long ncRNAs (IncRNA), have also been proposed as a new layer of gene regulation, however, up to now there are no studies to report IncRNAs regulating SR-BI expression. In addition, there are no studies to focus on the role of this kind of factors on SR-BI expression in tumor tissues or cells. Accessory proteins, PDZK1/NHERF3, NHERF1 and NHERF2, can interact with SR-BI and regulate the expression of SR-BI at the post-translational level [17]. Decrease in PDZK1 strongly down-regulated the SR-BI expression in liver, kidney and gut, while NHERF1 and NHERF2 overexpression down-regulated the SR-BI protein expression 
in liver and steroidogenic tissues/cells. It would be very interesting to investigate the changes of these factors in cancer tissues and cells, and further investigate their effect on SR-BI expression in cancer.

Natural products have been proven to be a promising pool for drug discovery. In this review, we summarized the identified natural products that regulate SR-BI expression, including polyphenols, alkaloids, terpenoids, unsaturated fatty acid, and polysaccharides. The natural products from polyphenols group reported to regulate SR-BI expression include quercetin, kaempferol, catechin, PGG, apigenin-7-O- $\beta$-D-glucuronide, luteolin, caffeic acid, ferulic acid, ellagic acid, resveratrol. In addition, caffeine, berberine, trimethylglycine, 19-methoxy-9,15-ene-puupehenol, 20-methoxy9,15-ene-puupehenol, $\beta$-carotene, DHA, EPA, 13-hydroxy linoleic acid, oleic acid, guar gum, and chenodeoxycholic acid from other groups were reported to regulate SR-BI expression. At present, most of the natural products regulating SR-BI expression were identified incidentally by studies examining lipid metabolism. There are no systematic studies screening the effect of natural products on SR-BI expression. In many cases the detailed molecular mechanisms of the studied natural products remain elusive or are just deduced from coincidental observations lacking experimental proof of causality. Thus, in-depth and stringent molecular analyses of active natural products may discover new strategies for the treatment or prevention of human diseases involving SR-BI, including cancer.

SR-BI plays a very important role in regulation of cholesterol metabolism in humans. In clinical studies, polyphenols were reported to exhibit the beneficial effects on hyperlipidemia while contrary opinions also exist. For example, supplementation of flavonoid-rich grape seed extracts and black/green tea, pycnogenol as well as red wine polyphenols were found to have a beneficial effect on plasma lipoprotein and cholesterol. On the contrary, some studies indicated that there was no relationship between polyphenol consumption and the risk of CVD or cholesterol profile. Interestingly, clinical trials have reported that supplementation of polyphenols-rich grape skin extract and flavonoids could reduce biochemically recurrent prostate cancer and ovarian cancer risk, respectively. Systematic reviews and meta-analyses studies have consistently demonstrated administration of alkaloid berberine reduced total cholesterol, triglycerides and LDL cholesterol levels in humans [248]. Moreover, a higher betaine intake was associated with lung cancer [250] and liver cancer [251]. Unsaturated fatty acid omega-3 fatty acids consumption increased in LDLcholesterol [267, 268], while OM-3A EE significantly reduced TG levels and VLDL-cholesterol levels compared with placebo in humans [269]. Omega-3 fatty acids DHA and EPA were reported 
to exhibit therapeutic effects on breast cancer and colorectal aberrant crypt foci, respectively [270, 271]. However, all these clinical studies are not able to prove whether the therapeutic effects of these natural products are due to their regulation of SR-BI expression or not.

Future directions in studying the SR-BI as a target of natural products and its significance in cancer include:

**Further understanding the role of SR-BI in cancer development. Recent studies indicated $\mathrm{SR}-\mathrm{BI}$ as a potential marker for cancer diagnosis and prognosis in humans [17], and plays an important role in cancer cell proliferation and apoptosis in vitro studies, but it is important to further confirm whether SR-BI could be used as an useful target to treat cancer in vivo and finally in humans.

${ }^{* *}$ Further understanding the regulatory mechanisms of SR-BI expression in cancer development by new biotechnologies. Although significant progress has recently been made in characterizing regulatory mechanisms of SR-BI, there are very limited studies to focus on its regulatory mechanisms in tumor tissues or cells. At present, new biotechnologies including RNAsequencing, IncRNA arrays, RNA interference (RNAi) or CRISPR/Cas9 library screening, has empowered the discovery of new epigenetic regulators (such as IncRNAs) that are associated with or regulate SR-BI expression [278]. Further investigation of the role of these new regulators will provide us a clear picture of how SR-BI expression is regulated in cancer development and can be therapeutically targeted.

\footnotetext{
${ }^{* *}$ Systematic studies screening of natural products targeting SR-BI expression in cancer models. Natural products have been proven to be a promising pool for drug discovery. At present, most of the natural products regulating SR-BI expression were identified incidentally by studies examining lipid metabolism. There are no systematic studies screening the effect of natural products on SR-BI expression. To identify potential drug leads with capability of regulating SR-BI expression in cancer cells or tissues from such large pool, it is important to do systematic screening of natural products targeting SR-BI expression in cancer models by high throughput drug screening platforms.
}

\section{Declaration of interests}


The authors state that there is no conflict of interest.

\section{Acknowledgements}

This work was supported by the Cultivation project for clinical medicine of the integrated traditional Chinese and western medicine and Cultivation project for education team of internal medicine of the integrated traditional Chinese and western medicine in the first-term subjects with special support in the first-class universities in Guizhou province (Qin Jiao Gao Fa No. 2017-158), Polish

KNOW (Leading National Research Centre) Scientific Consortium "Healthy Animal-Safe Food" decision of Ministry of Science and Higher Education No. 05-1/KNOW2/2015 and the Peter und Traudl Engelhorn Foundation for the promotion of Life Sciences.

\section{References}

[1] D. Calvo, M.A. Vega, Identification, primary structure, and distribution of CLA-1, a novel member of the CD36/LIMPII gene family, J Biol Chem 268(25) (1993) 18929-35.

[2] M.F. Linton, H. Tao, E.F. Linton, P.G. Yancey, SR-BI: A Multifunctional Receptor in Cholesterol Homeostasis and Atherosclerosis, Trends Endocrinol Metab 28(6) (2017) 461-472.

[3] M.C. Phillips, Molecular mechanisms of cellular cholesterol efflux, J Biol Chem 289(35) (2014) 240209.

[4] D.L. Williams, M.A. Connelly, R.E. Temel, S. Swarnakar, M.C. Phillips, M. de la Llera-Moya, G.H. Rothblat, Scavenger receptor BI and cholesterol trafficking, Curr Opin Lipidol 10(4) (1999) 329-39.

[5] J.M. Meyer, G.A. Graf, D.R. van der Westhuyzen, New developments in selective cholesteryl ester uptake, Curr Opin Lipidol 24(5) (2013) 386-92.

[6] W.J. Shen, S. Asthana, F.B. Kraemer, S. Azhar, Scavenger receptor B type 1: expression, molecular regulation, and cholesterol transport function, J Lipid Res 59(7) (2018) 1114-1131.

[7] M.A. Connelly, D.L. Williams, Scavenger receptor BI: a scavenger receptor with a mission to transport high density lipoprotein lipids, Curr Opin Lipidol 15(3) (2004) 287-95.

[8] G. Valacchi, C. Sticozzi, Y. Lim, A. Pecorelli, Scavenger receptor class B type I: a multifunctional receptor, Ann N Y Acad Sci 1229 (2011) E1-7.

[9] E. Reaven, Y.D. Chen, M. Spicher, S. Azhar, Morphological evidence that high density lipoproteins are not internalized by steroid-producing cells during in situ organ perfusion, The Journal of clinical investigation 74(4) (1984) 1384-1397.

[10] E. Reaven, L. Zhan, A. Nomoto, S. Leers-Sucheta, S. Azhar, Expression and microvillar localization of scavenger receptor class $\mathrm{B}$, type I (SR-BI) and selective cholesteryl ester uptake in Leydig cells from rat testis, J Lipid Res 41(3) (2000) 343-56. 
[11] E. Reaven, A. Nomoto, S. Leers-Sucheta, R. Temel, D.L. Williams, S. Azhar, Expression and microvillar localization of scavenger receptor, class $B$, type I (a high density lipoprotein receptor) in luteinized and hormone-desensitized rat ovarian models, Endocrinology 139(6) (1998) 2847-56.

[12] J. Babitt, B. Trigatti, A. Rigotti, E.J. Smart, R.G. Anderson, S. Xu, M. Krieger, Murine SR-BI, a high density lipoprotein receptor that mediates selective lipid uptake, is $\mathrm{N}$-glycosylated and fatty acylated and colocalizes with plasma membrane caveolae, J Biol Chem 272(20) (1997) 13242-9.

[13] Y. Peng, W. Akmentin, M.A. Connelly, S. Lund-Katz, M.C. Phillips, D.L. Williams, Scavenger receptor BI (SR-BI) clustered on microvillar extensions suggests that this plasma membrane domain is a way station for cholesterol trafficking between cells and high-density lipoprotein, Molecular biology of the cell 15(1) (2004) 384-96.

[14] E. Reaven, S. Leers-Sucheta, A. Nomoto, S. Azhar, Expression of scavenger receptor class B type 1 (SR$\mathrm{BI})$ promotes microvillar channel formation and selective cholesteryl ester transport in a heterologous reconstituted system, Proc Natl Acad Sci U S A 98(4) (2001) 1613-8.

[15] E. Reaven, A. Nomoto, Y. Cortez, S. Azhar, Consequences of over-expression of rat Scavenger Receptor, SR-BI, in an adrenal cell model, Nutr Metab (Lond) 3 (2006) 43.

[16] M.A. Connelly, M. de la Llera-Moya, P. Monzo, P.G. Yancey, D. Drazul, G. Stoudt, N. Fournier, S.M. Klein, G.H. Rothblat, D.L. Williams, Analysis of chimeric receptors shows that multiple distinct functional activities of scavenger receptor, class $\mathrm{B}$, type I (SR-BI), are localized to the extracellular receptor domain, Biochemistry 40(17) (2001) 5249-59.

[17] W.J. Shen, S. Azhar, F.B. Kraemer, SR-B1: A Unique Multifunctional Receptor for Cholesterol Influx and Efflux, Annu Rev Physiol 80 (2018) 95-116.

[18] M. Hoekstra, M. Sorci-Thomas, Rediscovering scavenger receptor type Bl: surprising new roles for the HDL receptor, Curr Opin Lipidol 28(3) (2017) 255-260.

[19] L.K. Mooberry, N.A. Sabnis, M. Panchoo, B. Nagarajan, A.G. Lacko, Targeting the SR-B1 Receptor as a Gateway for Cancer Therapy and Imaging, Front Pharmacol 7 (2016) 466-466.

[20] M.A. Rajora, G. Zheng, Targeting SR-BI for Cancer Diagnostics, Imaging and Therapy, Front Pharmacol 7 (2016) 326.

[21] A.G. Atanasov, B. Waltenberger, E.M. Pferschy-Wenzig, T. Linder, C. Wawrosch, P. Uhrin, V. Temml, L. Wang, S. Schwaiger, E.H. Heiss, J.M. Rollinger, D. Schuster, J.M. Breuss, V. Bochkov, M.D. Mihovilovic, B. Kopp, R. Bauer, V.M. Dirsch, H. Stuppner, Discovery and resupply of pharmacologically active plantderived natural products: A review, Biotechnol Adv 33(8) (2015) 1582-1614.

[22] D.A. Dias, S. Urban, U. Roessner, A historical overview of natural products in drug discovery, Metabolites 2(2) (2012) 303-36.

[23] G.M. Cragg, D.J. Newman, Natural products: a continuing source of novel drug leads, Biochimica et biophysica acta 1830(6) (2013) 3670-95.

[24] S. Acton, A. Rigotti, K.T. Landschulz, S. Xu, H.H. Hobbs, M. Krieger, Identification of scavenger receptor SR-BI as a high density lipoprotein receptor, Science 271(5248) (1996) 518-20.

[25] A. Rigotti, B.L. Trigatti, M. Penman, H. Rayburn, J. Herz, M. Krieger, A targeted mutation in the murine gene encoding the high density lipoprotein $(\mathrm{HDL})$ receptor scavenger receptor class $B$ type I reveals its key role in HDL metabolism, Proc Natl Acad Sci U S A 94(23) (1997) 12610-5.

[26] W.G. Chen, D.L. Silver, J.D. Smith, A.R. Tall, Scavenger receptor-BI inhibits ATP-binding cassette transporter 1-mediated cholesterol efflux in macrophages, Journal of Biological Chemistry 275(40) (2000) 30794-30800.

[27] K.F. Kozarsky, M.H. Donahee, A. Rigotti, S.N. Iqbal, E.R. Edelman, M. Krieger, Overexpression of the HDL receptor SR-BI alters plasma HDL and bile cholesterol levels, Nature 387(6631) (1997) 414-7.

[28] A. Rigotti, H.E. Miettinen, M. Krieger, The role of the high-density lipoprotein receptor SR-BI in the lipid metabolism of endocrine and other tissues, Endocr Rev 24(3) (2003) 357-87. 
[29] A. Ji, J.M. Meyer, L. Cai, A. Akinmusire, M.C. de Beer, N.R. Webb, D.R. van der Westhuyzen, Scavenger receptor SR-BI in macrophage lipid metabolism, Atherosclerosis 217(1) (2011) 106-12.

[30] B. Trigatti, H. Rayburn, M. Vinals, A. Braun, H. Miettinen, M. Penman, M. Hertz, M. Schrenzel, L. Amigo, A. Rigotti, M. Krieger, Influence of the high density lipoprotein receptor SR-BI on reproductive and cardiovascular pathophysiology, Proc Natl Acad Sci U S A 96(16) (1999) 9322-7.

[31] M. Van Eck, M. Hoekstra, R. Out, I.S. Bos, J.K. Kruijt, R.B. Hildebrand, T.J. Van Berkel, Scavenger receptor BI facilitates the metabolism of VLDL lipoproteins in vivo, J Lipid Res 49(1) (2008) 136-46.

[32] Y.Z. Zhang, J.R. Da Silva, M. Reilly, J.T. Billheimer, G.H. Rothblat, D.J. Rader, Hepatic expression of scavenger receptor class $\mathrm{B}$ type I (SR-BI) is a positive regulator of macrophage reverse cholesterol transport in vivo, Journal of Clinical Investigation 115(10) (2005) 2870-2874.

[33] P.G. Yancey, M. de la Llera-Moya, S. Swarnakar, P. Monzo, S.M. Klein, M.A. Connelly, W.J. Johnson, D.L. Williams, G.H. Rothblat, High density lipoprotein phospholipid composition is a major determinant of the bi-directional flux and net movement of cellular free cholesterol mediated by scavenger receptor $\mathrm{BI}$, Journal of Biological Chemistry 275(47) (2000) 36596-36604.

[34] Y. Ji, B. Jian, N. Wang, Y. Sun, M.D.L.L. Moya, M.C. Phillips, G.H. Rothblat, J.B. Swaney, A.R. Tall, Scavenger receptor BI promotes high density lipoprotein-mediated cellular cholesterol efflux, Journal of Biological Chemistry 272(34) (1997) 20982-20985.

[35] D.X. Luo, D.L. Cao, Y. Xiong, X.H. Peng, D.F. Liao, A novel model of cholesterol efflux from lipid-loaded cells, Acta Pharmacol Sin 31(10) (2010) 1243-57.

[36] L. Cai, A.L. Ji, F.C. de Beer, L.R. Tannock, D.R. van der Westhuyzen, SR-BI protects against endotoxemia in mice through its roles in glucocorticoid production and hepatic clearance, Journal of Clinical Investigation 118(1) (2008) 364-375.

[37] L. Guo, Z.Q. Song, M.T. Li, Q.G. Wu, D. Wang, H. Feng, P. Bernard, A. Daugherty, B. Huang, X.A. Li, Scavenger Receptor BI Protects against Septic Death through Its Role in Modulating Inflammatory Response, Journal of Biological Chemistry 284(30) (2009) 19826-19834.

[38] W. Khovidhunkit, A genetic variant of the scavenger receptor BI in humans, N Engl J Med 364(14) (2011) 1375-6; author reply 1376.

[39] M. Vergeer, S.J. Korporaal, R. Franssen, I. Meurs, R. Out, G.K. Hovingh, M. Hoekstra, J.A. Sierts, G.M. Dallinga-Thie, M.M. Motazacker, A.G. Holleboom, T.J. Van Berkel, J.J. Kastelein, M. Van Eck, J.A. Kuivenhoven, Genetic variant of the scavenger receptor BI in humans, N Engl J Med 364(2) (2011) 136-45. [40] M. Van Eck, M. Hoekstra, R.B. Hildebrand, Y. Yaong, D. Stengel, J.K. Kruijt, W. Sattler, U.J.F. Tietge, E. Ninio, T.J.C. Van Berkel, D. Pratico, Increased oxidative stress in scavenger receptor BI knockout mice with dysfunctional HDL, Arterioscl Throm Vas 27(11) (2007) 2413-2419.

[41] H. Tao, P.G. Yancey, V.R. Babaev, J.L. Blakemore, Y.M. Zhang, L. Ding, S. Fazio, M.F. Linton, Macrophage SR-BI mediates efferocytosis via Src/PI3K/Rac1 signaling and reduces atherosclerotic lesion necrosis, Journal of Lipid Research 56(8) (2015) 1449-1460.

[42] I.S. Yuhanna, Y. Zhu, B.E. Cox, L.D. Hahner, S. Osborne-Lawrence, Y.L. Marcel, R.G.W. Anderson, M.E. Mendelsohn, H.H. Hobbs, P.W. Shaul, High-density lipoprotein binding to scavenger receptor-BI activates endothelial nitric oxide synthase, Nat Med 7(7) (2001) 853-857.

[43] X.A. Li, W.B. Titlow, B.A. Jackson, N. Giltiay, M. Nikolova-Karakashian, A. Uittenbogaard, E.J. Smart, High density lipoprotein binding to scavenger receptor, class $B$, type I activates endothelial nitric-oxide synthase in a ceramide-dependent manner, Journal of Biological Chemistry 277(13) (2002) 11058-11063.

[44] C. Mineo, I.S. Yuhanna, M.J. Quon, P.W. Shaul, High density lipoprotein-induced endothelial nitricoxide synthase activation is mediated by Akt and MAP kinases, Journal of Biological Chemistry 278(11) (2003) 9142-9149.

[45] H. Feng, L. Guo, D. Wang, H.Q. Gao, G.H. Hou, Z. Zheng, J.T. Ai, O. Foreman, A. Daugherty, X.A. Li, Deficiency of Scavenger Receptor BI Leads to Impaired Lymphocyte Homeostasis and Autoimmune Disorders in Mice, Arterioscl Throm Vas 31(11) (2011) 2543-U454. 
[46] T.M. Holm, A. Braun, B.L. Trigatti, C. Brugnara, M. Sakamoto, M. Krieger, N.C. Andrews, Failure of red blood cell maturation in mice with defects in the high-density lipoprotein receptor SR-BI, Blood 99(5) (2002) 1817-1824.

[47] I. Meurs, M. Hoekstra, E.J.A. van Wanrooij, R.B. Hildebrand, J. Kuiper, F. Kuipers, M.R. Hardeman, T.J.C. Van Berkel, M. Van Eck, HDL cholesterol levels are an important factor for determining the lifespan of erythrocytes, Exp Hematol 33(11) (2005) 1309-1319.

[48] Y. Ma, M.Z. Ashraf, E.A. Podrez, Scavenger receptor BI modulates platelet reactivity and thrombosis in dyslipidemia, Blood 116(11) (2010) 1932-1941.

[49] M. van der Stoep, S.J.A. Korporaal, M. Van Eck, High-density lipoprotein as a modulator of platelet and coagulation responses, Cardiovasc Res 103(3) (2014) 362-371.

[50] S. Pfeiler, A.B. Khandagale, A. Magenau, M. Nichols, H.F.G. Heijnen, F. Rinninger, T. Ziegler, S. Seveau, S. Schubert, S. Zahler, A. Verschoor, E. Latz, S. Massberg, K. Gaus, B. Engelmann, Distinct surveillance pathway for immunopathology during acute infection via autophagy and SR-BI, Sci Rep-Uk 6 (2016).

[51] X. Liao, J.C. Sluimer, Y. Wang, M. Subramanian, K. Brown, J.S. Pattison, J. Robbins, J. Martinez, I. Tabas, Macrophage autophagy plays a protective role in advanced atherosclerosis, Cell Metab 15(4) (2012) 54553.

[52] M.F. Linton, V.R. Babaev, J. Huang, E.F. Linton, H. Tao, P.G. Yancey, Macrophage Apoptosis and Efferocytosis in the Pathogenesis of Atherosclerosis, Circ J 80(11) (2016) 2259-2268.

[53] K. Kotani, Y. Sekine, S. Ishikawa, I.Z. Ikpot, K. Suzuki, A.T. Remaley, High-Density Lipoprotein and Prostate Cancer: An Overview, J Epidemiol 23(5) (2013) 313-319.

[54] J.A. Vilchez, A. Martinez-Ruiz, N. Sancho-Rodriguez, P. Martinez-Hernandez, J.A. Noguera-Velasco, The real role of prediagnostic high-density lipoprotein cholesterol and the cancer risk: a concise review, Eur J Clin Invest 44(1) (2014) 103-114.

[55] S. Lebdai, R. Mathieu, J. Leger, O. Haillot, S. Vincendeau, N. Rioux-Leclercq, G. Fournier, M.A. PerrouinVerbe, L. Doucet, A.R. Azzouzi, J. Rigaud, K. Renaudin, T. Charles, F. Bruyere, G. Fromont, Metabolic syndrome and low high-density lipoprotein cholesterol are associated with adverse pathological features in patients with prostate cancer treated by radical prostatectomy, Urol Oncol-Semin Ori 36(2) (2018).

[56] M. Ruscica, M. Botta, N. Ferri, E. Giorgio, C. Macchi, G. Franceschini, P. Magni, L. Calabresi, M. Gomaraschi, High Density Lipoproteins Inhibit Oxidative Stress-Induced Prostate Cancer Cell Proliferation, Sci Rep-Uk 8 (2018).

[57] A. Picataggi, G.F. Lim, A.P. Kent, J.S. Millar, D.J. Rader, I.M. Stylianou, A coding variant in SR-BI (II79N) significantly increases atherosclerosis in mice, Mamm Genome 24(7-8) (2013) 257-265.

[58] P. Zanoni, S.A. Khetarpal, D.B. Larach, W.F. Hancock-Cerutti, J.S. Millar, M. Cuchel, S. DerOhannessian, A. Kontush, P. Surendran, D. Saleheen, S. Trompet, J.W. Jukema, A. De Craen, P. Deloukas, N. Sattar, I. Ford, C. Packard, A. Majumder, D.S. Alam, E. Di Angelantonio, G. Abecasis, R. Chowdhury, J. Erdmann, B.G. Nordestgaard, S.F. Nielsen, A. Tybjaerg-Hansen, R.F. Schmidt, K. Kuulasmaa, D.J. Liu, M. Perola, S. Blankenberg, V. Salomaa, S. Mannisto, P. Amouyel, D. Arveiler, J. Ferrieres, M. Muller-Nurasyid, M. Ferrario, F. Kee, C.J. Willer, N. Samani, H. Schunkert, A.S. Butterworth, J.M. Howson, G.M. Peloso, N.O. Stitziel, J. Danesh, S. Kathiresan, D.J. Rader, C.H.D.E. Consortium, C.A.E. Consortium, C. Global Lipids Genetics, Rare variant in scavenger receptor BI raises HDL cholesterol and increases risk of coronary heart disease, Science 351(6278) (2016) 1166-71.

[59] S. Samadi, Z. Farjami, Z.S. Hosseini, G.A. Ferns, A.H. Mohammadpour, M. Tayefi, H. Fal-Soleiman, M. Moohebati, M. Ghayour-Mobarhan, H. Esmaily, A. Avan, Rare P376L variant in the SR-BI gene associates with HDL dysfunction and risk of cardiovascular disease, Clin Biochem (2019).

[60] A. Helgadottir, P. Sulem, G. Thorgeirsson, S. Gretarsdottir, G. Thorleifssoni, B.O. Jensson, G.A. Arnadottir, I. Olafsson, G.I. Eyjolfsson, O. Sigurdardottir, U. Thorsteinsdottir, D.F. Gudbjartsson, H. Holm, K. Stefansson, Rare SCARB1 mutations associate with high-density lipoprotein cholesterol but not with coronary artery disease, Eur Heart J 39(23) (2018) 2172-2178. 
[61] C.G. Leon, J.A. Locke, H.H. Adomat, S.L. Etinger, A.L. Twiddy, R.D. Neumann, C.C. Nelson, E.S. Guns, K.M. Wasan, Alterations in Cholesterol Regulation Contribute to the Production of Intratumoral Androgens During Progression to Castration-Resistant Prostate Cancer in a Mouse Xenograft Model, Prostate 70(4) (2010) 390-400.

[62] W.J. Griffiths, P.J. Crick, A. Meljon, S. Theofilopoulos, J. Abdel-Khalik, E. Yutuc, J.E. Parker, D.E. Kelly, S.L. Kelly, E. Arenas, Y. Wang, Additional pathways of sterol metabolism: Evidence from analysis of Cyp27a1-/- mouse brain and plasma, Biochim Biophys Acta Mol Cell Biol Lipids 1864(2) (2019) 191-211.

[63] Y. Wang, W.J. Griffiths, Unravelling new pathways of sterol metabolism: lessons learned from in-born errors and cancer, Curr Opin Clin Nutr Metab Care 21(2) (2018) 90-96.

[64] G. Marwarha, S. Raza, K. Hammer, O. Ghribi, 27-hydroxycholesterol: A novel player in molecular carcinogenesis of breast and prostate cancer, Chem Phys Lipids 207(Pt B) (2017) 108-126.

[65] M.A. Alfaqih, E.R. Nelson, W. Liu, R. Safi, J.S. Jasper, E. Macias, J. Geradts, J.W. Thompson, L.G. Dubois, M.R. Freeman, C.Y. Chang, J.T. Chi, D.P. McDonnell, S.J. Freedland, CYP27A1 Loss Dysregulates Cholesterol Homeostasis in Prostate Cancer, Cancer Res 77(7) (2017) 1662-1673.

[66] A.E. Baek, Y.R.A. Yu, S.S. He, S.E. Wardell, C.Y. Chang, S. Kwon, R.V. Pillai, H.B. McDowell, J.W. Thompson, L.G. Dubois, P.M. Sullivan, J.K. Kemper, M.D. Gunn, D.P. McDonnell, E.R. Nelson, The cholesterol metabolite 27 hydroxycholesterol facilitates breast cancer metastasis through its actions on immune cells, Nat Commun 8 (2017).

[67] D. Schorghofer, K. Kinslechner, A. Preitschopf, B. Schutz, C. Rohrl, M. Hengstschlager, H. Stangl, M. Mikula, The HDL receptor SR-BI is associated with human prostate cancer progression and plays a possible role in establishing androgen independence, Reprod Biol Endocrin 13 (2015).

[68] C. Danilo, J.L. Gutierrez-Pajares, M.A. Mainieri, I. Mercier, M.P. Lisanti, P.G. Frank, Scavenger receptor class B type I regulates cellular cholesterol metabolism and cell signaling associated with breast cancer development, Breast Cancer Res 15(5) (2013).

[69] Y. Zheng, Y.Y. Liu, H.L. Jin, S.T. Pan, Y. Qian, C. Huang, Y.X. Zeng, Q.M. Luo, M.S. Zeng, Z.H. Zhang, Scavenger Receptor B1 is a Potential Biomarker of Human Nasopharyngeal Carcinoma and Its Growth is Inhibited by HDL-mimetic Nanoparticles, Theranostics 3(7) (2013) 477-486.

[70] P.J. Pussinen, B. Karten, A. Wintersperger, H. Reicher, M. McLean, E. Malle, W. Sattler, The human breast carcinoma cell line HBL-100 acquires exogenous cholesterol from high-density lipoprotein via CLA1 (CD-36 and LIMPII analogous 1)-mediated selective cholesteryl ester uptake, Biochem J 349 (2000) 559566.

[71] J.T. Gwynne, D.D. Mahaffee, Rat Adrenal Uptake and Metabolism of High-Density Lipoprotein Cholesteryl Ester, Journal of Biological Chemistry 264(14) (1989) 8141-8150.

[72] L.K. Mooberry, N.A. Sabnis, M. Panchoo, B. Nagarajan, A.G. Lacko, Targeting the SR-B1 Receptor as a Gateway for Cancer Therapy and Imaging, Front Pharmacol 7 (2016).

[73] C. Wadsack, A. Hammer, S. Levak-Frank, G. Desoye, K.F. Kozarsky, B. Hirschmugl, W. Sattler, E. Malle, Selective cholesteryl ester uptake from high density lipoprotein by human first trimester and term villous trophoblast cells, Placenta 24(2-3) (2003) 131-143.

[74] X.W. Wang, C.S. Wu, B.Y. Yuan, D. Wang, H.L. Liu, H. Feng, S. Sun, Low scavenger receptor class B type I expression is associated with gastric adenocarcinoma tumor aggressiveness, Oncol Lett 15(4) (2018) 4604-4610.

[75] G.A. Graf, K.L. Roswell, E.J. Smart, 17 beta-Estradiol promotes the up-regulation of SR-BII in HepG2 cells and in rat livers (vol 42, pg 1444, 2001), Journal of Lipid Research 54(4) (2013) 1151-1151.

[76] L.K. Mooberry, M. Nair, S. Paranjape, W.J. McConathy, A.G. Lacko, Receptor mediated uptake of paclitaxel from a synthetic high density lipoprotein nanocarrier, J Drug Target 18(1) (2010) 53-58.

[77] M.M.K. Shahzad, L.S. Mangala, H.D. Han, C.H. Lu, J. Bottsford-Miller, M. Nishimura, E.M. Mora, J.W. Lee, R.L. Stone, C.V. Pecot, D. Thanapprapasr, J.W. Roh, P. Gaur, M.P. Nair, Y.Y. Park, N. Sabnis, M.T. Deavers, J.S. Lee, L.M. Ellis, G. Lopez-Berestein, W.J. McConathy, L. Prokai, A.G. Lacko, A.K. Sood, Targeted 
Delivery of Small Interfering RNA Using Reconstituted High-Density Lipoprotein Nanoparticles, Neoplasia 13(4) (2011) 309-U142.

[78] W.M. Cao, K. Murao, H. Imachi, X. Yu, H. Abe, A. Yamauchi, M. Niimi, A. Miyauchi, N.C.W. Wong, T. Ishida, A mutant high-density lipoprotein receptor inhibits proliferation of human breast cancer cells, Cancer Res 64(4) (2004) 1515-1521.

[79] A.L. Twiddy, M.E. Cox, K.M. Wasan, Knockdown of scavenger receptor Class B Type I reduces prostate specific antigen secretion and viability of prostate cancer cells, Prostate 72(9) (2012) 955-965.

[80] K. Kinslechner, B. Schutz, M. Pistek, P. Rapolter, H.P. Weitzenbock, H. Hundsberger, W. Mikulits, J. Grillari, C. Rohrl, M. Hengstschlager, H. Stangl, M. Mikula, Loss of SR-BI Down-Regulates MITF and Suppresses Extracellular Vesicle Release in Human Melanoma, Int J Mol Sci 20(5) (2019).

[81] D.L. Silver, A carboxyl-terminal PDZ-interacting domain of scavenger receptor B, type I Is essential for cell surface expression in liver, Journal of Biological Chemistry 277(37) (2002) 34042-34047.

[82] O. Kocher, A. Yesilaltay, C. Cirovic, R. Pal, A. Rigotti, M. Krieger, Targeted disruption of the PDZK1 gene in mice causes tissue-specific depletion of the high density lipoprotein receptor scavenger receptor class B type I and altered lipoprotein metabolism, Journal of Biological Chemistry 278(52) (2003) 52820-52825. [83] M.G. Ghosh, D.A. Thompson, R.J. Weigel, PDZK1 and GREB1 are estrogen-regulated genes expressed in hormone-responsive breast cancer, Cancer Res 60(22) (2000) 6367-6375.

[84] H.Y. Kim, Z.Y. Abd Elmageed, J.H. Ju, A.S. Naura, A.B. Abdel-Mageed, S. Varughese, D. Paul, S. Alahari, A. Catling, J.G. Kim, A.H. Boulares, PDZK1 Is a Novel Factor in Breast Cancer That Is Indirectly Regulated by Estrogen through IGF-1R and Promotes Estrogen-Mediated Growth, Mol Med 19 (2013) 253-262.

[85] T. Shimizu, T. Sugiura, T. Wakayama, A. Kijima, N. Nakamichi, S. Iseki, D.L. Silver, Y. Kato, PDZK1 Regulates Breast Cancer Resistance Protein in Small Intestine, Drug Metab Dispos 39(11) (2011) 21482154.

[86] R. Noy, J.W. Pollard, Tumor-Associated Macrophages: From Mechanisms to Therapy (vol 41, pg 49, 2014), Immunity 41(5) (2014) 866-866.

[87] T. Chanmee, P. Ontong, K. Konno, N. Itano, Tumor-Associated Macrophages as Major Players in the Tumor Microenvironment, Cancers 6(3) (2014) 1670-1690.

[88] P.J.D. van Steenwijk, T.H. Ramwadhdoebe, R. Goedemans, E.M. Doorduijn, J.J. van Ham, A. Gorter, T. van Hall, M.L. Kuijjer, M.I.E. van Poelgeest, S.H. van der Burg, E.S. Jordanova, Tumor-infiltrating CD14positive myeloid cells and CD8-positive T-cells prolong survival in patients with cervical carcinoma, Int J Cancer 133(12) (2013) 2884-2894.

[89] J. Zhang, C. Qu, T. Li, W. Cui, X. Wang, J. Du, Phagocytosis mediated by scavenger receptor class BI promotes macrophage transition during skeletal muscle regeneration, J Biol Chem 294(43) (2019) 1567215685.

[90] P. Goossens, J. Rodriguez-Vita, A. Etzerodt, M. Masse, O. Rastoin, V. Gouirand, T. Ulas, O. Papantonopoulou, M. Van Eck, N. Auphan-Anezin, M. Bebien, C. Verthuy, T.P.V. Manh, M. Turner, M. Dalod, J.L. Schultze, T. Lawrence, Membrane Cholesterol Efflux Drives Tumor-Associated Macrophage Reprogramming and Tumor Progression, Cell Metabolism 29(6) (2019) 1376-+.

[91] M.M. Kaneda, K.S. Messer, N. Ralainirina, H.Y. Li, C.J. Leem, S. Gorjestani, G. Woo, A.V. Nguyen, C.C. Figueiredo, P. Foubert, M.C. Schmid, M. Pink, D.G. Winkler, M. Rausch, V.J. Palombella, J. Kutok, K. McGovern, K.A. Frazer, X.F. Wu, M. Karin, R. Sasik, E.E.W. Cohen, J.A. Varner, PI3K gamma is a molecular switch that controls immune suppression (vol 539, pg 437, 2016), Nature 542(7639) (2017) 124-124.

[92] S.C.C. Huang, A.M. Smith, B. Everts, M. Colonna, E.L. Pearce, J.D. Schilling, E.J. Pearce, Metabolic Reprogramming Mediated by the mTORC2-IRF4 Signaling Axis Is Essential for Macrophage Alternative Activation, Immunity 45(4) (2016) 817-830.

[93] M.J. Rauh, V. Ho, C. Pereira, A. Sham, L.M. Sly, V. Lam, L. Huxham, A.I. Minchinton, A. Mui, G. Krystal, SHIP represses the generation of alternatively activated macrophages, Immunity 23(4) (2005) 361-374. 
[94] V.R. Babaev, J. Huang, L. Ding, Y. Zhang, J.M. May, M.F. Linton, Loss of Rictor in Monocyte/Macrophages Suppresses Their Proliferation and Viability Reducing Atherosclerosis in LDLR Null Mice, Front Immunol 9 (2018) 215-215.

[95] R. Galandrini, F. Tassi, G. Mattia, L. Lenti, M. Piccoli, L. Frati, A. Santoni, SH2-containing inositol phosphatase (SHIP-1) transiently translocates to raft domains and modulates CD16-mediated cytotoxicity in human NK cells, Blood 100(13) (2002) 4581-4589.

[96] V. Hiebl, A. Ladurner, S. Latkolik, V.M. Dirsch, Natural products as modulators of the nuclear receptors and metabolic sensors LXR, FXR and RXR, Biotechnology Advances 36(6) (2018) 1657-1698.

[97] L. Malerod, L.K. Juvet, A. Hanssen-Bauer, W. Eskild, T. Berg, Oxysterol-activated LXRalpha/RXR induces hSR-BI-promoter activity in hepatoma cells and preadipocytes, Biochem Biophys Res Commun 299(5) (2002) 916-23.

[98] O. Briand, V. Touche, S. Colin, G. Brufau, A. Davalos, M. Schonewille, F. Bovenga, V. Carriere, J.F. de Boer, C. Dugardin, B. Riveau, V. Clavey, A. Tailleux, A. Moschetta, M.A. Lasuncion, A.K. Groen, B. Staels, S. Lestavel, Liver $X$ Receptor Regulates Triglyceride Absorption Through Intestinal Down-regulation of Scavenger Receptor Class B, Type 1, Gastroenterology 150(3) (2016) 650-8.

[99] B. Dong, A.B. Singh, G.L. Guo, M. Young, J. Liu, Activation of FXR by obeticholic acid induces hepatic gene expression of SR-BI through a novel mechanism of transcriptional synergy with the nuclear receptor LXR, International journal of molecular medicine 43(5) (2019) 1927-1938.

[100] A. Grefhorst, M.H. Oosterveer, G. Brufau, M. Boesjes, F. Kuipers, A.K. Groen, Pharmacological LXR activation reduces presence of SR-B1 in liver membranes contributing to LXR-mediated induction of HDLcholesterol, Atherosclerosis 222(2) (2012) 382-9.

[101] V. Chandra, P. Huang, Y. Hamuro, S. Raghuram, Y. Wang, T.P. Burris, F. Rastinejad, Structure of the intact PPAR-gamma-RXR- nuclear receptor complex on DNA, Nature 456(7220) (2008) 350-356.

[102] D. Lopez, M.P. McLean, Activation of the rat scavenger receptor class B type I gene by PPARalpha, Mol Cell Endocrinol 251(1-2) (2006) 67-77.

[103] L. Malerod, M. Sporstol, L.K. Juvet, A. Mousavi, T. Gjoen, T. Berg, Hepatic scavenger receptor class $B$, type I is stimulated by peroxisome proliferator-activated receptor gamma and hepatocyte nuclear factor 4alpha, Biochem Biophys Res Commun 305(3) (2003) 557-65.

[104] D.K. Spady, D.M. Kearney, H.H. Hobbs, Polyunsaturated fatty acids up-regulate hepatic scavenger receptor B1 (SR-BI) expression and HDL cholesteryl ester uptake in the hamster, J Lipid Res 40(8) (1999) 1384-94.

[105] G. Chinetti, F.G. Gbaguidi, S. Griglio, Z. Mallat, M. Antonucci, P. Poulain, J. Chapman, J.C. Fruchart, A. Tedgui, J. Najib-Fruchart, B. Staels, CLA-1/SR-BI is expressed in atherosclerotic lesion macrophages and regulated by activators of peroxisome proliferator-activated receptors, Circulation 101(20) (2000) 24117.

[106] P. Mardones, A. Pilon, M. Bouly, D. Duran, T. Nishimoto, H. Arai, K.F. Kozarsky, M. Altayo, J.F. Miquel, G. Luc, V. Clavey, B. Staels, A. Rigotti, Fibrates down-regulate hepatic scavenger receptor class B type I protein expression in mice, J Biol Chem 278(10) (2003) 7884-90.

[107] D. Lan, D.L. Silver, Fenofibrate induces a novel degradation pathway for scavenger receptor B-I independent of PDZK1, J Biol Chem 280(24) (2005) 23390-6.

[108] F. Forcheron, A. Cachefo, S. Thevenon, C. Pinteur, M. Beylot, Mechanisms of the triglyceride- and cholesterol-lowering effect of fenofibrate in hyperlipidemic type 2 diabetic patients, Diabetes 51(12) (2002) 3486-91.

[109] R.A. Ahmed, K. Murao, H. Imachi, X. Yu, J. Li, N.C. Wong, T. Ishida, Human scavenger receptor class $B$ type 1 is regulated by activators of peroxisome proliferators-activated receptor-gamma in hepatocytes, Endocrine 35(2) (2009) 233-42. 
[110] S.-A. Toh, J.S. Millar, J. Billheimer, I. Fuki, S.U. Naik, C. Macphee, M. Walker, D.J. Rader, PPARy activation redirects macrophage cholesterol from fecal excretion to adipose tissue uptake in mice via SRBI, Biochem Pharmacol 81(7) (2011) 934-941.

[111] L. Malerod, M. Sporstol, L.K. Juvet, S.A. Mousavi, T. Gjoen, T. Berg, N. Roos, W. Eskild, Bile acids reduce SR-BI expression in hepatocytes by a pathway involving FXR/RXR, SHP, and LRH-1, Biochem Biophys Res Commun 336(4) (2005) 1096-105.

[112] A. Leiva, H. Verdejo, M.L. Benitez, A. Martinez, D. Busso, A. Rigotti, Mechanisms regulating hepatic SR-BI expression and their impact on HDL metabolism, Atherosclerosis 217(2) (2011) 299-307.

[113] T. Claudel, E. Sturm, H. Duez, I.P. Torra, A. Sirvent, V. Kosykh, J.C. Fruchart, J. Dallongeville, D.W. Hum, F. Kuipers, B. Staels, Bile acid-activated nuclear receptor FXR suppresses apolipoprotein A-I transcription via a negative FXR response element, J Clin Invest 109(7) (2002) 961-71.

[114] Z.Y. Wu, H. Li, J.R. Li, X.Q. Lv, J.D. Jiang, Z.G. Peng, Farnesoid X receptor agonist GW4064 indirectly inhibits HCV entry into cells via down-regulating scavenger receptor class B type I, Eur J Pharmacol 853 (2019) 111-120.

[115] Y. Zhang, L. Yin, J. Anderson, H. Ma, F.J. Gonzalez, T.M. Willson, P.A. Edwards, Identification of novel pathways that control farnesoid X receptor-mediated hypocholesterolemia, J Biol Chem 285(5) (2010) 3035-43.

[116] B. Dong, M. Young, X. Liu, A.B. Singh, J. Liu, Regulation of lipid metabolism by obeticholic acid in hyperlipidemic hamsters, J Lipid Res 58(2) (2017) 350-363.

[117] G. Li, A.M. Thomas, J.A. Williams, B. Kong, J. Liu, Y. Inaba, W. Xie, G.L. Guo, Farnesoid X receptor induces murine scavenger receptor Class B type I via intron binding, PLoS One 7(4) (2012) e35895.

[118] F. Chao, W. Gong, Y. Zheng, Y. Li, G. Huang, M. Gao, J. Li, R. Kuruba, X. Gao, S. Li, F. He, Upregulation of scavenger receptor class B type I expression by activation of FXR in hepatocyte, Atherosclerosis 213(2) (2010) 443-8.

[119] G. Lambert, M.J. Amar, G. Guo, H.B. Brewer, Jr., F.J. Gonzalez, C.J. Sinal, The farnesoid X-receptor is an essential regulator of cholesterol homeostasis, J Biol Chem 278(4) (2003) 2563-70.

[120] G.D. Norata, M. Ongari, P. Uboldi, F. Pellegatta, A.L. Catapano, Liver X receptor and retinoic X receptor agonists modulate the expression of genes involved in lipid metabolism in human endothelial cells, International journal of molecular medicine 16(4) (2005) 717-22.

[121] D. Lopez, M.P. McLean, Sterol regulatory element-binding protein-1a binds to cis elements in the promoter of the rat high density lipoprotein receptor SR-BI gene, Endocrinology 140(12) (1999) 5669-81. [122] W.K. Shea-Eaton, M.J. Trinidad, D. Lopez, A. Nackley, M.P. McLean, Sterol regulatory element binding protein-1a regulation of the steroidogenic acute regulatory protein gene, Endocrinology 142(4) (2001) 1525-33.

[123] D. Lopez, M.D. Sanchez, W. Shea-Eaton, M.P. McLean, Estrogen activates the high-density lipoprotein receptor gene via binding to estrogen response elements and interaction with sterol regulatory element binding protein-1A, Endocrinology 143(6) (2002) 2155-68.

[124] M. Treguier, C. Doucet, M. Moreau, C. Dachet, J. Thillet, M.J. Chapman, T. Huby, Transcription factor sterol regulatory element binding protein 2 regulates scavenger receptor Cla-1 gene expression, Arterioscler Thromb Vasc Biol 24(12) (2004) 2358-64.

[125] A. Niemeier, W.J. Kovacs, W. Strobl, H. Stangl, Atherogenic diet leads to posttranslational downregulation of murine hepatocyte SR-BI expression, Atherosclerosis 202(1) (2009) 169-75.

[126] K.I. Ansari, S. Kasiri, I. Hussain, S.A. Bobzean, L.I. Perrotti, S.S. Mandal, MLL histone methylases regulate expression of HDLR-SR-B1 in presence of estrogen and control plasma cholesterol in vivo, Mol Endocrinol 27(1) (2013) 92-105.

[127] K.T. Landschulz, R.K. Pathak, A. Rigotti, M. Krieger, H.H. Hobbs, Regulation of scavenger receptor, class B, type I, a high density lipoprotein receptor, in liver and steroidogenic tissues of the rat, J Clin Invest 98(4) (1996) 984-95. 
[128] H. Stangl, G.A. Graf, L. Yu, G. Cao, K. Wyne, Effect of estrogen on scavenger receptor BI expression in the rat, J Endocrinol 175(3) (2002) 663-72.

[129] S. Ghaffari, F. Naderi Nabi, M.G. Sugiyama, W.L. Lee, Estrogen Inhibits LDL (Low-Density Lipoprotein) Transcytosis by Human Coronary Artery Endothelial Cells via GPER (G-Protein-Coupled Estrogen Receptor) and SR-BI (Scavenger Receptor Class B Type 1), Arterioscler Thromb Vasc Biol 38(10) (2018) 2283-2294.

[130] D. Lopez, M.P. McLean, Estrogen regulation of the scavenger receptor class B gene: Anti-atherogenic or steroidogenic, is there a priority?, Mol Cell Endocrinol 247(1-2) (2006) 22-33.

[131] G. Cao, C.K. Garcia, K.L. Wyne, R.A. Schultz, K.L. Parker, H.H. Hobbs, Structure and localization of the human gene encoding SR-BI/CLA-1. Evidence for transcriptional control by steroidogenic factor 1, J Biol Chem 272(52) (1997) 33068-76.

[132] D. Lopez, T.W. Sandhoff, M.P. McLean, Steroidogenic factor-1 mediates cyclic 3',5'-adenosine monophosphate regulation of the high density lipoprotein receptor, Endocrinology 140(7) (1999) 303444.

[133] G. Cao, L. Zhao, H. Stangl, T. Hasegawa, J.A. Richardson, K.L. Parker, H.H. Hobbs, Developmental and hormonal regulation of murine scavenger receptor, class B, type 1, Mol Endocrinol 13(9) (1999) 1460-73. [134] Y. Zhang, C. Shen, D. Ai, X. Xie, Y. Zhu, Upregulation of Scavenger Receptor BI by Hepatic Nuclear Factor 4alpha through a Peroxisome Proliferator-Activated Receptor gamma-Dependent Mechanism in Liver, PPAR Res 2011 (2011) 164925.

[135] K. Schoonjans, J.S. Annicotte, T. Huby, O.A. Botrugno, E. Fayard, Y. Ueda, J. Chapman, J. Auwerx, Liver receptor homolog 1 controls the expression of the scavenger receptor class B type I, EMBO Rep 3(12) (2002) 1181-7.

[136] X. Yu, K. Murao, H. Imachi, J. Li, T. Nishiuchi, H. Dobashi, N. Hosomi, H. Masugata, G.X. Zhang, H. Iwama, T. Ishida, The transcription factor prolactin regulatory element-binding protein mediates prolactin transcription induced by thyrotropin-releasing hormone in GH3 cells, Endocrine 38(1) (2010) 53-9.

[137] K. Murao, H. Imachi, X. Yu, W.M. Cao, T. Muraoka, H. Dobashi, N. Hosomi, R. Haba, H. Iwama, T. Ishida, The transcriptional factor prolactin regulatory element-binding protein mediates the gene transcription of adrenal scavenger receptor class B type I via 3',5'-cyclic adenosine 5'-monophosphate, Endocrinology 149(12) (2008) 6103-12.

[138] S.X. Lee, M. Heine, C. Schlein, R. Ramakrishnan, J. Liu, G. Belnavis, I. Haimi, A.W. Fischer, H.N. Ginsberg, J. Heeren, F. Rinninger, R.A. Haeusler, FoxO transcription factors are required for hepatic HDL cholesterol clearance, J Clin Invest 128(4) (2018) 1615-1626.

[139] D. Lopez, W. Shea-Eaton, M.D. Sanchez, M.P. McLean, DAX-1 represses the high-density lipoprotein receptor through interaction with positive regulators sterol regulatory element-binding protein-1a and steroidogenic factor-1, Endocrinology 142(12) (2001) 5097-106.

[140] Y. Shi, J.S. Lee, K.M. Galvin, Everything you have ever wanted to know about Yin Yang 1, Biochimica et biophysica acta 1332(2) (1997) F49-66.

[141] W. Shea-Eaton, D. Lopez, M.P. McLean, Yin yang 1 protein negatively regulates high-density lipoprotein receptor gene transcription by disrupting binding of sterol regulatory element binding protein to the sterol regulatory element, Endocrinology 142(1) (2001) 49-58.

[142] M. Sporstol, G. Tapia, L. Malerod, S.A. Mousavi, T. Berg, Pregnane X receptor-agonists downregulate hepatic ATP-binding cassette transporter A1 and scavenger receptor class B type I, Biochem Biophys Res Commun 331(4) (2005) 1533-41.

[143] W. de Haan, J. de Vries-van der Weij, I.M. Mol, M. Hoekstra, J.A. Romijn, J.W. Jukema, L.M. Havekes, H.M. Princen, P.C. Rensen, PXR agonism decreases plasma HDL levels in ApoE3-Leiden.CETP mice, Biochimica et biophysica acta 1791(3) (2009) 191-7.

[144] K. Murao, H. Imachi, X. Yu, W.M. Cao, T. Nishiuchi, K. Chen, J. Li, R.A. Ahmed, N.C. Wong, T. Ishida, Interferon alpha decreases expression of human scavenger receptor class $\mathrm{BI}$, a possible HCV receptor in hepatocytes, Gut 57(5) (2008) 664-71. 
[145] Z. Hu, J. Li, Z. Kuang, M. Wang, S. Azhar, Z. Guo, Cell-Specific Polymorphism and Hormonal Regulation of DNA Methylation in Scavenger Receptor Class B, Type I, DNA Cell Biol 35(6) (2016) 280-9.

[146] Y. Sun, N. Wang, A.R. Tall, Regulation of adrenal scavenger receptor-BI expression by ACTH and cellular cholesterol pools, J Lipid Res 40(10) (1999) 1799-805.

[147] A. Rigotti, E.R. Edelman, P. Seifert, S.N. Iqbal, R.B. DeMattos, R.E. Temel, M. Krieger, D.L. Williams, Regulation by adrenocorticotropic hormone of the in vivo expression of scavenger receptor class $B$ type I (SR-BI), a high density lipoprotein receptor, in steroidogenic cells of the murine adrenal gland, J Biol Chem 271(52) (1996) 33545-9.

[148] N.C. Lucki, D. Li, M.B. Sewer, Sphingosine-1-phosphate rapidly increases cortisol biosynthesis and the expression of genes involved in cholesterol uptake and transport in H295R adrenocortical cells, Mol Cell Endocrinol 348(1) (2012) 165-75.

[149] W.J. Shen, S. Azhar, F.B. Kraemer, ACTH Regulation of Adrenal SR-B1, Front Endocrinol (Lausanne) 7 (2016) 42.

[150] S. Mavridou, M. Venihaki, O. Rassouli, C. Tsatsanis, D. Kardassis, Feedback inhibition of human scavenger receptor class B type I gene expression by glucocorticoid in adrenal and ovarian cells, Endocrinology 151(7) (2010) 3214-24.

[151] M. Sporstol, S.A. Mousavi, W. Eskild, N. Roos, T. Berg, ABCA1, ABCG1 and SR-BI: hormonal regulation in primary rat hepatocytes and human cell lines, BMC Mol Biol 8 (2007) 5.

[152] X. Yu, K. Murao, H. Imachi, W.M. Cao, J. Li, K. Matsumoto, T. Nishiuchi, R.A. Ahmed, N.C. Wong, H. Kosaka, T.G. Unterman, T. Ishida, Regulation of scavenger receptor class BI gene expression by angiotensin II in vascular endothelial cells, Hypertension 49(6) (2007) 1378-84.

[153] G. Wolf, U. Wenzel, K. Jablonski, M. Brundert, F. Rinninger, Angiotensin II down-regulates the SR-BI HDL receptor in proximal tubular cells, Nephrol Dial Transplant 20(6) (2005) 1222-7.

[154] A. Pilon, G. Martin, S. Bultel-Brienne, D. Junquero, A. Delhon, J.C. Fruchart, B. Staels, V. Clavey, Regulation of the scavenger receptor $\mathrm{BI}$ and the $\mathrm{LDL}$ receptor by activators of aldosterone production, angiotensin II and PMA, in the human NCl-H295R adrenocortical cell line, Biochimica et biophysica acta 1631(3) (2003) 218-28.

[155] M. Fuentes, N. Santander, V. Cortes, Insulin increases cholesterol uptake, lipid droplet content, and apolipoprotein $B$ secretion in CaCo-2 cells by upregulating SR-BI via a PI3K, AKT, and mTOR-dependent pathway, J Cell Biochem (2018).

[156] A.A. Hayashi, J. Webb, J. Choi, C. Baker, M. Lino, B. Trigatti, K.E. Trajcevski, T.J. Hawke, K. Adeli, Intestinal SR-BI is upregulated in insulin-resistant states and is associated with overproduction of intestinal apoB48-containing lipoproteins, American journal of physiology. Gastrointestinal and liver physiology 301(2) (2011) G326-37.

[157] S.L. Tang, W.J. Chen, K. Yin, G.J. Zhao, Z.C. Mo, Y.C. Lv, X.P. Ouyang, X.H. Yu, H.J. Kuang, Z.S. Jiang, Y.C. Fu, C.K. Tang, PAPP-A negatively regulates ABCA1, ABCG1 and SR-B1 expression by inhibiting LXRalpha through the IGF-I-mediated signaling pathway, Atherosclerosis 222(2) (2012) 344-54.

[158] W.M. Cao, K. Murao, H. Imachi, X. Yu, H. Dobashi, K. Yoshida, T. Muraoka, N. Kotsuna, S. Nagao, N.C. Wong, T. Ishida, Insulin-like growth factor-i regulation of hepatic scavenger receptor class $\mathrm{BI}$, Endocrinology 145(12) (2004) 5540-7.

[159] S.L. Tang, Z.W. Zhao, S.M. Liu, G. Wang, X.H. Yu, J. Zou, S.Q. Wang, X.Y. Dai, M.G. Fu, X.L. Zheng, D.W. Zhang, H. Fu, C.K. Tang, Pregnancy-Associated Plasma Protein-A Accelerates Atherosclerosis by Regulating Reverse Cholesterol Transport and Inflammation, Circ J 83(3) (2019) 515-523.

[160] L. Johansson, M. Rudling, T.S. Scanlan, T. Lundasen, P. Webb, J. Baxter, B. Angelin, P. Parini, Selective thyroid receptor modulation by GC-1 reduces serum lipids and stimulates steps of reverse cholesterol transport in euthyroid mice, Proc Natl Acad Sci U S A 102(29) (2005) 10297-302. 
[161] D. Vieira-van Bruggen, I. Kalkman, T. van Gent, A. van Tol, H. Jansen, Induction of adrenal scavenger receptor $\mathrm{BI}$ and increased high density lipoprotein-cholesteryl ether uptake by in vivo inhibition of hepatic lipase, J Biol Chem 273(48) (1998) 32038-41.

[162] N. Wang, W. Weng, J.L. Breslow, A.R. Tall, Scavenger receptor BI (SR-BI) is up-regulated in adrenal gland in apolipoprotein $A-I$ and hepatic lipase knock-out mice as a response to depletion of cholesterol stores. In vivo evidence that SR-BI is a functional high density lipoprotein receptor under feedback control, J Biol Chem 271(35) (1996) 21001-4.

[163] C. Langer, B. Gansz, C. Goepfert, T. Engel, Y. Uehara, G. von Dehn, H. Jansen, G. Assmann, A. von Eckardstein, Testosterone up-regulates scavenger receptor $\mathrm{BI}$ and stimulates cholesterol efflux from macrophages, Biochem Biophys Res Commun 296(5) (2002) 1051-7.

[164] T. Lundasen, W. Liao, B. Angelin, M. Rudling, Leptin induces the hepatic high density lipoprotein receptor scavenger receptor B type I (SR-BI) but not cholesterol 7alpha-hydroxylase (Cyp7a1) in leptindeficient (ob/ob) mice, J Biol Chem 278(44) (2003) 43224-8.

[165] D.M. Wu, Z. He, L.P. Ma, L.L. Wang, J. Ping, H. Wang, Increased DNA methylation of scavenger receptor class $B$ type I contributes to inhibitory effects of prenatal caffeine ingestion on cholesterol uptake and steroidogenesis in fetal adrenals, Toxicol Appl Pharmacol 285(2) (2015) 89-97.

[166] R. Towns, K.M. Menon, The role of cyclic AMP response element binding protein in transactivation of scavenger receptor class B type I promoter in transfected cells and in primary cultures of rat thecainterstitial cells, Mol Cell Endocrinol 245(1-2) (2005) 23-30.

[167] M.V. Lobo, M.I. Arenas, L. Huerta, S. Sacristan, M. Perez-Crespo, A. Gutierrez-Adan, J.J. Diaz-Gil, M.A. Lasuncion, A. Martin-Hidalgo, Liver growth factor induces testicular regeneration in EDS-treated rats and increases protein levels of class B scavenger receptors, Am J Physiol Endocrinol Metab 308(2) (2015) E11121.

[168] M.E. Casado, L. Huerta, A.I. Ortiz, M. Perez-Crespo, A. Gutierrez-Adan, F.B. Kraemer, M.A. Lasuncion, R. Busto, A. Martin-Hidalgo, HSL-knockout mouse testis exhibits class B scavenger receptor upregulation and disrupted lipid raft microdomains, J Lipid Res 53(12) (2012) 2586-97.

[169] F. Moheimani, J.T. Tan, B.E. Brown, A.K. Heather, D.M. van Reyk, M.J. Davies, Effect of exposure of human monocyte-derived macrophages to high, versus normal, glucose on subsequent lipid accumulation from glycated and acetylated low-density lipoproteins, Exp Diabetes Res 2011 (2011) 851280.

[170] Z. Ravid, M. Bendayan, E. Delvin, A.T. Sane, M. Elchebly, J. Lafond, M. Lambert, G. Mailhot, E. Levy, Modulation of intestinal cholesterol absorption by high glucose levels: impact on cholesterol transporters, regulatory enzymes, and transcription factors, American journal of physiology. Gastrointestinal and liver physiology 295(5) (2008) G873-85.

[171] K. Murao, X. Yu, H. Imachi, W.M. Cao, K. Chen, K. Matsumoto, T. Nishiuchi, N.C. Wong, T. Ishida, Hyperglycemia suppresses hepatic scavenger receptor class B type I expression, Am J Physiol Endocrinol Metab 294(1) (2008) E78-87.

[172] A. Gantman, B. Fuhrman, M. Aviram, T. Hayek, High glucose stimulates macrophage SR-BI expression and induces a switch in its activity from cholesterol efflux to cholesterol influx, Biochem Biophys Res Commun 391(1) (2010) 523-8.

[173] K. Ren, X. Zhu, Z. Zheng, Z.C. Mo, X.S. Peng, Y.Z. Zeng, H.X. Ou, Q.H. Zhang, H.Z. Qi, G.J. Zhao, G.H. $\mathrm{Yi}$, MicroRNA-24 aggravates atherosclerosis by inhibiting selective lipid uptake from HDL cholesterol via the post-transcriptional repression of scavenger receptor class B type I, Atherosclerosis 270 (2018) 57-67. [174] M. Wang, L. Li, R. Liu, Y. Song, X. Zhang, W. Niu, A.K. Kumar, Z. Guo, Z. Hu, Obesity-induced overexpression of miRNA-24 regulates cholesterol uptake and lipid metabolism by targeting SR-B1, Gene 668 (2018) 196-203.

[175] L. Wang, X.J. Jia, H.J. Jiang, Y. Du, F. Yang, S.Y. Si, B. Hong, MicroRNAs 185, 96, and 223 repress selective high-density lipoprotein cholesterol uptake through posttranscriptional inhibition, Mol Cell Biol 33(10) (2013) 1956-64. 
[176] Z. Hu, W.J. Shen, F.B. Kraemer, S. Azhar, MicroRNAs 125a and 455 repress lipoprotein-supported steroidogenesis by targeting scavenger receptor class B type I in steroidogenic cells, Mol Cell Biol 32(24) (2012) 5035-45.

[177] H. Liu, X. Li, Y. Song, Z. Wang, MicroRNA-217 attenuates intima-media complex thickness of ascending aorta measured by ultrasound bio-microscopy and inhibits inflammation and lipid metabolism in atherosclerotic models of ApoE(-/-) mice, Lipids Health Dis 17(1) (2018) 170.

[178] O. Kocher, A. Yesilaltay, C. Cirovic, R. Pal, A. Rigotti, M. Krieger, Targeted disruption of the PDZK1 gene in mice causes tissue-specific depletion of the high density lipoprotein receptor scavenger receptor class B type I and altered lipoprotein metabolism, J Biol Chem 278(52) (2003) 52820-5.

[179] A. Bretscher, K. Edwards, R.G. Fehon, ERM proteins and merlin: integrators at the cell cortex, Nature reviews. Molecular cell biology 3(8) (2002) 586-99.

[180] Z. Hu, J. Hu, Z. Zhang, W.J. Shen, C.C. Yun, C.H. Berlot, F.B. Kraemer, S. Azhar, Regulation of expression and function of scavenger receptor class $\mathrm{B}$, type I (SR-BI) by $\mathrm{Na}+\mathrm{H}+$ exchanger regulatory factors (NHERFs), J Biol Chem 288(16) (2013) 11416-35.

[181] T. Nakamura, N. Shibata, T. Nishimoto-Shibata, D. Feng, M. Ikemoto, K. Motojima, O.N. Iso, K. Tsukamoto, M. Tsujimoto, H. Arai, Regulation of SR-BI protein levels by phosphorylation of its associated protein, PDZK1, Proc Natl Acad Sci U S A 102(38) (2005) 13404-9.

[182] C. Ferreira, R. Meyer, H.E. Meyer Zu Schwabedissen, The nuclear receptors PXR and LXR are regulators of the scaffold protein PDZK1, Biochim Biophys Acta Gene Regul Mech 1862(4) (2019) 447-456. [183] L. Wang, B. Waltenberger, E.M. Pferschy-Wenzig, M. Blunder, X. Liu, C. Malainer, T. Blazevic, S. Schwaiger, J.M. Rollinger, E.H. Heiss, D. Schuster, B. Kopp, R. Bauer, H. Stuppner, V.M. Dirsch, A.G. Atanasov, Natural product agonists of peroxisome proliferator-activated receptor gamma (PPARgamma): a review, Biochem Pharmacol 92(1) (2014) 73-89.

[184] R.B. El-Houri, J. Mortier, M.S. Murgueitio, G. Wolber, L.P. Christensen, Identification of PPARgamma Agonists from Natural Sources Using Different In Silico Approaches, Planta medica 81(6) (2015) 488-94.

[185] K. Zeka, K.C. Ruparelia, M.A. Continenza, D. Stagos, F. Veglio, R.R.J. Arroo, Petals of Crocus sativus L. as a potential source of the antioxidants crocin and kaempferol, Fitoterapia 107 (2015) 128-134.

[186] K. Zeka, K. Ruparelia, R.R.J. Arroo, R. Budriesi, M. Micucci, Flavonoids and Their Metabolites: Prevention in Cardiovascular Diseases and Diabetes, Diseases 5(3) (2017) 19.

[187] M. Dei Cas, R. Ghidoni, Cancer Prevention and Therapy with Polyphenols: Sphingolipid-Mediated Mechanisms, Nutrients 10(7) (2018).

[188] L. Marin, E.M. Miguelez, C.J. Villar, F. Lombo, Bioavailability of dietary polyphenols and gut microbiota metabolism: antimicrobial properties, BioMed research international 2015 (2015) 905215.

[189] C.L. Millar, Q. Duclos, C.N. Blesso, Effects of Dietary Flavonoids on Reverse Cholesterol Transport, HDL Metabolism, and HDL Function, Advances in nutrition 8(2) (2017) 226-239.

[190] K. Ren, T. Jiang, G.J. Zhao, Quercetin induces the selective uptake of HDL-cholesterol via promoting SR-BI expression and the activation of the PPARgamma/LXRalpha pathway, Food \& function 9(1) (2018) 624-635.

[191] X.Y. Li, L.X. Kong, J. Li, H.X. He, Y.D. Zhou, Kaempferol suppresses lipid accumulation in macrophages through the downregulation of cluster of differentiation 36 and the upregulation of scavenger receptor class B type I and ATP-binding cassette transporters A1 and G1, International journal of molecular medicine 31(2) (2013) 331-8.

[192] R.R. Erna Susanti, Aulanni'am Aulanni'am, Achmad Rudijanto, Catechins green tea upregulates the expression of $A B C A 1, A B C G 1$, and SRB1 in rats induced atherogenic diet, Journal of Applied Pharmaceutical Science (2019) 9(3) 091-097.

[193] W. Zhao, V. Haller, A. Ritsch, The polyphenol PGG enhances expression of SR-BI and ABCA1 in J774 and THP-1 macrophages, Atherosclerosis 242(2) (2015) 611-7. 
[194] G.L. Hostetler, R.A. Ralston, S.J. Schwartz, Flavones: Food Sources, Bioavailability, Metabolism, and Bioactivity, Advances in nutrition 8(3) (2017) 423-435.

[195] G. Serreli, M. Deiana, Biological Relevance of Extra Virgin Olive Oil Polyphenols Metabolites, Antioxidants 7(12) (2018).

[196] M.S. Kim, D.S. Kim, H.S. Kim, S.W. Kang, Y.H. Kang, Inhibitory effects of luteolin on transendothelial migration of monocytes and formation of lipid-laden macrophages, Nutrition 28(10) (2012) 1044-54.

[197] V. Saibabu, Z. Fatima, L.A. Khan, S. Hameed, Therapeutic Potential of Dietary Phenolic Acids, Advances in pharmacological sciences 2015 (2015) 823539.

[198] H. Uto-Kondo, M. Ayaori, M. Ogura, K. Nakaya, M. Ito, A. Suzuki, S. Takiguchi, E. Yakushiji, Y. Terao, H. Ozasa, T. Hisada, M. Sasaki, F. Ohsuzu, K. Ikewaki, Coffee consumption enhances high-density lipoprotein-mediated cholesterol efflux in macrophages, Circulation research 106(4) (2010) 779-87.

[199] S.H. Park, J.L. Kim, E.S. Lee, S.Y. Han, J.H. Gong, M.K. Kang, Y.H. Kang, Dietary ellagic acid attenuates oxidized LDL uptake and stimulates cholesterol efflux in murine macrophages, The Journal of nutrition 141(11) (2011) 1931-7.

[200] H. Chen, T. Tuck, X. Ji, X. Zhou, G. Kelly, A. Cuerrier, J. Zhang, Quality assessment of Japanese knotweed (Fallopia japonica) grown on Prince Edward Island as a source of resveratrol, Journal of agricultural and food chemistry 61(26) (2013) 6383-92.

[201] A. Rauf, M. Imran, M.S. Butt, M. Nadeem, D.G. Peters, M.S. Mubarak, Resveratrol as an anti-cancer agent: A review, Critical reviews in food science and nutrition 58(9) (2018) 1428-1447.

[202] S.S. Kulkarni, C. Canto, The molecular targets of resveratrol, Biochimica et biophysica acta 1852(6) (2015) 1114-23.

[203] D. Bonnefont-Rousselot, Resveratrol and Cardiovascular Diseases, Nutrients 8(5) (2016).

[204] C. Sticozzi, G. Belmonte, F. Cervellati, X.M. Muresan, F. Pessina, Y. Lim, H.J. Forman, G. Valacchi, Resveratrol protects SR-B1 levels in keratinocytes exposed to cigarette smoke, Free radical biology \& medicine 69 (2014) 50-7.

[205] I. Voloshyna, O. Hai, M.J. Littlefield, S. Carsons, A.B. Reiss, Resveratrol mediates anti-atherogenic effects on cholesterol flux in human macrophages and endothelium via PPARgamma and adenosine, Eur J Pharmacol 698(1-3) (2013) 299-309.

[206] O. Vang, N. Ahmad, C.A. Baile, J.A. Baur, K. Brown, A. Csiszar, D.K. Das, D. Delmas, C. Gottfried, H.Y. Lin, Q.Y. Ma, P. Mukhopadhyay, N. Nalini, J.M. Pezzuto, T. Richard, Y. Shukla, Y.J. Surh, T. Szekeres, T. Szkudelski, T. Walle, J.M. Wu, What is new for an old molecule? Systematic review and recommendations on the use of resveratrol, PLoS One 6(6) (2011) e19881.

[207] B. Halliwell, Dietary polyphenols: good, bad, or indifferent for your health?, Cardiovasc Res 73(2) (2007) 341-7.

[208] V. Habauzit, C. Morand, Evidence for a protective effect of polyphenols-containing foods on cardiovascular health: an update for clinicians, Therapeutic advances in chronic disease 3(2) (2012) 87106.

[209] D. Del Rio, A. Rodriguez-Mateos, J.P. Spencer, M. Tognolini, G. Borges, A. Crozier, Dietary (poly)phenolics in human health: structures, bioavailability, and evidence of protective effects against chronic diseases, Antioxidants \& redox signaling 18(14) (2013) 1818-92.

[210] R. Menezes, A. Rodriguez-Mateos, A. Kaltsatou, A. Gonzalez-Sarrias, A. Greyling, C. Giannaki, C. Andres-Lacueva, D. Milenkovic, E.R. Gibney, J. Dumont, M. Schar, M. Garcia-Aloy, S.A. Palma-Duran, T. Ruskovska, V. Maksimova, E. Combet, P. Pinto, Impact of Flavonols on Cardiometabolic Biomarkers: A Meta-Analysis of Randomized Controlled Human Trials to Explore the Role of Inter-Individual Variability, Nutrients 9(2) (2017).

[211] R.M. van Dam, N. Naidoo, R. Landberg, Dietary flavonoids and the development of type 2 diabetes and cardiovascular diseases: review of recent findings, Curr Opin Lipidol 24(1) (2013) 25-33. 
[212] N.M. Wedick, A. Pan, A. Cassidy, E.B. Rimm, L. Sampson, B. Rosner, W. Willett, F.B. Hu, Q. Sun, R.M. van Dam, Dietary flavonoid intakes and risk of type 2 diabetes in US men and women, The American journal of clinical nutrition 95(4) (2012) 925-33.

[213] Y. Arai, S. Watanabe, M. Kimira, K. Shimoi, R. Mochizuki, N. Kinae, Dietary intakes of flavonols, flavones and isoflavones by Japanese women and the inverse correlation between quercetin intake and plasma LDL cholesterol concentration, The Journal of nutrition 130(9) (2000) 2243-50.

[214] I. Onakpoya, E. Spencer, C. Heneghan, M. Thompson, The effect of green tea on blood pressure and lipid profile: a systematic review and meta-analysis of randomized clinical trials, Nutrition, metabolism, and cardiovascular diseases : NMCD 24(8) (2014) 823-36.

[215] G. Pounis, M. Bonaccio, A. Di Castelnuovo, S. Costanzo, A. de Curtis, M. Persichillo, S. Sieri, M.B. Donati, C. Cerletti, G. de Gaetano, L. lacoviello, Polyphenol intake is associated with low-grade inflammation, using a novel data analysis from the Moli-sani study, Thrombosis and haemostasis 115(2) (2016) 344-52.

[216] F. Rizzi, C. Conti, E. Dogliotti, A. Terranegra, E. Salvi, D. Braga, F. Ricca, S. Lupoli, A. Mingione, F. Pivari, C. Brasacchio, M. Barcella, M. Chittani, F. D'Avila, M. Turiel, M. Lazzaroni, L. Soldati, D. Cusi, C. Barlassina, Interaction between polyphenols intake and PON1 gene variants on markers of cardiovascular disease: a nutrigenetic observational study, Journal of translational medicine 14(1) (2016) 186.

[217] P. Kar, D. Laight, H.K. Rooprai, K.M. Shaw, M. Cummings, Effects of grape seed extract in Type 2 diabetic subjects at high cardiovascular risk: a double blind randomized placebo controlled trial examining metabolic markers, vascular tone, inflammation, oxidative stress and insulin sensitivity, Diabetic medicine : a journal of the British Diabetic Association 26(5) (2009) 526-31.

[218] S. Zibadi, P.J. Rohdewald, D. Park, R.R. Watson, Reduction of cardiovascular risk factors in subjects with type 2 diabetes by Pycnogenol supplementation, Nutrition research 28(5) (2008) 315-20.

[219] G. Chiva-Blanch, M. Urpi-Sarda, E. Ros, P. Valderas-Martinez, R. Casas, S. Arranz, M. Guillen, R.M. Lamuela-Raventos, R. Llorach, C. Andres-Lacueva, R. Estruch, Effects of red wine polyphenols and alcohol on glucose metabolism and the lipid profile: a randomized clinical trial, Clinical nutrition 32(2) (2013) 2006.

[220] I. Stensvold, A. Tverdal, K. Solvoll, O.P. Foss, Tea consumption. relationship to cholesterol, blood pressure, and coronary and total mortality, Preventive medicine 21(4) (1992) 546-53.

[221] A. Basu, K. Sanchez, M.J. Leyva, M. Wu, N.M. Betts, C.E. Aston, T.J. Lyons, Green tea supplementation affects body weight, lipids, and lipid peroxidation in obese subjects with metabolic syndrome, Journal of the American College of Nutrition 29(1) (2010) 31-40.

[222] A.L. Brown, J. Lane, C. Holyoak, B. Nicol, A.E. Mayes, T. Dadd, Health effects of green tea catechins in overweight and obese men: a randomised controlled cross-over trial, The British journal of nutrition 106(12) (2011) 1880-9.

[223] J.K. Bhatt, S. Thomas, M.J. Nanjan, Resveratrol supplementation improves glycemic control in type 2 diabetes mellitus, Nutrition research 32(7) (2012) 537-41.

[224] Y.K. Bashmakov, S.H. Assaad-Khalil, M. Abou Seif, R. Udumyan, M. Megallaa, K.H. Rohoma, M. Zeitoun, I.M. Petyaev, Resveratrol promotes foot ulcer size reduction in type 2 diabetes patients, ISRN endocrinology 2014 (2014) 816307.

[225] S. Rodenas, S. Rodriguez-Gil, M.C. Merinero, F.J. Sanchez-Muniz, Dietary exchange of an olive oil and sunflower oil blend for extra virgin olive oil decreases the estimate cardiovascular risk and LDL and apolipoprotein All concentrations in postmenopausal women, Journal of the American College of Nutrition 24(5) (2005) 361-9.

[226] A. Movahed, I. Nabipour, X. Lieben Louis, S.J. Thandapilly, L. Yu, M. Kalantarhormozi, S.J. Rekabpour, T. Netticadan, Antihyperglycemic effects of short term resveratrol supplementation in type 2 diabetic patients, Evidence-based complementary and alternative medicine : eCAM 2013 (2013) 851267. 
[227] M. Fantini, M. Benvenuto, L. Masuelli, G.V. Frajese, I. Tresoldi, A. Modesti, R. Bei, In vitro and in vivo antitumoral effects of combinations of polyphenols, or polyphenols and anticancer drugs: perspectives on cancer treatment, Int J Mol Sci 16(5) (2015) 9236-82.

[228] C.J. Paller, M.A. Rudek, X.C. Zhou, W.D. Wagner, T.S. Hudson, N. Anders, H.J. Hammers, D. Dowling, S. King, E.S. Antonarakis, C.G. Drake, M.A. Eisenberger, S.R. Denmeade, G.L. Rosner, M.A. Carducci, A phase I study of muscadine grape skin extract in men with biochemically recurrent prostate cancer: Safety, tolerability, and dose determination, Prostate 75(14) (2015) 1518-25.

[229] A. Cassidy, T. Huang, M.S. Rice, E.B. Rimm, S.S. Tworoger, Intake of dietary flavonoids and risk of epithelial ovarian cancer, The American journal of clinical nutrition 100(5) (2014) 1344-51.

[230] R. Shafabakhsh, Z. Asemi, Quercetin: a natural compound for ovarian cancer treatment, Journal of ovarian research 12(1) (2019) 55.

[231] D.M. Wu, X. Wen, W. Qu, H.X. Liu, L.P. Ma, T. Chen, J. Ping, Prenatal caffeine ingestion induces longterm alterations in scavenger receptor class $B$ type I expression and glucocorticoid synthesis in adult male offspring rat adrenals, Food and chemical toxicology : an international journal published for the British Industrial Biological Research Association 120 (2018) 24-31.

[232] J.M. Hagel, P.J. Facchini, Benzylisoquinoline alkaloid metabolism: a century of discovery and a brave new world, Plant \& cell physiology 54(5) (2013) 647-72.

[233] X. Feng, A. Sureda, S. Jafari, Z. Memariani, D. Tewari, G. Annunziata, L. Barrea, S.T.S. Hassan, K. Smejkal, M. Malanik, A. Sychrova, D. Barreca, L. Ziberna, M.F. Mahomoodally, G. Zengin, S. Xu, S.M. Nabavi, A.Z. Shen, Berberine in Cardiovascular and Metabolic Diseases: From Mechanisms to Therapeutics, Theranostics 9(7) (2019) 1923-1951.

[234] S. Guan, B. Wang, W. Li, J. Guan, X. Fang, Effects of berberine on expression of LOX-1 and SR-BI in human macrophage-derived foam cells induced by ox-LDL, The American journal of Chinese medicine 38(6) (2010) 1161-9.

[235] H.R. Millard, S.K. Musani, D.T. Dibaba, S.A. Talegawkar, H.A. Taylor, K.L. Tucker, A. Bidulescu, Dietary choline and betaine; associations with subclinical markers of cardiovascular disease risk and incidence of CVD, coronary heart disease and stroke: the Jackson Heart Study, European journal of nutrition 57(1) (2018) 51-60.

[236] C.R. Day, S.A. Kempson, Betaine chemistry, roles, and potential use in liver disease, Biochimica et biophysica acta 1860(6) (2016) 1098-106.

[237] D. Cai, M. Yuan, H. Liu, S. Pan, W. Ma, J. Hong, R. Zhao, Maternal Betaine Supplementation throughout Gestation and Lactation Modifies Hepatic Cholesterol Metabolic Genes in Weaning Piglets via AMPK/LXR-Mediated Pathway and Histone Modification, Nutrients 8(10) (2016).

[238] M.R. Lakshman, K. Reyes-Gordillo, R. Varatharajalu, J. Arellanes-Robledo, L.C. Leckey, M. Garige, R. Shah, Novel modulators of hepatosteatosis, inflammation and fibrogenesis, Hepatology international 8 Suppl 2 (2014) 413-20.

[239] X. Wei, C. Wang, S. Hao, H. Song, L. Yang, The Therapeutic Effect of Berberine in the Treatment of Nonalcoholic Fatty Liver Disease: A Meta-Analysis, Evidence-based complementary and alternative medicine : eCAM 2016 (2016) 3593951.

[240] J. Lan, Y. Zhao, F. Dong, Z. Yan, W. Zheng, J. Fan, G. Sun, Meta-analysis of the effect and safety of berberine in the treatment of type 2 diabetes mellitus, hyperlipemia and hypertension, Journal of ethnopharmacology 161 (2015) 69-81.

[241] T.C. Weng, Y.H. Yang, S.J. Lin, S.H. Tai, A systematic review and meta-analysis on the therapeutic equivalence of statins, Journal of clinical pharmacy and therapeutics 35(2) (2010) 139-51.

[242] W. Kong, J. Wei, P. Abidi, M. Lin, S. Inaba, C. Li, Y. Wang, Z. Wang, S. Si, H. Pan, S. Wang, J. Wu, Y. Wang, Z. Li, J. Liu, J.D. Jiang, Berberine is a novel cholesterol-lowering drug working through a unique mechanism distinct from statins, Nat Med 10(12) (2004) 1344-51. 
[243] G. Marazzi, L. Cacciotti, F. Pelliccia, L. laia, M. Volterrani, G. Caminiti, B. Sposato, R. Massaro, F. Grieco, G. Rosano, Long-term effects of nutraceuticals (berberine, red yeast rice, policosanol) in elderly hypercholesterolemic patients, Advances in therapy 28(12) (2011) 1105-13.

[244] F. Affuso, A. Ruvolo, F. Micillo, L. Sacca, S. Fazio, Effects of a nutraceutical combination (berberine, red yeast rice and policosanols) on lipid levels and endothelial function randomized, double-blind, placebo-controlled study, Nutrition, metabolism, and cardiovascular diseases : NMCD 20(9) (2010) 65661.

[245] K.G. Perez-Rubio, M. Gonzalez-Ortiz, E. Martinez-Abundis, J.A. Robles-Cervantes, M.C. EspinelBermudez, Effect of berberine administration on metabolic syndrome, insulin sensitivity, and insulin secretion, Metabolic syndrome and related disorders 11(5) (2013) 366-9.

[246] F. Affuso, V. Mercurio, A. Ruvolo, C. Pirozzi, F. Micillo, G. Carlomagno, F. Grieco, S. Fazio, A nutraceutical combination improves insulin sensitivity in patients with metabolic syndrome, World journal of cardiology 4(3) (2012) 77-83.

[247] G. Derosa, A. D'Angelo, A. Bonaventura, L. Bianchi, D. Romano, P. Maffioli, Effects of berberine on lipid profile in subjects with low cardiovascular risk, Expert opinion on biological therapy 13(4) (2013) 47582.

[248] H. Dong, Y. Zhao, L. Zhao, F. Lu, The effects of berberine on blood lipids: a systemic review and metaanalysis of randomized controlled trials, Planta medica 79(6) (2013) 437-46.

[249] H. Zhang, J. Wei, R. Xue, J.D. Wu, W. Zhao, Z.Z. Wang, S.K. Wang, Z.X. Zhou, D.Q. Song, Y.M. Wang, H.N. Pan, W.J. Kong, J.D. Jiang, Berberine lowers blood glucose in type 2 diabetes mellitus patients through increasing insulin receptor expression, Metabolism: clinical and experimental 59(2) (2010) 285-92.

[250] J. Ying, M.H. Rahbar, D.M. Hallman, L.M. Hernandez, M.R. Spitz, M.R. Forman, O.Y. Gorlova, Associations between dietary intake of choline and betaine and lung cancer risk, PLoS One 8(2) (2013) e54561.

[251] R.F. Zhou, X.L. Chen, Z.G. Zhou, Y.J. Zhang, Q.Y. Lan, G.C. Liao, Y.M. Chen, H.L. Zhu, Higher dietary intakes of choline and betaine are associated with a lower risk of primary liver cancer: a case-control study, Sci Rep 7(1) (2017) 679.

[252] S. Sun, X. Li, A. Ren, M. Du, H. Du, Y. Shu, L. Zhu, W. Wang, Choline and betaine consumption lowers cancer risk: a meta-analysis of epidemiologic studies, Sci Rep 6 (2016) 35547.

[253] M. Hashibe, C. Galeone, S.S. Buys, L. Gren, P. Boffetta, Z.F. Zhang, C. La Vecchia, Coffee, tea, caffeine intake, and the risk of cancer in the PLCO cohort, British journal of cancer 113(5) (2015) 809-16.

[254] M. Styrczewska, A. Kulma, K. Kostyn, K. Hasiewicz-Derkacz, J. Szopa, Flax terpenoid pathway as a source of health promoting compounds, Mini reviews in medicinal chemistry 13(3) (2013) 353-64.

[255] H.A. Wahab, N.B. Pham, T.S. Muhammad, J.N. Hooper, R.J. Quinn, Merosesquiterpene Congeners from the Australian Sponge Hyrtios digitatus as Potential Drug Leads for Atherosclerosis Disease, Marine drugs 15(1) (2016).

[256] E. Reboul, Mechanisms of Carotenoid Intestinal Absorption: Where Do We Stand?, Nutrients 11(4) (2019).

[257] M.Y. Choi, A.I. Romer, M. Hu, M. Lepourcelet, A. Mechoor, A. Yesilaltay, M. Krieger, P.A. Gray, R.A. Shivdasani, A dynamic expression survey identifies transcription factors relevant in mouse digestive tract development, Development 133(20) (2006) 4119-4129.

[258] G.P. Lobo, S. Hessel, A. Eichinger, N. Noy, A.R. Moise, A. Wyss, K. Palczewski, J. von Lintig, ISX is a retinoic acid-sensitive gatekeeper that controls intestinal beta,beta-carotene absorption and vitamin $A$ production, FASEB journal : official publication of the Federation of American Societies for Experimental Biology 24(6) (2010) 1656-66.

[259] S.B. Ateba, M.A. Mvondo, S.T. Ngeu, J. Tchoumtchoua, C.F. Awounfack, D. Njamen, L. Krenn, Natural Terpenoids Against Female Breast Cancer: A 5-year Recent Research, Curr Med Chem 25(27) (2018) 31623213. 
[260] B. Salehi, P.V.T. Fokou, L.R.T. Yamthe, B.T. Tali, C.O. Adetunji, A. Rahavian, F.N. Mudau, M. Martorell, W.N. Setzer, C.F. Rodrigues, N. Martins, W.C. Cho, J. Sharifi-Rad, Phytochemicals in Prostate Cancer: From Bioactive Molecules to Upcoming Therapeutic Agents, Nutrients 11(7) (2019).

[261] H. Wan, J. Li, K. Zhang, X. Zou, L. Ge, F. Zhu, H. Zhou, M. Gong, T. Wang, D. Chen, S. Peng, B. Zhou, X. Zeng, A new meroterpenoid functions as an anti-tumor agent in hepatoma cells by downregulating mTOR activation and inhibiting EMT, Sci Rep-Uk 8(1) (2018) 13152.

[262] F. Kasbi Chadli, H. Nazih, M. Krempf, P. Nguyen, K. Ouguerram, Omega 3 fatty acids promote macrophage reverse cholesterol transport in hamster fed high fat diet, PLoS One 8(4) (2013) e61109.

[263] M. Farras, R.M. Valls, S. Fernandez-Castillejo, M. Giralt, R. Sola, I. Subirana, M.J. Motilva, V. Konstantinidou, M.I. Covas, M. Fito, Olive oil polyphenols enhance the expression of cholesterol efflux related genes in vivo in humans. A randomized controlled trial, The Journal of nutritional biochemistry 24(7) (2013) 1334-9.

[264] B. Konig, K. Eder, Differential action of 13-HPODE on PPARalpha downstream genes in rat Fao and human HepG2 hepatoma cell lines, The Journal of nutritional biochemistry 17(6) (2006) 410-8.

[265] I. Kammerer, R. Ringseis, R. Biemann, G. Wen, K. Eder, 13-hydroxy linoleic acid increases expression of the cholesterol transporters ABCA1, ABCG1 and SR-BI and stimulates apoA-I-dependent cholesterol efflux in RAW264.7 macrophages, Lipids Health Dis 10 (2011) 222.

[266] M.E. Surette, The science behind dietary omega-3 fatty acids, CMAJ : Canadian Medical Association journal = journal de l'Association medicale canadienne 178(2) (2008) 177-80.

[267] H.J. Pownall, D. Brauchi, C. Kilinc, K. Osmundsen, Q. Pao, C. Payton-Ross, A.M. Gotto, Jr., C.M. Ballantyne, Correlation of serum triglyceride and its reduction by omega-3 fatty acids with lipid transfer activity and the neutral lipid compositions of high-density and low-density lipoproteins, Atherosclerosis 143(2) (1999) 285-97.

[268] W.S. Harris, H.N. Ginsberg, N. Arunakul, N.S. Shachter, S.L. Windsor, M. Adams, L. Berglund, K. Osmundsen, Safety and efficacy of Omacor in severe hypertriglyceridemia, Journal of cardiovascular risk 4(5-6) (1997) 385-91.

[269] M.H. Davidson, E.A. Stein, H.E. Bays, K.C. Maki, R.T. Doyle, R.A. Shalwitz, C.M. Ballantyne, H.N. Ginsberg, C.O.o.p.O.-w.S. Investigators, Efficacy and tolerability of adding prescription omega-3 fatty acids $4 \mathrm{~g} / \mathrm{d}$ to simvastatin $40 \mathrm{mg} / \mathrm{d}$ in hypertriglyceridemic patients: an 8-week, randomized, double-blind, placebo-controlled study, Clinical therapeutics 29(7) (2007) 1354-67.

[270] T.M. Brasky, J.W. Lampe, J.D. Potter, R.E. Patterson, E. White, Specialty supplements and breast cancer risk in the VITamins And Lifestyle (VITAL) Cohort, Cancer epidemiology, biomarkers \& prevention : a publication of the American Association for Cancer Research, cosponsored by the American Society of Preventive Oncology 19(7) (2010) 1696-708.

[271] T. Higurashi, K. Hosono, H. Endo, H. Takahashi, H. Iida, T. Uchiyama, A. Ezuka, S. Uchiyama, E. Yamada, H. Ohkubo, E. Sakai, S. Maeda, S. Morita, Y. Natsumeda, H. Nagase, A. Nakajima, Eicosapentaenoic acid (EPA) efficacy for colorectal aberrant crypt foci (ACF): a double-blind randomized controlled trial, BMC cancer 12 (2012) 413.

[272] S.F. Nabavi, S. Bilotto, G.L. Russo, I.E. Orhan, S. Habtemariam, M. Daglia, K.P. Devi, M.R. Loizzo, R. Tundis, S.M. Nabavi, Omega-3 polyunsaturated fatty acids and cancer: lessons learned from clinical trials, Cancer metastasis reviews 34(3) (2015) 359-80.

[273] M.L. Fernandez, Distinct mechanisms of plasma LDL lowering by dietary fiber in the guinea pig: specific effects of pectin, guar gum, and psyllium, J Lipid Res 36(11) (1995) 2394-404.

[274] M.L. Favier, P.E. Bost, C. Demigne, C. Remesy, The cholesterol-lowering effect of guar gum in rats is not accompanied by an interruption of bile acid cycling, Lipids 33(8) (1998) 765-71.

[275] K. Landin, G. Holm, L. Tengborn, U. Smith, Guar gum improves insulin sensitivity, blood lipids, blood pressure, and fibrinolysis in healthy men, The American journal of clinical nutrition 56(6) (1992) 1061-5. 
[276] T.C. Rideout, Z. Yuan, M. Bakovic, Q. Liu, R.K. Li, Y. Mine, M.Z. Fan, Guar gum consumption increases hepatic nuclear SREBP2 and LDL receptor expression in pigs fed an atherogenic diet, The Journal of nutrition 137(3) (2007) 568-72.

[277] X. Yu, C. Guo, P.B. Fisher, J.R. Subjeck, X.Y. Wang, Scavenger Receptors: Emerging Roles in Cancer Biology and Immunology, Advances in cancer research 128 (2015) 309-64.

[278] D. Wang, Y. Yang, Y. Lei, N.T. Tzvetkov, X. Liu, A.W.K. Yeung, S. Xu, A.G. Atanasov, Targeting Foam Cell Formation in Atherosclerosis: Therapeutic Potential of Natural Products, Pharmacol Rev 71(4) (2019) 596-670.

[279] S. Acton, D. Osgood, M. Donoghue, D. Corella, M. Pocovi, A. Cenarro, P. Mozas, J. Keilty, S. Squazzo, E.A. Woolf, J.M. Ordovas, Association of Polymorphisms at the SR-BI Gene Locus With Plasma Lipid Levels and Body Mass Index in a White Population, Arteriosclerosis, Thrombosis, and Vascular Biology 19(7) (1999) 1734-1743.

[280] L.R. Brunham, I. Tietjen, A.E. Bochem, R.R. Singaraja, P.L. Franchini, C. Radomski, M. Mattice, A. Legendre, G.K. Hovingh, J.J. Kastelein, M.R. Hayden, Novel mutations in scavenger receptor BI associated with high HDL cholesterol in humans, Clin Genet 79(6) (2011) 575-81.

[281] L.A. Hsu, Y.L. Ko, S. Wu, M.S. Teng, T.Y. Peng, C.F. Chen, C.F. Chen, Y.S. Lee, Association between a novel 11-base pair deletion mutation in the promoter region of the scavenger receptor class $B$ type I gene and plasma HDL cholesterol levels in Taiwanese Chinese, Arterioscler Thromb Vasc Biol 23(10) (2003) 1869-74.

[282] C.G. Roberts, H. Shen, B.D. Mitchell, C.M. Damcott, A.R. Shuldiner, A. Rodriguez, Variants in scavenger receptor class $B$ type I gene are associated with HDL cholesterol levels in younger women, Hum Hered 64(2) (2007) 107-13.

[283] A. Picataggi, G.F. Lim, A.P. Kent, J.S. Millar, D.J. Rader, I.M. Stylianou, A coding variant in SR-BI (I179N) significantly increases atherosclerosis in mice, Mamm Genome 24(7-8) (2013) 257-65.

[284] V. Niemsiri, X. Wang, D. Pirim, Z.H. Radwan, J.E. Hokanson, R.F. Hamman, M.M. Barmada, F.Y. Demirci, M.I. Kamboh, Impact of genetic variants in human scavenger receptor class B type I (SCARB1) on plasma lipid traits, Circ Cardiovasc Genet 7(6) (2014) 838-47.

[285] A. Morabia, B.M. Ross, M.C. Costanza, E. Cayanis, M.S. Flaherty, G.B. Alvin, K. Das, R. James, A.S. Yang, O. Evagrafov, T.C. Gilliam, Population-based study of SR-BI genetic variation and lipid profile, Atherosclerosis 175(1) (2004) 159-68.

[286] A. Helgadottir, P. Sulem, G. Thorgeirsson, S. Gretarsdottir, G. Thorleifsson, B.O. Jensson, G.A. Arnadottir, I. Olafsson, G.I. Eyjolfsson, O. Sigurdardottir, U. Thorsteinsdottir, D.F. Gudbjartsson, H. Holm, K. Stefansson, Rare SCARB1 mutations associate with high-density lipoprotein cholesterol but not with coronary artery disease, Eur Heart J 39(23) (2018) 2172-2178.

[287] I.C. Arts, P.C. Hollman, E.J. Feskens, H.B. Bueno de Mesquita, D. Kromhout, Catechin intake might explain the inverse relation between tea consumption and ischemic heart disease: the Zutphen Elderly Study, The American journal of clinical nutrition 74(2) (2001) 227-32.

[288] R. Varatharajalu, M. Garige, L.C. Leckey, J. Arellanes-Robledo, K. Reyes-Gordillo, R. Shah, M.R. Lakshman, Adverse signaling of scavenger receptor class B1 and PGC1s in alcoholic hepatosteatosis and steatohepatitis and protection by betaine in rat, The American journal of pathology $184(7)$ (2014) 203544. 
Figure 1

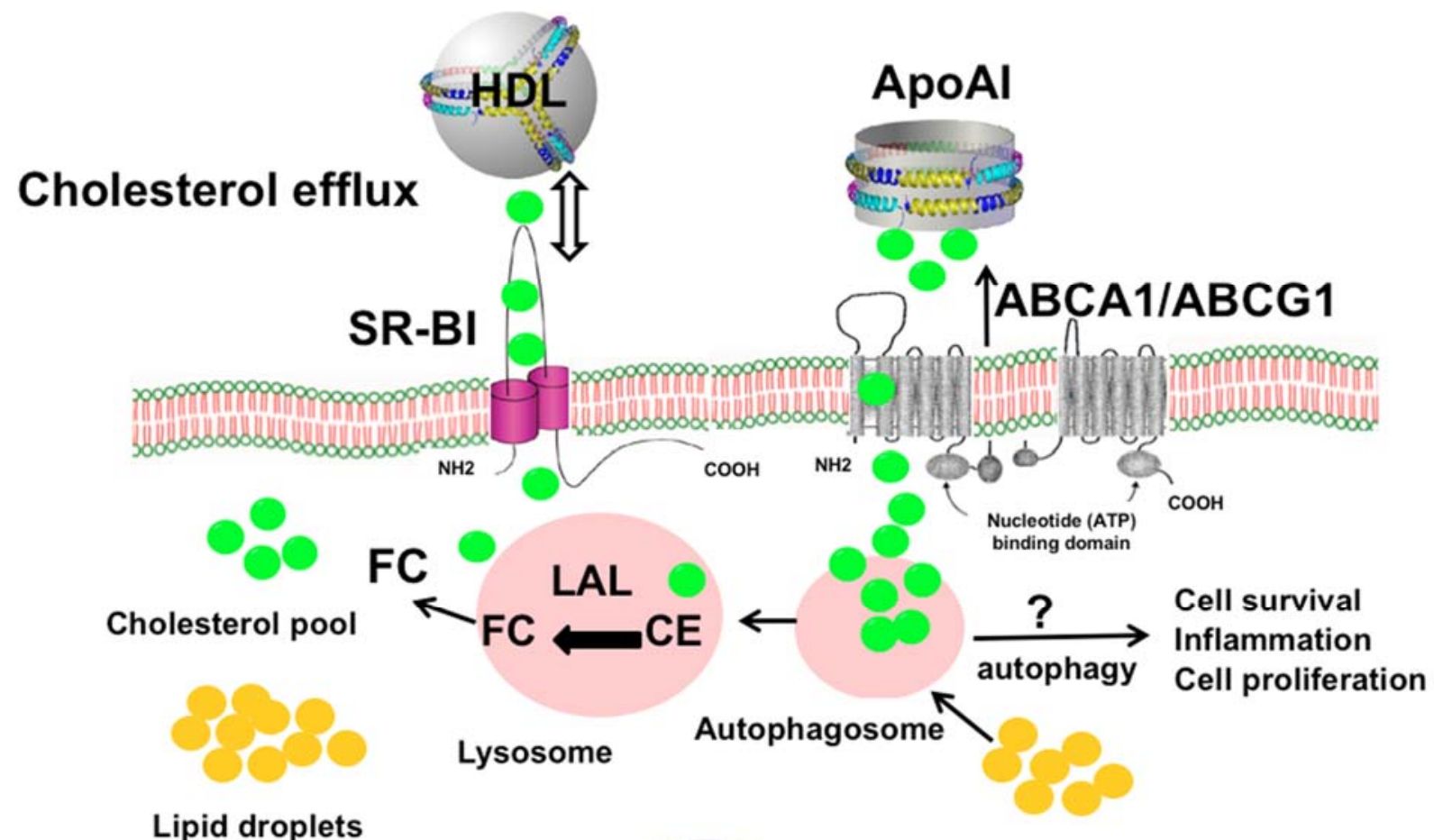

Lipid droplets

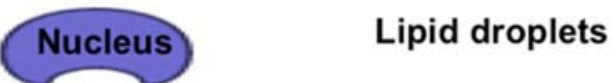

Figure 1. Role of scavenger receptor class $B$ type I (SR-BI) in preventing macrophage foam cell formation by promoting cholesterol metabolism. Three main proteins, including SR-BI, ATPbinding cassette transporter $A 1$ ( $A B C A 1$ ), and ABCG1, mediate the efflux of free cholesterol (FC) in macrophages. SR-BI transports cholesterol to high-density lipoprotein (HDL), whereas ABCA1 effluxes cholesterol to lipid-poor apolipoprotein $\mathrm{Al}$ (apoAI) or to apoE which is released by macrophages. There are two pathways to clear cytoplasmic cholesteryl ester (CE): (i) CE is converted by neutral $\mathrm{CE}$ hydrolase $(\mathrm{NCEH})$ and the FC transported to the plasma membrane for efflux; (ii) cytoplasmic CE is also trafficked into autophagosomes that fuse with lysosomes, where the CE is converted into cholesterol by lysosomal acid lipase (LAL) and the FC transported for efflux from macrophages. 
Figure 2

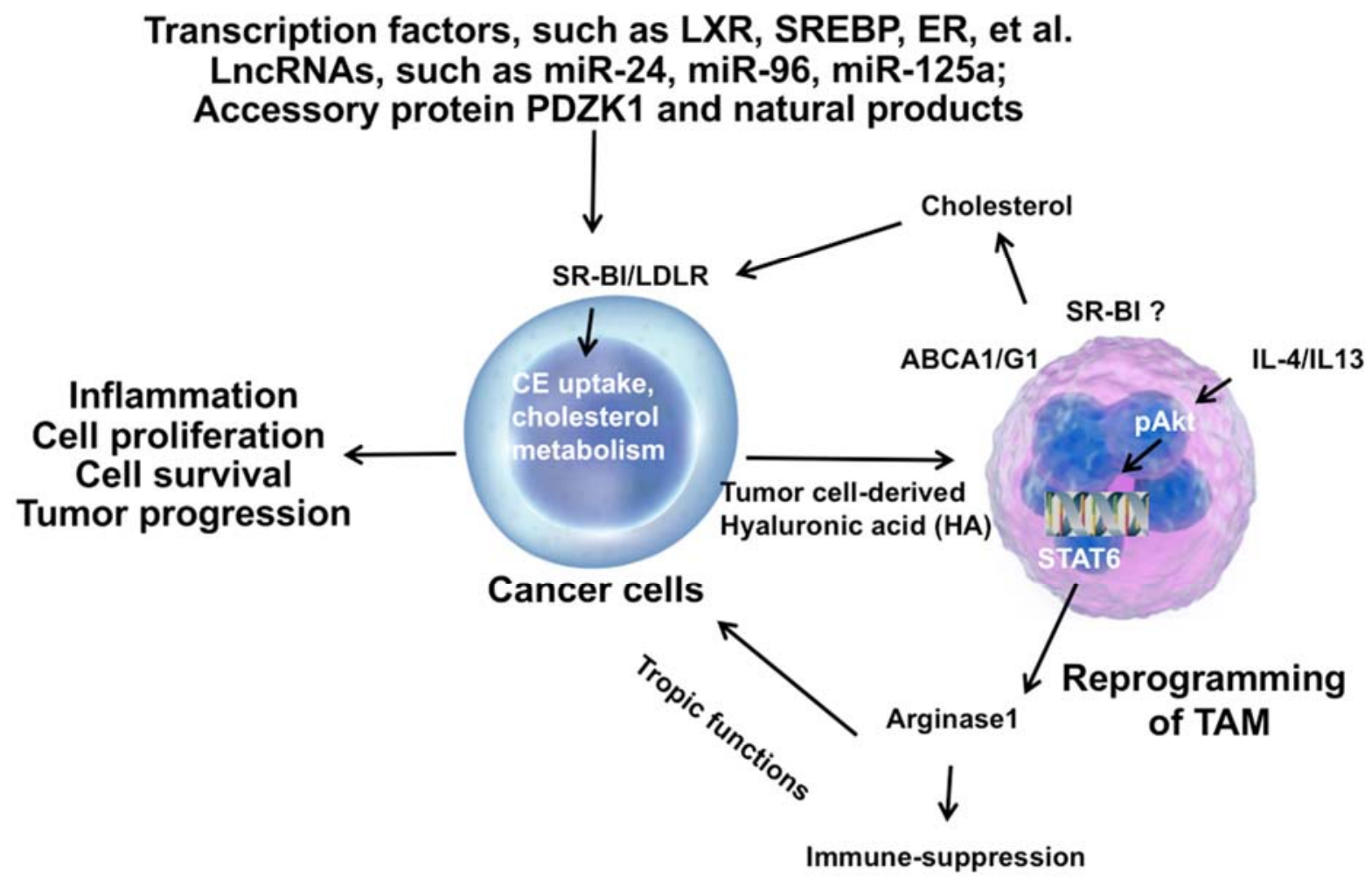

Figure 2. Effects of natural products, transcription factors and LcnRNAs on SRBI expression and reprogramming of tumor-associated macrophages (TAM) through cholesterol efflux in tumor progression. Natural products, transcription factors and LncRNAs regulate the expression of SR$\mathrm{BI}$, which controls the cholesterol ester uptake in cancer cells. Tumor cell-derived hyaluronic acid (HA) promotes ABCA1-ABCG1-mediated membrane cholesterol efflux in TAM and causes the reprogramming of TAM through p-Akt/STAT3 pathway. IL-4-induced gene expression in TAMs is related to tumor-promoting functions, including increased arginine metabolism and promoting immune suppression and trophic functions, which further results in cancer invasion and metastasis. 
Figure 3

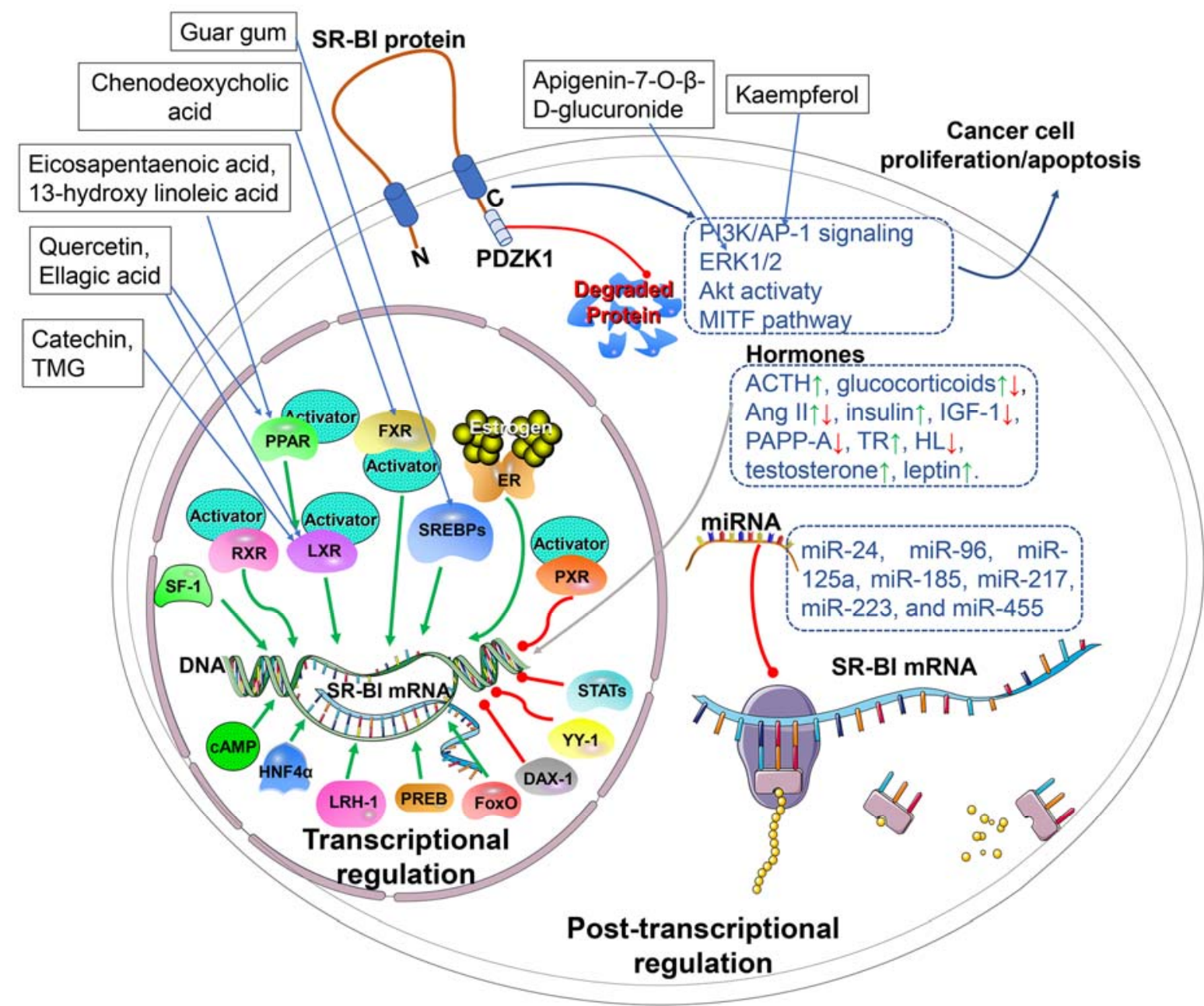

Figure 3. Regulatory mechanisms of SR-BI expression at transcriptional and post-transcriptional and post-translational levels, as well as targets by which natural products regulate SR-BI expression. At the transcriptional level, SR-BI protein expression is regulated by a variety of molecules, including transcription factors $(L X R \alpha / \beta, P P A R \alpha / \gamma, F X R, R X R, S R E B P-1 a / 1 c / 2, E R-$ $\alpha / \beta$, SF-1, HNF4a, LRH-1, PREB, FoxO1/3/4, DAX-1, YY-1, PXR and STAT1/2), hormones (ACTH, glucocorticoids, Ang II, insulin, IGF-1, PAPP-A, TR $\beta, H L$, testosterone and leptin), miRNAs (miR-24, miR-96, miR-125a, miR-185, miR-217, miR-223, and miR-455), and SR-BI accessory proteins (PDZK1/NHERF3, NHERF1 and NHERF2) ( $\rightarrow$ : Activation; $\longrightarrow$ : Inhibition). 
Table 1. SR-BI variants identified from human subjects with abnormal HDL-C levels

\begin{tabular}{|c|c|c|}
\hline $\begin{array}{l}\text { SR-BI } \\
\text { variants }\end{array}$ & Phenotype & References \\
\hline G2S & $\begin{array}{l}\text { Higher levels of HDL-C and lower levels } \\
\text { of LDL-C in males, confirmed an } \\
\text { increased } \\
\text { risk of CHD }\end{array}$ & {$[279]$} \\
\hline S112F & $\begin{array}{l}37 \% \text { increase in HDL-C in } \\
\text { heterozygotes }\end{array}$ & [280] \\
\hline $\begin{array}{l}\text { SR-BI } \\
\text { deletion of } \\
140-15011- \\
\text { bp }\end{array}$ & $\begin{array}{l}\text { The deletion allele exhibited higher } \\
\text { HDL-C levels }\end{array}$ & [281] \\
\hline V135I & Higher HDL-C levels in Amish women & [282] \\
\hline $\begin{array}{l}142 \mathrm{C} \rightarrow \mathrm{T} \\
\text { Polymorphism }\end{array}$ & $\begin{array}{l}\text { No significant differences in plasma } \\
\text { HDL-C levels between the different } \\
\text { genotype groups }\end{array}$ & {$[281]$} \\
\hline T175A & $\begin{array}{l}37 \% \text { increase in HDL-C in } \\
\text { heterozygotes }\end{array}$ & [280] \\
\hline I179N & $\begin{array}{l}\text { Impaired uptake of HDL-CE and } \\
\text { increase in atherosclerosis in mice }\end{array}$ & [283] \\
\hline G239R & Higher HDL-C, higher TG levels & [284] \\
\hline P297S & $\begin{array}{l}\text { Increase in HDL-C levels and reduction } \\
\text { in cholesterol efflux }\end{array}$ & [39] \\
\hline
\end{tabular}


Synonymous exon $8 \mathrm{C}-\mathrm{T}$ (allelic

A350A, C-T frequency 48\%) polymorphism, A350A,

polymophism associated with atheroprotection in

men, but not in women

V32M,

$\mathrm{V} 111 \mathrm{M}$,

G319V

Increase in HDL-C, but not associated

with CAD

2.8-fold increase of HDL-C in

heterzyotes and a 6.1-fold increase in

P376L

the homozygotes, larger HDL-2b

[58]

particles, also associated with increased

risk of $\mathrm{CHD}$ 
Table 2. The factors regulating SR-BI expression

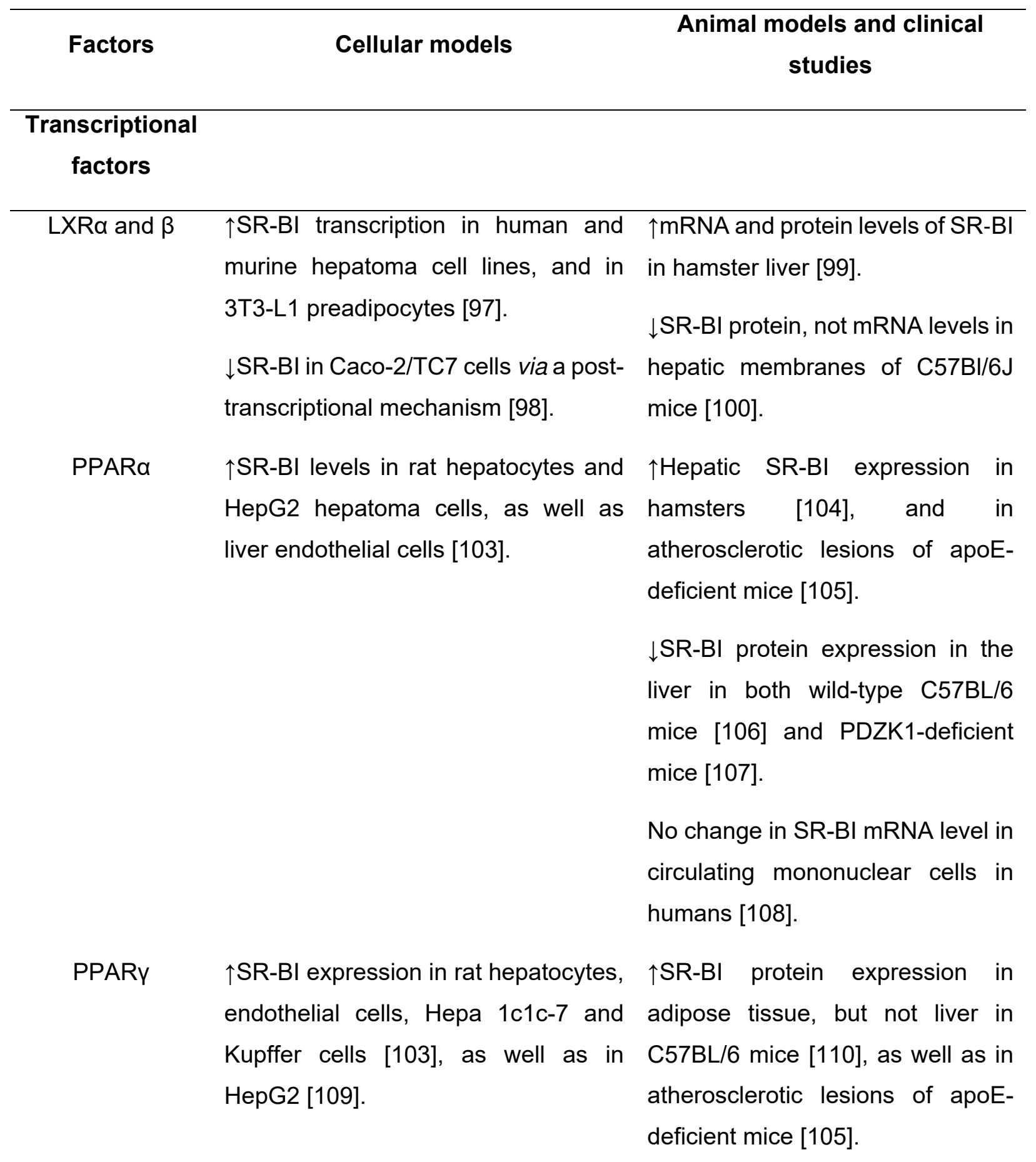




\begin{tabular}{|c|c|c|}
\hline FXR & $\begin{array}{l}\uparrow m R N A \text { and protein levels of hepatic } \\
\text { SR-BI [115]. } \\
\downarrow \text { SR-BI expression in hepatocytes } \\
\text { [111], and Huh7.5 cells [114]. }\end{array}$ & $\begin{array}{l}\text { 个hepatic SR-BI mRNA and protein } \\
\text { levels in hyperlipidemic hamsters, } \\
\text { but not in normolipidemic hamsters } \\
\text { [116]. }\end{array}$ \\
\hline $\mathrm{RXR}$ & $\uparrow S R-B I$ mRNA in HUVECs [120]. & N.A. ${ }^{1)}$ \\
\hline $\begin{array}{l}\text { SREBP-1a and } \\
\text { c }\end{array}$ & $\begin{array}{l}\uparrow S R-B I \text { gene expression by activation } \\
\text { of SREBP-1a [123]. }\end{array}$ & $\begin{array}{l}\downarrow \text { hepatic SR-BI in SREBP-1a and - } \\
\text { 1c transgenic mice on normal chow } \\
\text { [125]. }\end{array}$ \\
\hline SREBP-2 & $\begin{array}{l}\uparrow S R-B I \text { mRNA and protein levels in } \\
\text { transfected HEK293 and HepG } 2 \text { cells } \\
{[124] .}\end{array}$ & N.A. \\
\hline ER & $\begin{array}{l}\uparrow S R-B I \text { promoter activity by activation } \\
\text { of ER- } \alpha \text { and - } \beta \text { by binding to ER } \\
\text { element [123]. } \\
\downarrow \text { Endothelial SR-BI in human coronary } \\
\text { artery endothelial cells [129]. }\end{array}$ & $\begin{array}{l}\uparrow S R-B I \text { in the adrenal gland and } \\
\text { corpus luteal cells of the ovary in } \\
\text { rats [127]. } \\
\downarrow S R-B I \text { in the liver and the ovary in } \\
\text { rats [127]. }\end{array}$ \\
\hline SF-1 & $\begin{array}{l}\uparrow \text { SR-BI gene expression in both } \\
\text { human HTB9 bladder carcinoma and } \\
\text { mouse Y-1 tumor cells [132]. }\end{array}$ & $\begin{array}{l}\text { No SR-BI mRNA in the gonadal } \\
\text { ridge of day } 11.5 \text { SF- } 1 \mathrm{KO} \text { embryos } \\
\text { [133]. }\end{array}$ \\
\hline HNF4a & $\begin{array}{l}\uparrow S R-B I \text { expression at both mRNA and } \\
\text { protein levels in cultured hepatocytes } \\
{[134] .}\end{array}$ & $\begin{array}{l}\uparrow S R-B I \text { mRNA and protein levels in } \\
\text { the liver in rat }\end{array}$ \\
\hline LRH-1 & $\uparrow S R-B I$ expression in vitro [135]. & $\begin{array}{l}\downarrow \text { SR-BI mRNA levels in livers of the } \\
\text { heterozygous LRH-1-KO mice } \\
\text { [135]. }\end{array}$ \\
\hline
\end{tabular}




\begin{tabular}{|c|c|c|}
\hline PREB & $\begin{array}{l}\uparrow S R-B I \text { protein in the adrenocortical } \\
\text { cell line } \mathrm{Y}-1 \text { [137]. }\end{array}$ & N.A. \\
\hline FoxO & N.A. & $\begin{array}{l}\downarrow \text { hepatic SR-BI expression in the } \\
\text { mice with liver-specific triple FoxO } \\
\mathrm{KO}(\text { FoxO } 1,3,4)[138] \text {. }\end{array}$ \\
\hline DAX-1 & $\begin{array}{l}\downarrow \text { SR-BI promoter activity in } \\
\text { transfected adrenal } Y-1, \text { HTB-9, and } \\
\text { HepG2 cells [139]. }\end{array}$ & N.A. \\
\hline YY-1 & $\begin{array}{l}\downarrow \text { activity of the SR-BI promoter in } \\
\text { transfected HTB9 cells [141]. }\end{array}$ & N.A. \\
\hline PXR & $\begin{array}{l}\downarrow S R-B I \text { in HepG2 cells and in primary } \\
\text { rat hepatocytes [142]. }\end{array}$ & $\begin{array}{l}\downarrow \text { hepatic SR-BI level in ApoE3- } \\
\text { Leiden (E3L) and E3L.CETP mice } \\
\text { [143]. }\end{array}$ \\
\hline STAT & $\begin{array}{l}\downarrow \text { SR-BI promoter activity upon } \\
\text { mutagenesis of a STAT1/STAT2 } \\
\text { response element in the SR-BI } \\
\text { promoter [137]. }\end{array}$ & N.A. \\
\hline \multicolumn{3}{|l|}{$\begin{array}{l}\text { Endogenous } \\
\text { factors }\end{array}$} \\
\hline ACTH & $\begin{array}{l}\uparrow S R-B I \text { protein and mRNA expression } \\
\text { in the cultured murine } Y 1-B S 1 \text { adrenal } \\
\text { cells [17]. }\end{array}$ & $\begin{array}{l}\uparrow S R-B I \text { protein expression in } \\
\text { adrenal glands in C57BL/6 mice } \\
\text { [147]. }\end{array}$ \\
\hline Glucocorticoid & $\begin{array}{l}\downarrow S R-B I \text { expression in adrenocortical } \\
\text { H295R and ovarian SKOV-3 cells } \\
\text { [150]. } \\
\uparrow S R-B I \text { mRNA expression in primary } \\
\text { rat hepatocytes by a glucocorticoid } \\
\text { dexamethasone [151]. }\end{array}$ & $\begin{array}{l}\downarrow \text { SR-BI gene expression in } \\
\text { adrenals of corticosterone- } \\
\text { deficient mice [150]. }\end{array}$ \\
\hline
\end{tabular}


No effect in HepG2 cells and THP-1
macrophages treatment with
dexamethasone [151].

Angiotensin II $\quad \downarrow S R-B I$ expression in human umbilical vein endothelial cells [152], and the mouse proximal tubular cell line MCT cells [153].

$\uparrow \mathrm{SR}-\mathrm{BI}$ mRNA and protein expression in the human adrenocortical carcinoma cell line $\mathrm{NCl}-\mathrm{H} 295 \mathrm{R}$ cells [154].

Insulin $\quad \uparrow S R-B I$ mRNA and protein levels in polarized CaCo-2 cells [155].

IGF-1 $\downarrow$ SR-BI mRNA and protein levels in THP-1-derived macrophages [157], and in cultured HepG2 cells [158].

PAPP-A $\quad \downarrow S R-B I$ expression in THP-1 $\uparrow S R-B I$ expression in both aorta macrophage-derived foam cells [158]. and peritoneal macrophages in apoE-deficient mice with PAPP-A knockdown [159].

TR $\quad$ TSR-BI expression [160]. N.A.

$\mathrm{HL} \quad \uparrow \mathrm{SR}-\mathrm{BI}$ expression in adrenal gland in N.A. mice when inhibition of HL $[161,162]$.

Testosterone $\uparrow$ SR-BI mRNA and protein levels in N.A. both cultivated HepG2 cells and primary human monocyte-derived macrophages (HMDMs) [163].

$\uparrow S R-B I$ expression in all intestinal segments in two diet-induced animal models of insulin resistance (fructose-fed hamster and high-fatfed mouse) [156].

$\downarrow$ SR-BI mRNA level in rats [158]. 


\begin{tabular}{|c|c|c|}
\hline Leptin & N.A. & $\begin{array}{l}\text { 个hepatic SR-BI protein and mRNA } \\
\text { levels in leptin-deficient mice [164]. }\end{array}$ \\
\hline IFNa & $\downarrow$ SR-BI expression in HepG2 [144]. & N.A. \\
\hline cAMP & $\begin{array}{l}\uparrow S R-B I \text { mRNA expression in } \\
\text { transfected 293T cells, human } \\
\text { granulosa SVOG-4o cells, and in } \\
\text { primary cultures of rat theca-interstitial } \\
\text { cells [166]. }\end{array}$ & N.A. \\
\hline LGF & N.A. & $\begin{array}{l}\uparrow S R-B I \text { protein level in ethane } \\
\text { dimethanesulfonate (EDS)-treated } \\
\text { rats [167]. }\end{array}$ \\
\hline HSL & N.A. & $\begin{array}{l}\uparrow S R-B I \text { protein expression, but not } \\
\text { mRNA levels in the testis of } \\
\text { hormone-sensitive lipase (HSL) } \\
\text { KO male mice [168]. }\end{array}$ \\
\hline Glucose & $\begin{array}{l}\downarrow \text { SR-BI mRNA and protein levels in } \\
\text { HMDMs [169], Caco-2/15 cells [170], } \\
\text { and HepG2 cells [171] upon treatment } \\
\text { with high glucose ( } 25-30 \mathrm{mM}) \text {. } \\
\uparrow \text { SR-BI mRNA and protein expression } \\
\text { in J774A.1 macrophage-like cells } \\
\text { upon treatment with high glucose (30 } \\
\text { mM) [172]. } \\
\text { No changes in SR-BI abundance in } \\
\text { polarized CaCo-2 cells upon } \\
\text { treatment with high glucose [155]. }\end{array}$ & $\begin{array}{l}\uparrow S R-B I \text { mRNA and protein } \\
\text { expression in mouse peritoneal } \\
\text { macrophages (MPM) harvested } \\
\text { from C57BI/6 diabetic mice, } \\
\text { compared to MPM from control } \\
\text { non-diabetic mice [172]. }\end{array}$ \\
\hline
\end{tabular}

\section{Noncoding \\ RNAs (ncRNA)}



miR-24 $\downarrow S R-B I$ protein expression in HepG2, $\downarrow$ hepatic SR-BI expression in THP-1 cells [173], steroidogenic cells apoE-deficient mice [173]. MLTC and $\mathrm{Y}-1$, and HepG2 cells [174].
miR-96 لlevel of SR-BI expression in HepG2 $\uparrow S R-B I$ in the liver of apoE- cells [175]. deficient mice with a high fat diet (HFD) when decrease of miR-96 [175].
miR-125a $\downarrow$ mRNA and protein levels of SR-BI in N.A. the rat Leydig tumor $\mathrm{R} 2 \mathrm{C}$ cells, the cAMP-sensitive MLTC cells [176], and mouse hepatic cell line Hepa 1-6 [176], as well as mouse and rat liver cells [176].
miR-185 $\downarrow$ level of SR-BI expression in HepG2 $\uparrow S R-B I$ in the liver of apoE- cells [175]. deficient mice with a HFD when decrease of miR-185 [175].
miR-217 N.A.
$\downarrow$ SR-BI mRNA levels in apoE- deficient mice [177].
miR-223 $\downarrow$ level of SR-BI expression in HepG2 cells [175].
miR-455 $\downarrow$ mRNA and protein levels of SR-BI in N.A. the rat Leydig tumor R2C cells and the cAMP-sensitive MLTC cells [176].
Does not influence expression of SR- $\mathrm{BI}$ in mouse and rat liver cells [176].

\section{Accessory}

proteins 
NHERF1 $\quad \downarrow$ SR-BI protein expression in liver and steroidogenic cells [180].

NHERF2 $\quad \downarrow$ SR-BI protein expression in liver and steroidogenic cells [180].

\section{PDZK1/NHERF3} translational level in vitro [17]. $\downarrow$ SR-BI protein expression in liver and steroidogenic tissues [180].

$\downarrow$ SR-BI protein expression in liver and steroidogenic tissues [180].

post- $\downarrow$ SR-BI protein expression in PDZK1-deficient mice in the liver and the proximal intestine [178].

Not affected SR-BI expression in steroidogenic organs in mice [178].

1) N.A. = not applicable. 
Table 3. Natural products regulating SR-BI expression

\begin{tabular}{|c|c|c|c|c|}
\hline Classification & Sub-classes & Compounds & Structures & References \\
\hline Polyphenols & Flavonols & Quercetin & & [190] \\
\hline
\end{tabular}

Kaempferol<smiles>O=c1c(O)c(-c2ccc(O)cc2)oc2cc(O)cc(O)c12</smiles>

[191]

Flavanols Catechin<smiles>O=C1c2c(O)cc(O)cc2O[C@H](c2ccc(O)c(O)c2)C1O</smiles>

[287]

Gallotannin 1,2,3,4,6-

Pentagalloyl

glucose (PGG)<smiles>O=C(OC1OC(OC(=O)c2cc(O)c(O)c(O)c2)C(OC(=O)c2cc(O)c(O)c(O)c2)C(OC(=O)c2cc(O)c(O)c(O)c2)C1OC(=O)c1cc(O)c(O)c(O)c1)c1cc(O)c(O)c(O)c1</smiles>

Flavones Apigenin-7-O- $\beta$ -

[195]

D-glucuronide<smiles>O=C(O)C1OC(Oc2cc(O)c3c(=O)cc(-c4ccc(O)cc4)oc3c2)C(O)C(O)C1O</smiles>

Luteolin<smiles>O=c1cc(-c2ccc(O)c(O)c2)oc2cc(O)cc(O)c12</smiles>

[196] 
Phenolic Caffeic acid
acids

Ferulic acid<smiles>COc1cc(/C=C/C(=O)O)ccc1O</smiles>

Ellagic acid<smiles>O=c1oc2c(O)c(O)cc3c(=O)oc4c(O)c(O)cc1c4c23</smiles>

Stilbenes

Resveratrol
[198]

[198]

[199]

[204]

[205]

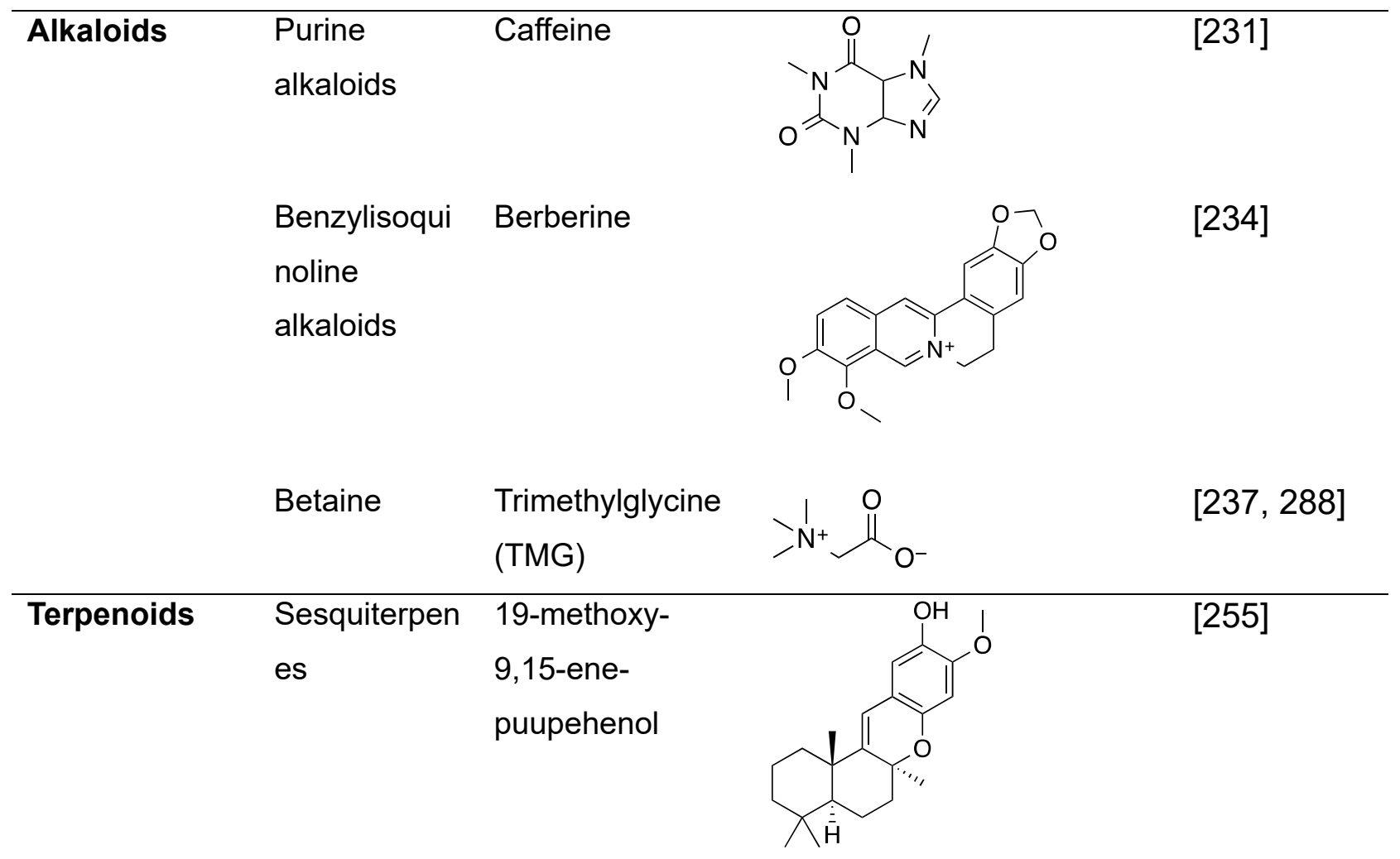




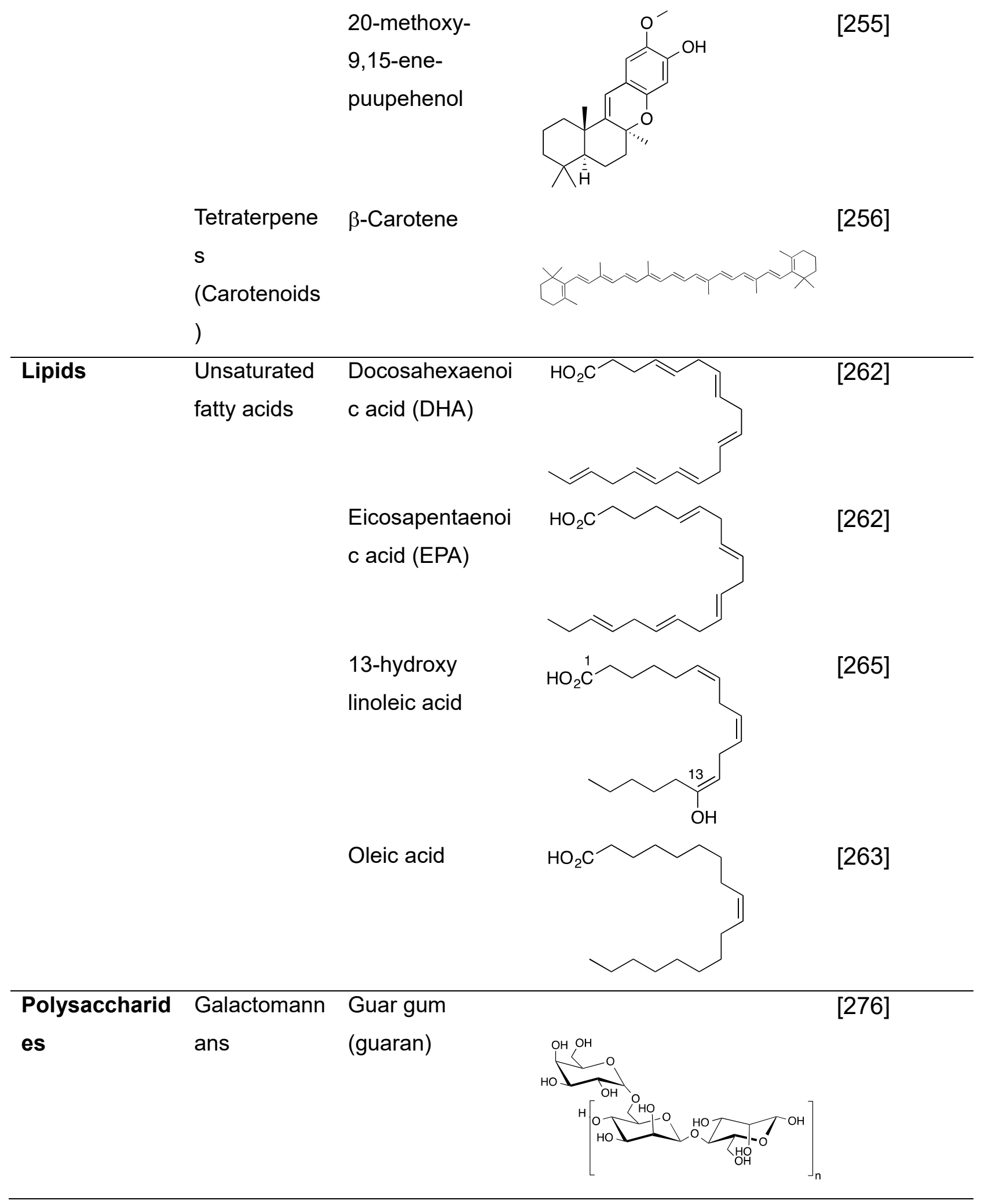




\begin{tabular}{llll}
\hline Bile acids & Primary bile & Chenodeoxychol \\
acids & ic acid
\end{tabular}

